\title{
Energy-Transfer-Mediated Photocatalysis by a Bioinspired Organic
}

\section{Perylenephotosensitizer HiBRCP}

Yan Zhang, ${ }^{\dagger}$ Mingze Xia ${ }^{\dagger}$ Min Li, ${ }^{\ddagger}$ Qian Ping, ${ }^{\dagger}$ Zhenbo Yuan, ${ }^{\ddagger}$ Xuanzhong Liu, ${ }^{\ddagger}$ Huimin Yin, ${ }^{\S}$ Shuping Huang $^{\S}$ and Yijian Rao*,

$\dagger$ Key Laboratory of Carbohydrate Chemistry and Biotechnology, Ministry of Education, School of Pharmaceutical Science, Jiangnan University, Wuxi 214122, P. R. China

$\$$ Key Laboratory of Carbohydrate Chemistry and Biotechnology, Ministry of Education, School of Biotechnology, Jiangnan University, Wuxi 214122, P. R. China

$\S$ College of Chemistry, Fuzhou University, Fuzhou 350108, P. R. China

*Corresponding author email: raoyijian@jiangnan.edu.cn 


\section{Table of Contents}

1. Photophysical properties of CP, HARCP, HiBRCP and perylene ......................... S3

2. Triplet energies of $\mathrm{CP}, \mathrm{HARCP}, \mathrm{HiBRCP}$ and perylene ….................................. S3

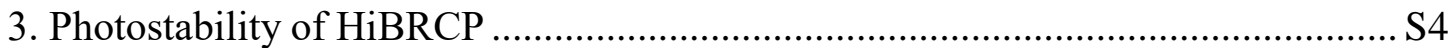

4. Emission spectrum of the light source CFL …................................................. $\mathrm{S} 4$

5. Optimizations for the energy transfer photocatalysis with HiBRCP ……............. S5

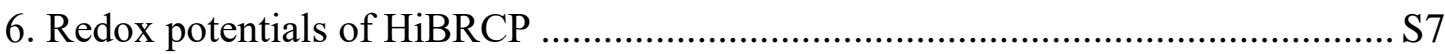

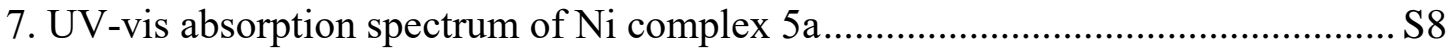

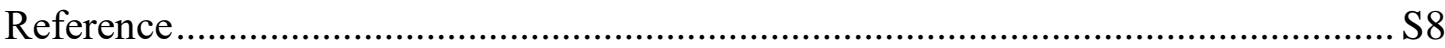

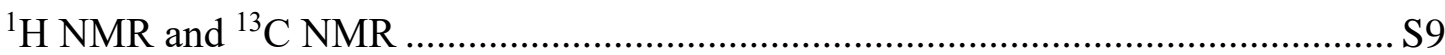




\section{Photophysical properties of CP, HARCP, HiBRCP and perylene}

(a)

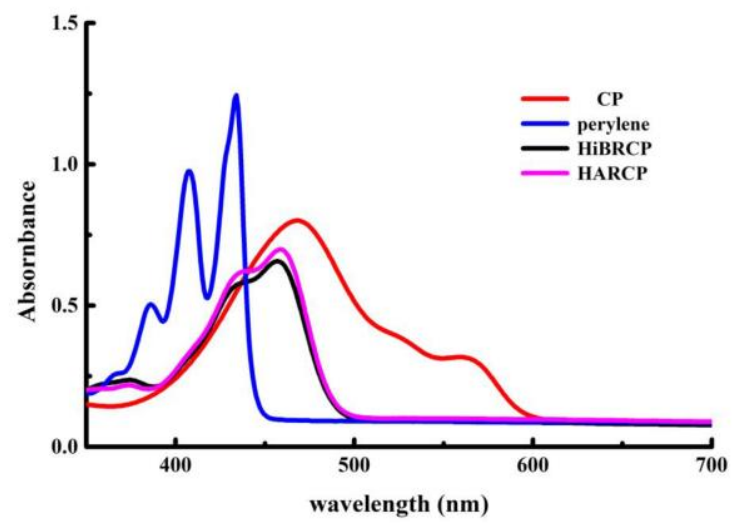

(b)

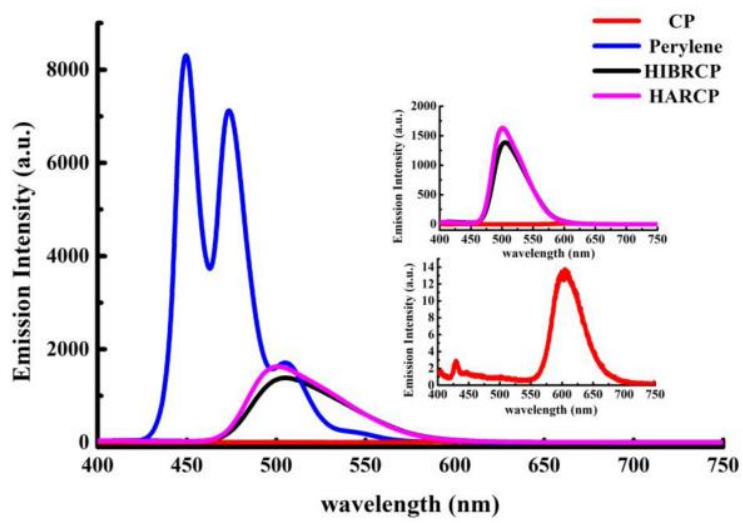

Figure S1. UV-vis absorption (a) and fluorescence emission (b) spectra of CP, HARCP, HiBRCP and perylene in toluene. The concentrations were all $3.1 * 10^{-5} \mathrm{~mol} \mathrm{\textrm {L } ^ { - 1 }}$. The excitation wavelength for fluorescence emission spectra was $380 \mathrm{~nm}$.

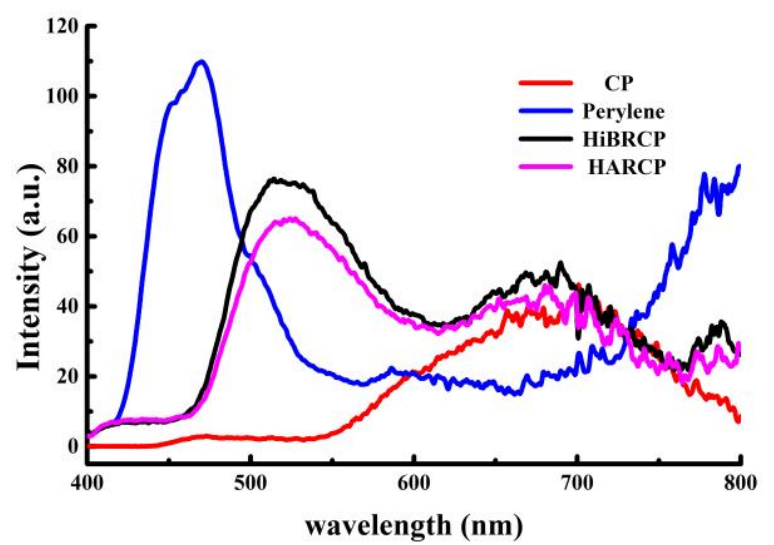

Figure S2. Phosphorescence spectra of CP, HARCP, HiBRCP and perylene in toluene at room temperature. The concentrations were all $3.1 * 10^{-5} \mathrm{~mol} \mathrm{~L}^{-1}$. The excitation wavelength was $380 \mathrm{~nm}$.

\section{Triplet energies of CP, HARCP, HiBRCP and perylene}

Triplet energies for $\mathrm{CP}$, HARCP, HiBRCP and perylene were calculated from phosphorescence spectra wavelength at room temperature. ${ }^{1}$

Table S1. Triplet energies of CP, HARCP, HiBRCP and perylene.

\begin{tabular}{lll}
\hline Photocatalyst & $\lambda_{\max }$ of phosphorescence spectrum $(\mathrm{nm})$ & $E_{\mathrm{T}}\left(\mathrm{kcal} \mathrm{mol}^{-1}\right)$ \\
\hline $\mathrm{CP}$ & 700 & 40.8
\end{tabular}




\begin{tabular}{lcc}
\hline HARCP & 514 & 55.6 \\
HiBRCP & 527 & 54.2 \\
perylene & 469 & 61.0 \\
\hline
\end{tabular}

\section{Photostability of HiBRCP}

The changes of ${ }^{1} \mathrm{H}$ NMR before and after irradiation was used to study the photostability of HiBRCP. It was irradiated with $32 \mathrm{~W} \mathrm{CFL}$ for $24 \mathrm{~h}$ in toluene and the photostability was obtained through ${ }^{1} \mathrm{H}$ NMR. $0.1 \mathrm{mmol} \mathrm{HiBRCP}(95.7 \mathrm{mg})$ and $1 \mathrm{~mL}$ toluene was put into Schlenk tube and irradiated with $32 \mathrm{~W} \mathrm{CFL}$ for $24 \mathrm{~h}$ under nitrogen. After the irradiation, toluene was removed with rotary evaporation. $\mathrm{CDCl}_{3}(730.1$ $\mathrm{mg})$ containing hexamethyldisiloxane $\left(3.2 * 10^{-4} \mathrm{~mol} \mathrm{~g}^{-1}\right)$ was added and detected with ${ }^{1} \mathrm{H}$ NMR. The recovery rate was $95 \%$ according to ${ }^{1} \mathrm{H}$ NMR spectra.

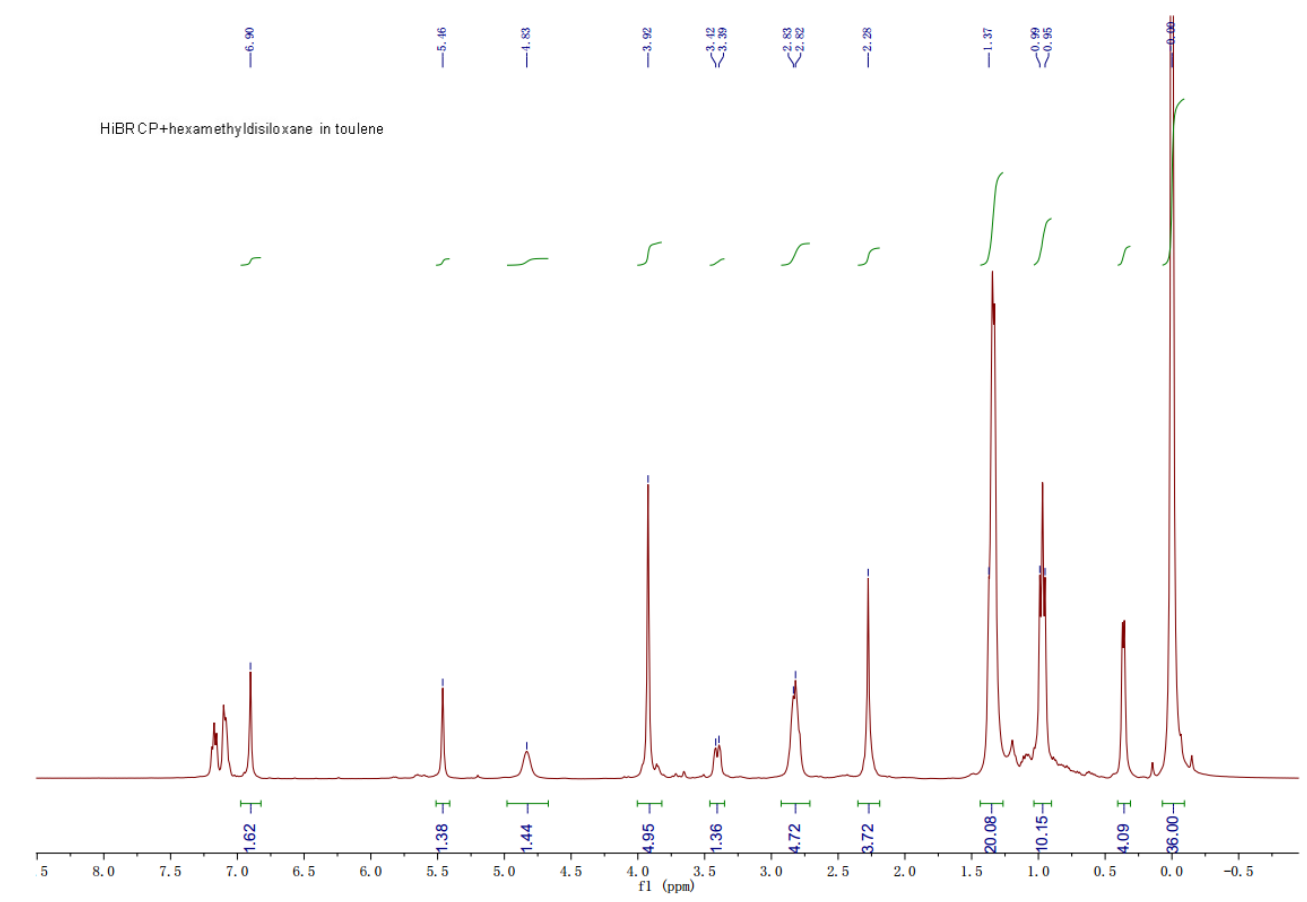

Figure S3. ${ }^{1} \mathrm{H}$ NMR of irradiated HiBRCP with $32 \mathrm{~W}$ CFL in toluene for $24 \mathrm{~h}$ with hexamethyldisiloxane as internal standard.

\section{Emission spectrum of the light source CFL}




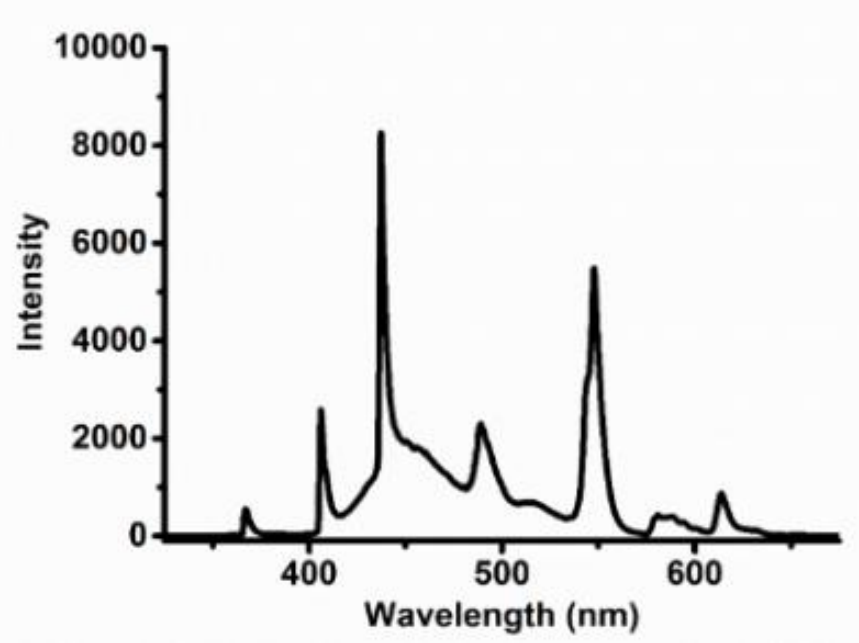

Figure S4. Emission spectrum of light source CFL.

\section{Optimizations for the energy transfer photocatalysis with HiBRCP}

\subsection{The screening of solvent for the geometrical isomerisation of $\alpha$, $\beta$-unsaturated ester}

Table S2. The screening of solvent for the geometrical isomerisation of $\alpha, \beta$-unsaturated ester.<smiles>CC=C(OCC)c1ccccc1</smiles>

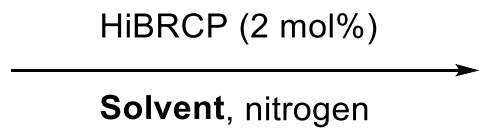<smiles>CC=C(OCC)c1ccccc1</smiles>

$E-1 \mathrm{p}$ 32 W CFL, room temperature $Z-1 p$

\begin{tabular}{lll}
\hline Entry & Solvent & $Z / E$ Ratio $^{\text {a) }}$ \\
\hline 1 & toluene & $17: 83$ \\
2 & acetone & $97: 3$ \\
3 & THF & $20: 80$ \\
4 & DMF & $12: 88$ \\
5 & $\mathrm{CH}_{3} \mathrm{CN}$ & $98: 2$ \\
\hline
\end{tabular}

Reaction conditions: $\boldsymbol{E}-\mathbf{1 p}(0.2 \mathrm{mmol})$, HiBRCP (2 mol\%), different solvent $(2 \mathrm{~mL})$ upon irradiation with $32 \mathrm{~W}$ CFL for $36 \mathrm{~h}$ at room temperature under nitrogen atmosphere. ${ }^{\text {a) }} \mathrm{Z} / \mathrm{E}$ ratio was determined by ${ }^{1} \mathrm{H}$ NMR.

5.2 The screening of nickel salt and ligand for the EnT-mediated organometallic catalysis 


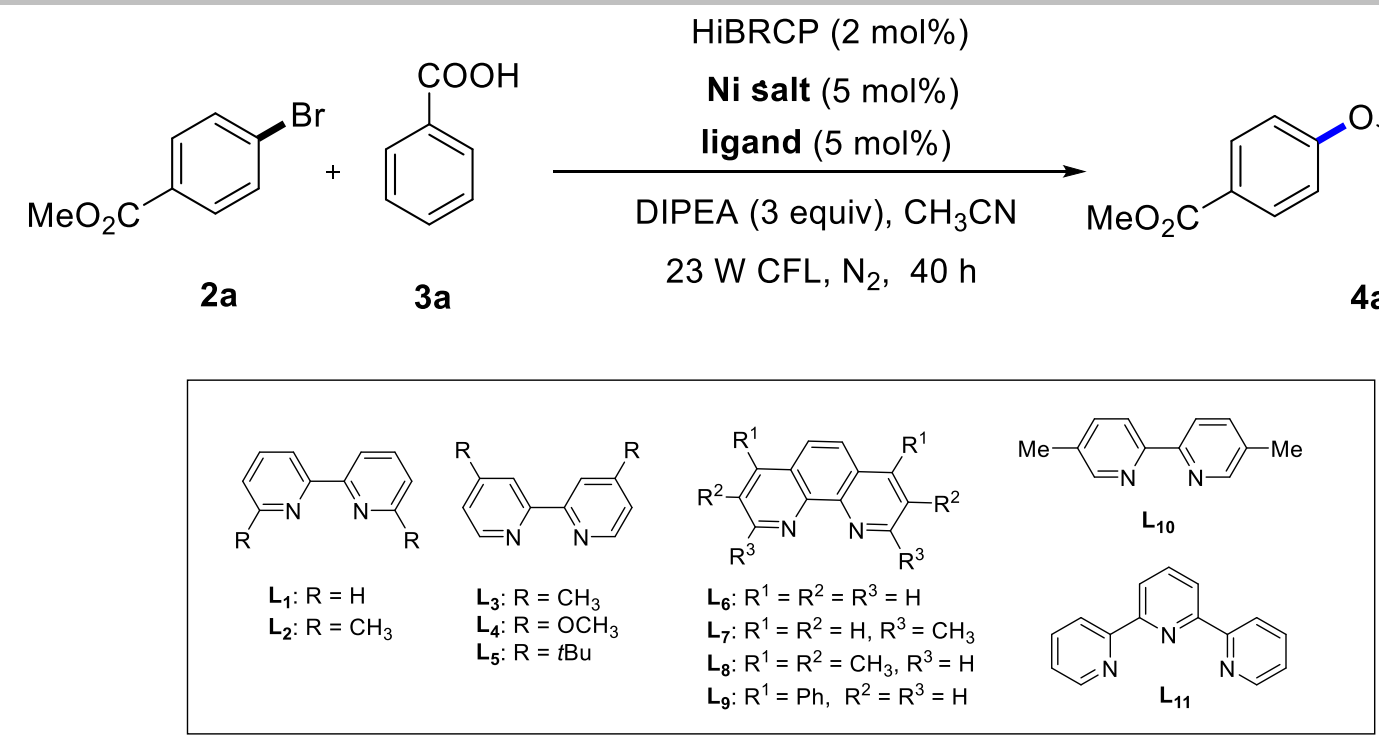

Table S3. The screening of nickel salt and ligand for the EnT-mediated organometallic catalysis. ${ }^{\text {a) }}$

\begin{tabular}{|c|c|c|c|c|c|c|c|}
\hline & $\mathrm{NiBr}_{2} \cdot 3 \mathrm{H}_{2} \mathrm{O}$ & $\mathrm{NiBr}_{2} \cdot \mathrm{DME}$ & $\mathrm{NiCl}_{2}$ & $\mathrm{NiCl}_{2} \cdot \mathrm{DME}$ & $\mathrm{NiF}_{2}$ & $\mathrm{NiI}_{2}$ & $\mathrm{NiSO}_{4} \cdot 6 \mathrm{H}_{2} \mathrm{O}$ \\
\hline $\mathbf{L}_{1}$ & $0 \%$ & $46 \%$ & $29 \%$ & $73 \%$ & $41 \%$ & $20 \%$ & $21 \%$ \\
\hline $\mathbf{L}_{2}$ & $0 \%$ & $10 \%$ & $0 \%$ & $8 \%$ & $0 \%$ & $0 \%$ & $0 \%$ \\
\hline $\mathbf{L}_{3}$ & $21 \%$ & $0 \%$ & $0 \%$ & $15 \%$ & $8 \%$ & $18 \%$ & $0 \%$ \\
\hline $\mathbf{L}_{4}$ & $72 \%$ & $6 \%$ & $39 \%$ & $50 \%$ & $38 \%$ & $55 \%$ & $59 \%$ \\
\hline L5 & $81 \%$ & $11 \%$ & $22 \%$ & $16 \%$ & $31 \%$ & $25 \%$ & $47 \%$ \\
\hline $\mathbf{L}_{6}$ & $42 \%$ & $23 \%$ & $39 \%$ & $33 \%$ & $37 \%$ & $33 \%$ & $24 \%$ \\
\hline L7 & $5 \%$ & $3 \%$ & $7 \%$ & $11 \%$ & $0 \%$ & $0 \%$ & $1 \%$ \\
\hline L8 & $69 \%$ & $59 \%$ & $17 \%$ & $33 \%$ & $0 \%$ & $13 \%$ & $61 \%$ \\
\hline L9 & $22 \%$ & $0 \%$ & $32 \%$ & $13 \%$ & $53 \%$ & $19 \%$ & $60 \%$ \\
\hline $\mathbf{L}_{10}$ & $25 \%$ & $11 \%$ & $0 \%$ & $10 \%$ & $0 \%$ & $15 \%$ & $0 \%$ \\
\hline $\mathbf{L}_{11}$ & $0 \%$ & $0 \%$ & $2 \%$ & $0 \%$ & $2 \%$ & $3 \%$ & $0 \%$ \\
\hline
\end{tabular}

Reaction conditions: $\mathbf{2 a}(0.2 \mathrm{mmol})$, 3a (2 equiv, $0.4 \mathrm{mmol})$, HiBRCP $(2 \mathrm{~mol} \%)$, Ni salt ( $5 \mathrm{~mol} \%)$, ligand (5 mol\%), DIPEA (3 equiv), $\mathrm{CH}_{3} \mathrm{CN}(2 \mathrm{~mL})$ under irradiation with $23 \mathrm{~W}$ CFL under nitrogen atmosphere. a) Yields of the isolated products.

5.3 The screening of solvent for the EnT-mediated organometallic catalysis 


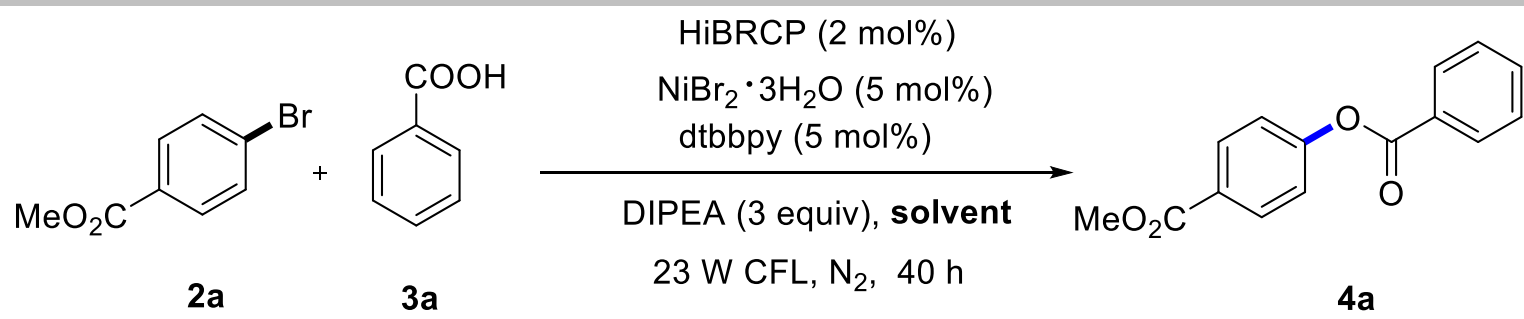

Table S4. The screening of solvent for the EnT-mediated organometallic catalysis.

\begin{tabular}{lll}
\hline Entry & Solvent & Yield $(\%)^{\mathrm{a})}$ \\
\hline 1 & acetone & trace \\
2 & $\mathrm{DMSO}$ & trace \\
3 & $\mathrm{DMF}$ & trace \\
4 & $\mathrm{CH}_{3} \mathrm{CN}$ & 81 \\
5 & $\mathrm{CH}_{2} \mathrm{Cl}{ }_{2}$ & trace \\
6 & $\mathrm{CHCl}_{3}$ & trace
\end{tabular}

Reaction conditions: 2a (0.2 mmol), 3a (2 equiv, $0.4 \mathrm{mmol}), \mathrm{HiBRCP}(2 \mathrm{~mol} \%), \mathrm{NiBr}_{2} \cdot 3 \mathrm{H}_{2} \mathrm{O}(5 \mathrm{~mol} \%)$, dtbbpy (5 mol\%), DIPEA (3 equiv), different solvent $(2 \mathrm{~mL})$ under irradiation with $23 \mathrm{~W}$ CFL under nitrogen atmosphere. ${ }^{\text {a) }}$ Yields of the isolated products.

\section{Redox potentials of HiBRCP}

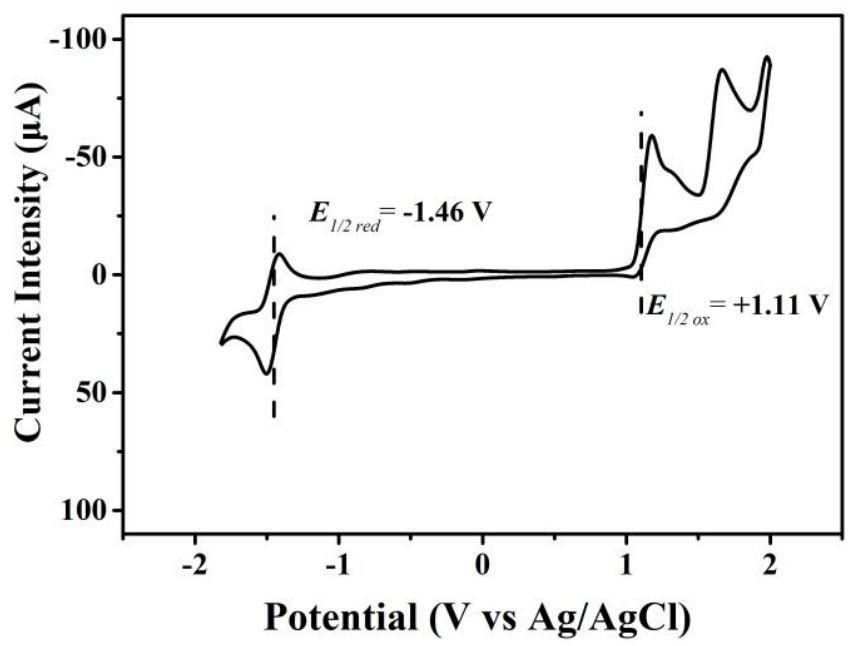

Figure S5. Cyclic voltammogram of $\operatorname{HiBRCP}\left(1.2 * 10^{-3} \mathrm{~mol} \mathrm{~L}^{-1}\right)$ in $\mathrm{CH}_{3} \mathrm{CN}$ with $0.1 \mathrm{M} \mathrm{Et}_{4} \mathrm{NBF}_{4}$ as the supporting electrolyte with a scan rate of $50 \mathrm{mV} / \mathrm{s}$. 
$E_{1 / 2}^{r e d}\left(\mathrm{HiBRCP} / \mathrm{HiBRCP}^{\bullet-}\right)=-1.46 \mathrm{~V}$ vs $\mathrm{Ag} / \mathrm{AgCl}$

$E_{1 / 2}^{o x}\left(\mathrm{HiBRCP}^{\cdot+} / \mathrm{HiBRCP}\right)=+1.11 \mathrm{~V}$ vs $\mathrm{Ag} / \mathrm{AgCl}$

The potential of saturated $\mathrm{Ag} / \mathrm{AgCl}$ electrode relative to $\mathrm{NHE}$ is $0.197 \mathrm{~V}$, and that of saturated $\mathrm{SCE}$ relative to NHE is $0.241 \mathrm{~V}$, so $\mathrm{SCE}=\mathrm{Ag} / \mathrm{AgCl}+0.044 \mathrm{~V}$.

$$
\begin{aligned}
& E_{1 / 2}^{r e d}\left(\mathrm{HiBRCP} / \mathrm{HiBRCP}^{--}\right)=-1.42 \mathrm{~V} \text { vs SCE } \\
& E_{1 / 2}^{o x}\left(\mathrm{HiBRCP}^{\cdot+} / \mathrm{HiBRCP}\right)=+1.20 \mathrm{~V} \text { vs SCE }
\end{aligned}
$$

As shown in above, the triplet excited energies of HiBRCP is $2.35 \mathrm{eV}$. The redox potentials of the excited state of HiBRCP can be calculated according to "Gibbs Energy of Photoinduced Electron Transfer":

$$
\begin{aligned}
& E_{\text {red }}^{*}\left(\mathrm{HiBRCP}^{*} / \mathrm{HiBRCP}^{{ }^{-}}\right)=E_{1 / 2}^{\text {red }}\left(\mathrm{HiBRCP} / \mathrm{HiBRCP}^{\cdot-}\right)+E_{0,0}=+0.93 \mathrm{~V} \text { vs SCE } \\
& E_{o x}^{*}\left(\mathrm{HiBRCP}^{\bullet+} / \mathrm{HiBRCP}^{*}\right)=E_{1 / 2}^{o x}\left(\mathrm{HiBRCP}^{\bullet+} / \mathrm{HiBRCP}\right)-E_{0,0}=-1.15 \mathrm{~V} \text { vs } \mathrm{SCE}
\end{aligned}
$$

\section{UV-vis absorption spectrum of Ni complex 5a}

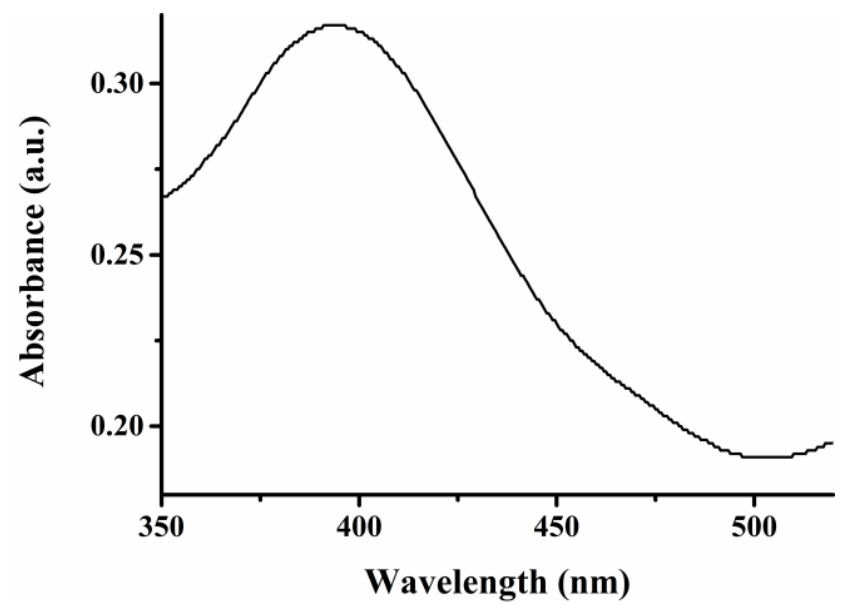

Figure S6. UV-vis absorption spectrum of Ni complex 5a in DMSO. The concentrations were all 7.2*10${ }^{5} \mathrm{~mol} \mathrm{~L}^{-1}$.

\section{Reference}

1. Strieth-Kalthoff, F.; James, M. J.; Teders, M.; Pitzer, L.; Glorius, F., Energy Transfer Catalysis Mediated by Visible light: Principles, Applications, Directions. Chem. Soc. Rev. 2018, 47 (19), $7190-$ 7202. 


\section{${ }^{1} \mathrm{H}$ NMR and ${ }^{13} \mathrm{C}$ NMR}

\section{Characterizations of photosensitizers}

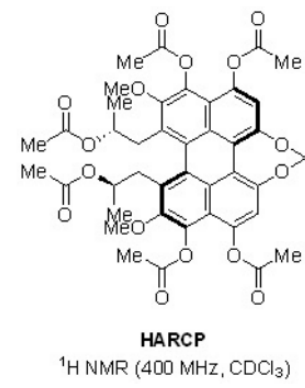

$$
\begin{aligned}
& \substack{n \\
: \\
0 \\
i} \\
& 1
\end{aligned}
$$

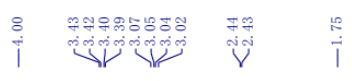

${ }^{1} \mathrm{H} \mathrm{NMR}\left(400 \mathrm{MHz}, \mathrm{CDCl}_{3}\right)$
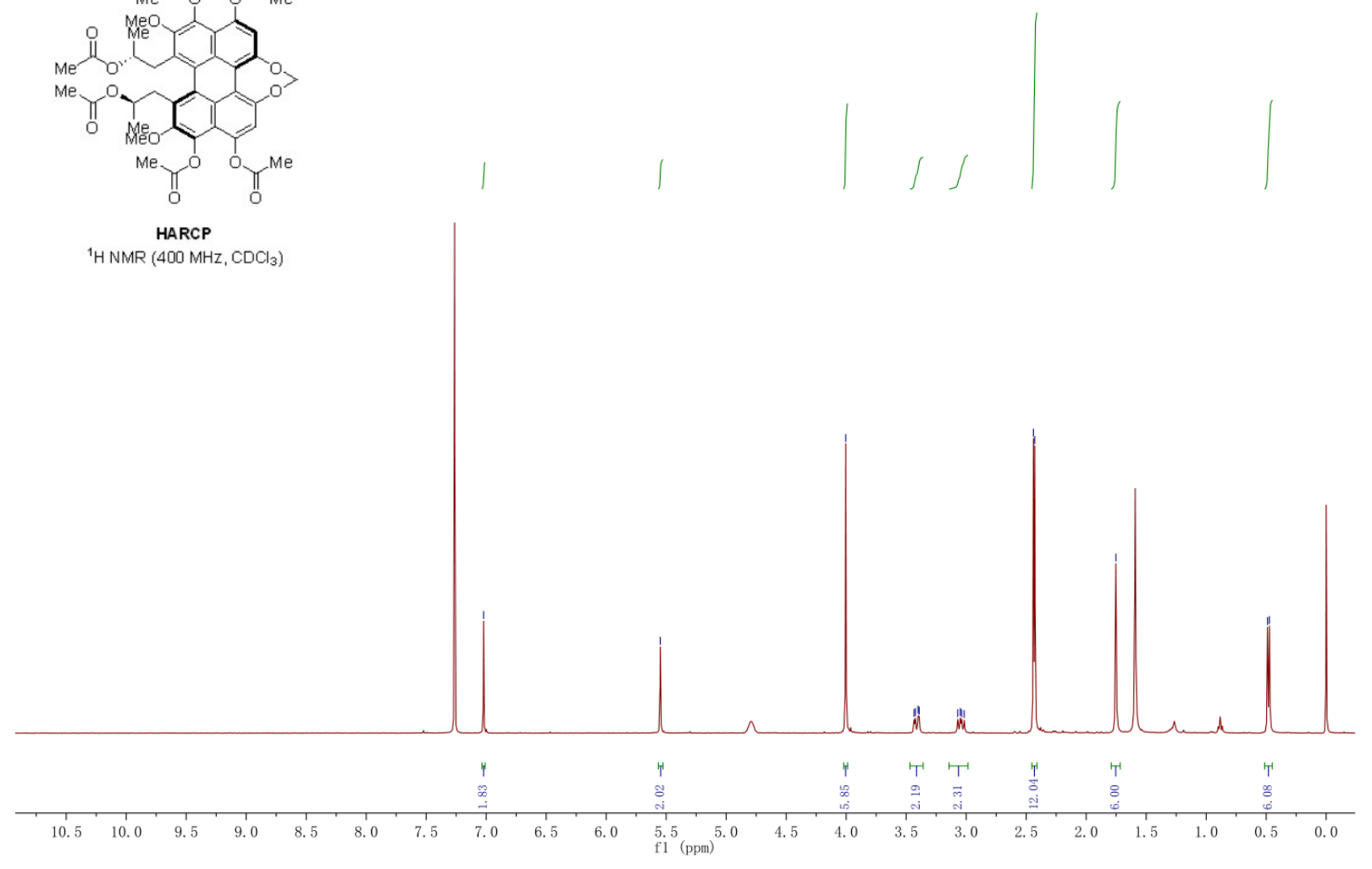

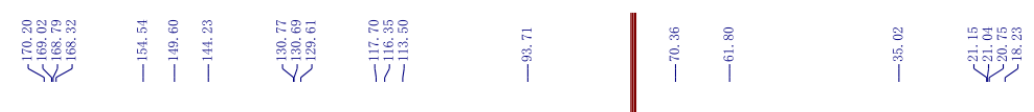

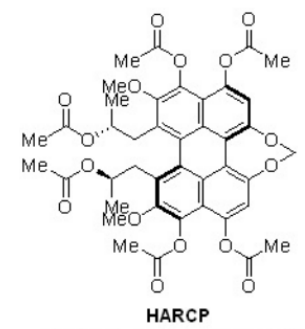

${ }^{13} \mathrm{C}\left\{{ }^{1} \mathrm{H}\right\} \operatorname{NMR}\left(100 \mathrm{MHz}, \mathrm{CDCl}_{3}\right)$

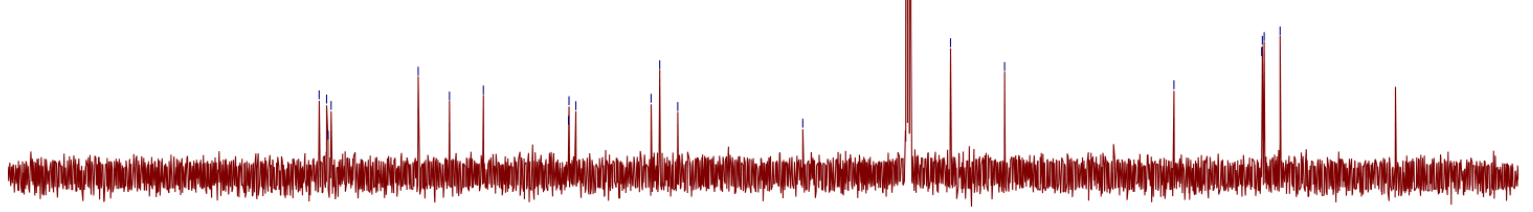

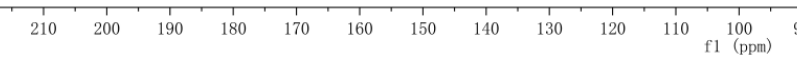



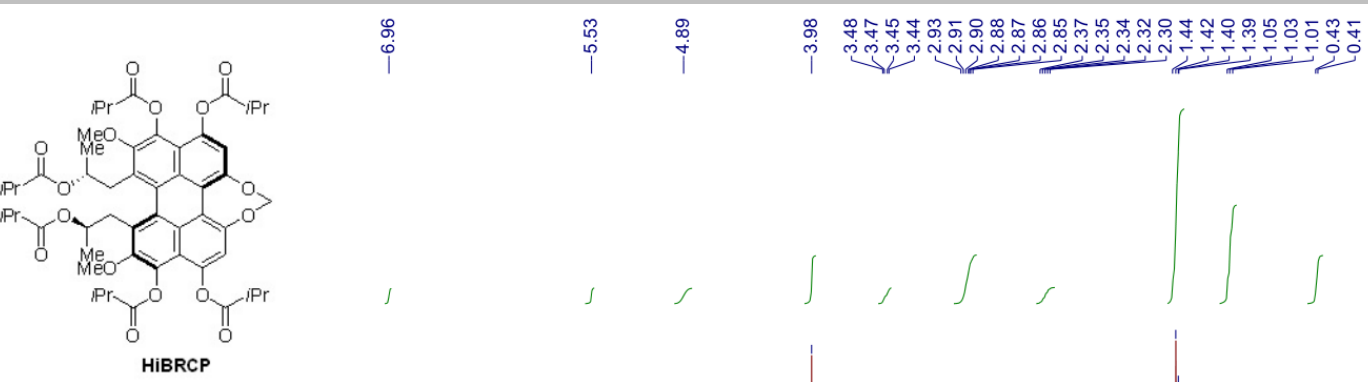

${ }^{1} \mathrm{HNMR}\left(400 \mathrm{MHz}_{1} \mathrm{CDCl}_{3}\right)$
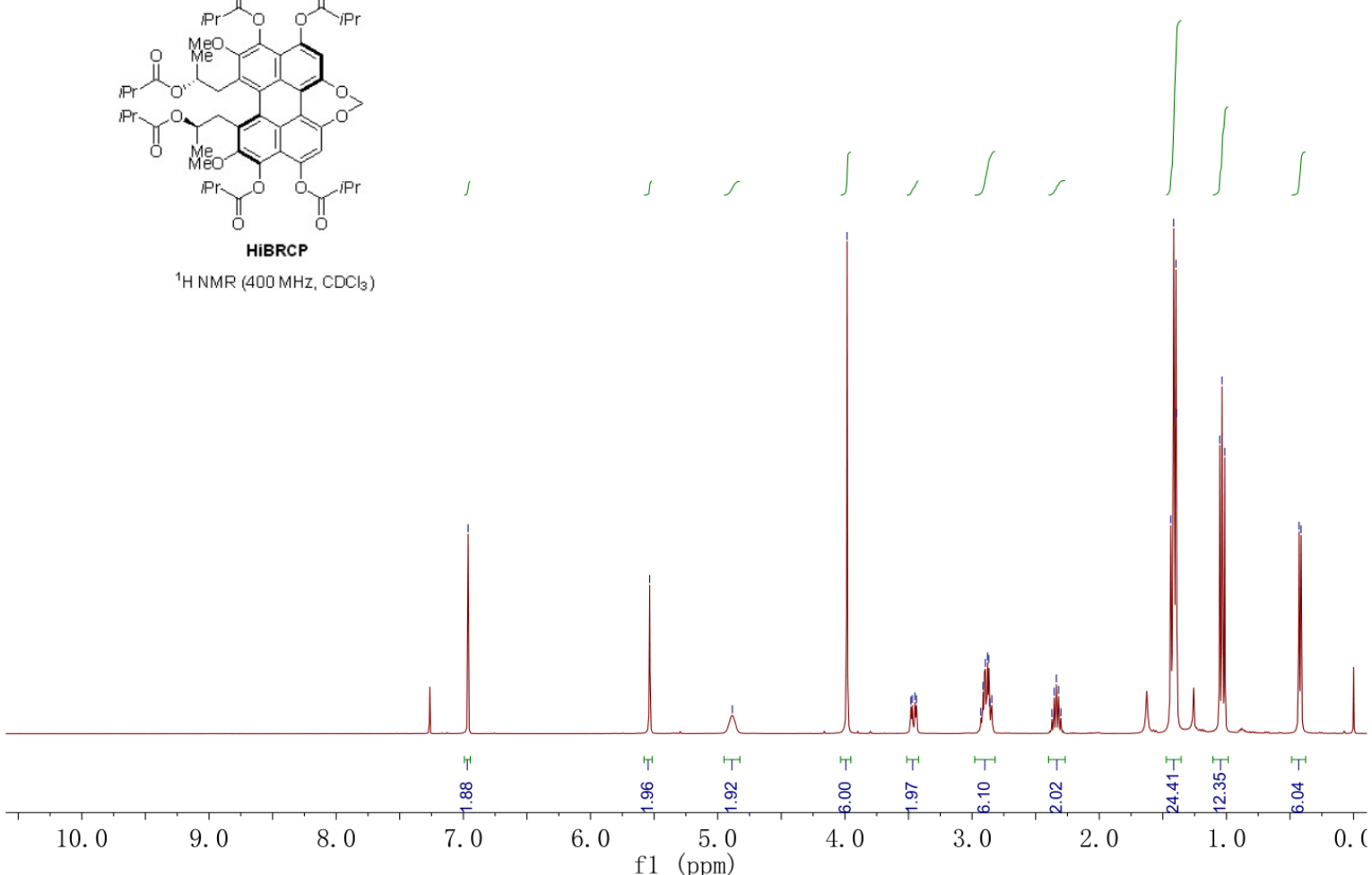

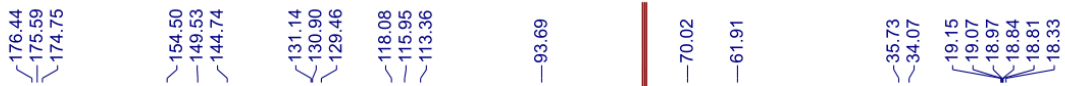

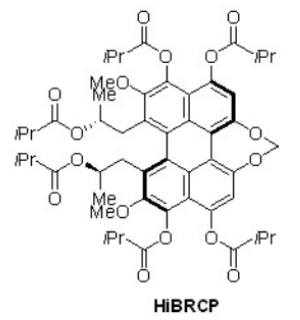

${ }^{13} \mathrm{C}\left\{{ }^{1} \mathrm{H}\right\} \mathrm{NMR}\left(100 \mathrm{MHz}, \mathrm{CDCl}_{3}\right)$

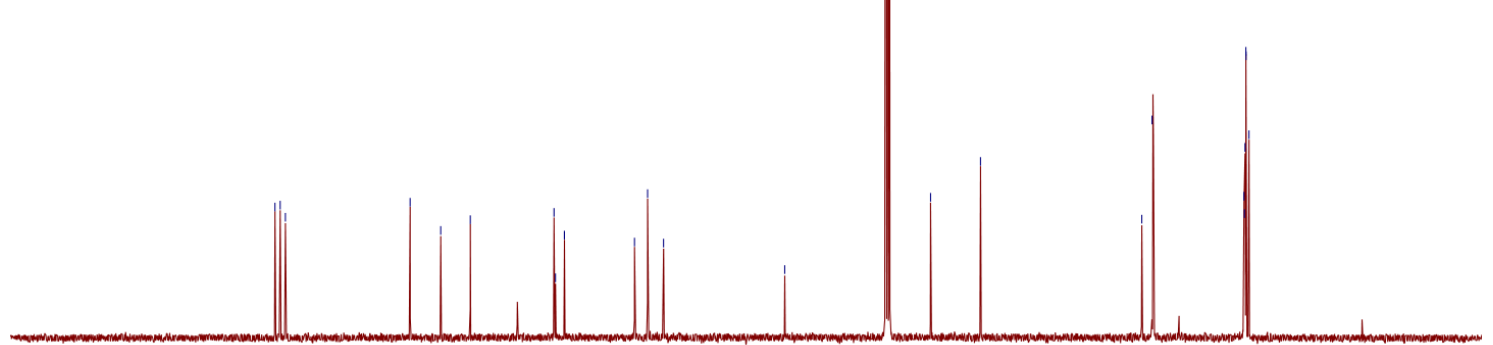

$\begin{array}{lllllllllllllllllllllll}210 & 200 & 190 & 180 & 170 & 160 & 150 & 140 & 130 & 120 & 110 & 100 & 90 & 80 & 70 & 60 & 50 & 40 & 30 & 20 & 10 & 0 & -10\end{array}$

2. Characterizations of E-alkenes, Z-alkenes and reactions mixtures of geometrical isomerisation ${ }^{1} \mathrm{H}$ NMR of $\boldsymbol{Z}$-1a and reaction mixture of geometric isomerization of $\boldsymbol{E}$-1a to $\boldsymbol{Z}$-1a 


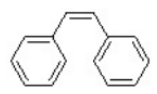

z-1 a

${ }^{1} \mathrm{H} \mathrm{NMR}\left(400 \mathrm{MHz}, \mathrm{CDCl}_{3}\right)$

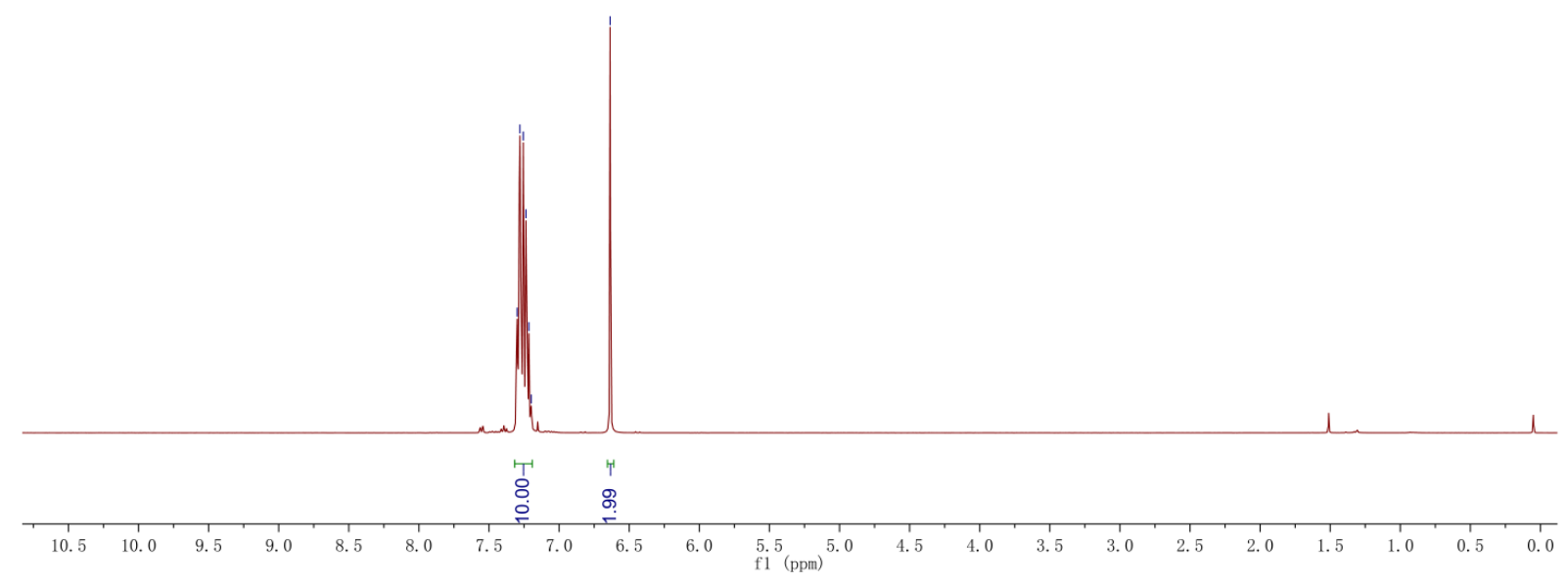

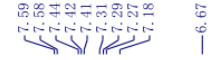
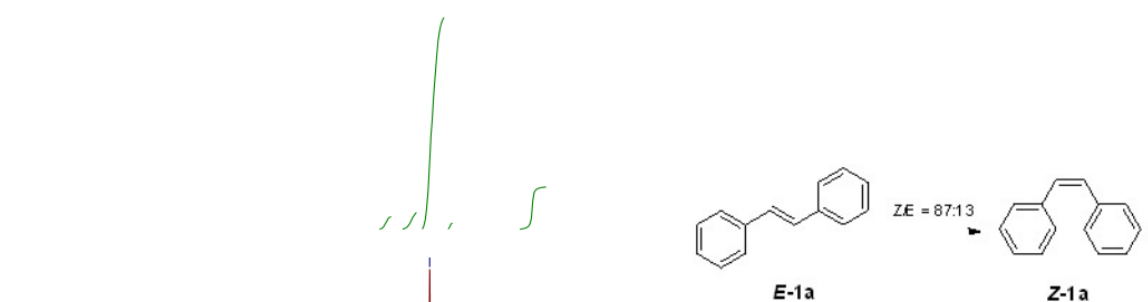

${ }^{1} \mathrm{H} \mathrm{NMR}\left(400 \mathrm{MHz}, \mathrm{CDCl}_{3}\right)$

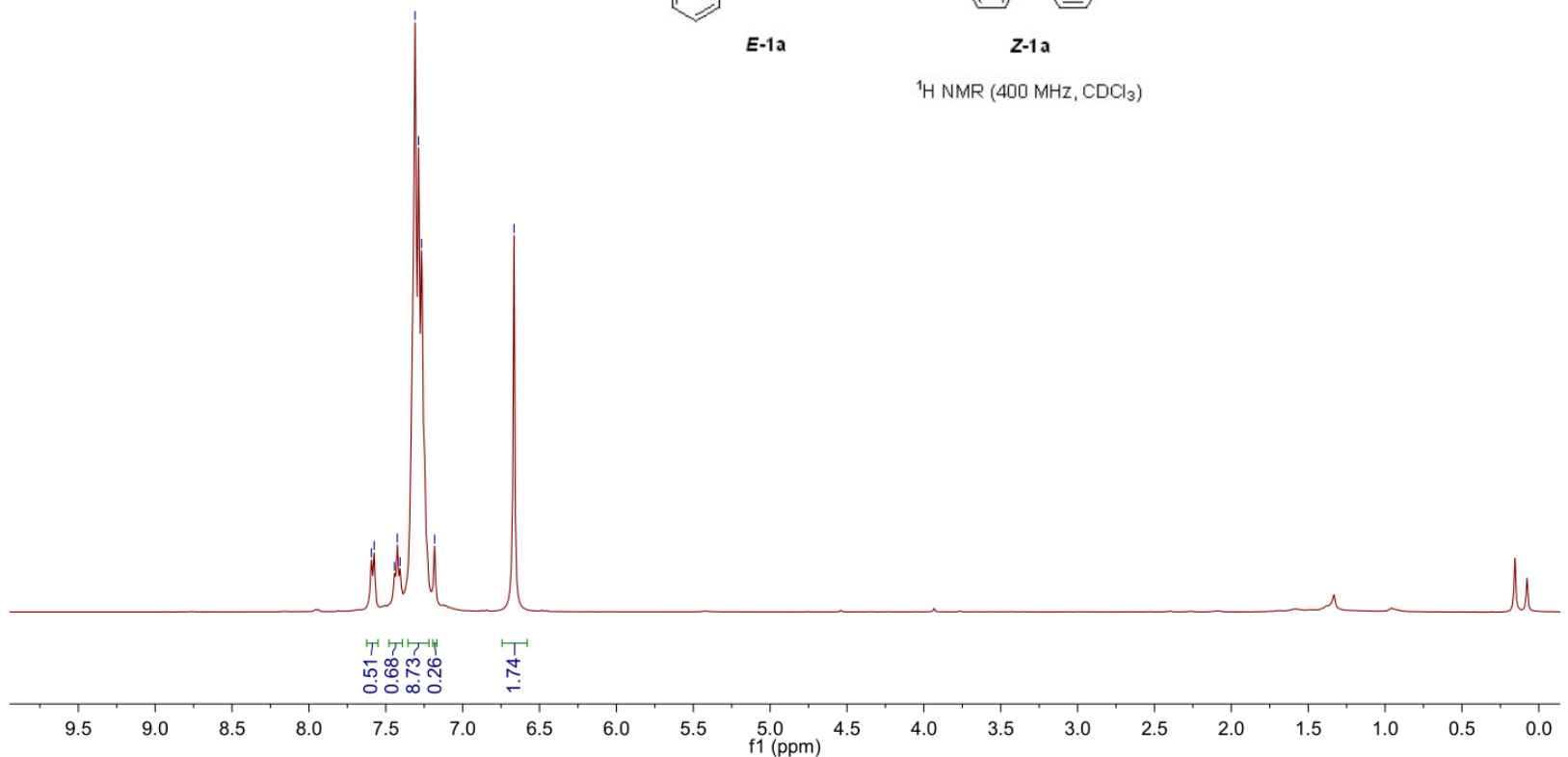

${ }^{1} \mathrm{H}$ NMR of $\boldsymbol{E}-\mathbf{1 b}, \boldsymbol{Z}-\mathbf{1 b}$ and reaction mixture of geometric isomerization of $\boldsymbol{E}-\mathbf{1 b}$ to $\boldsymbol{Z}-\mathbf{1 b}$ 


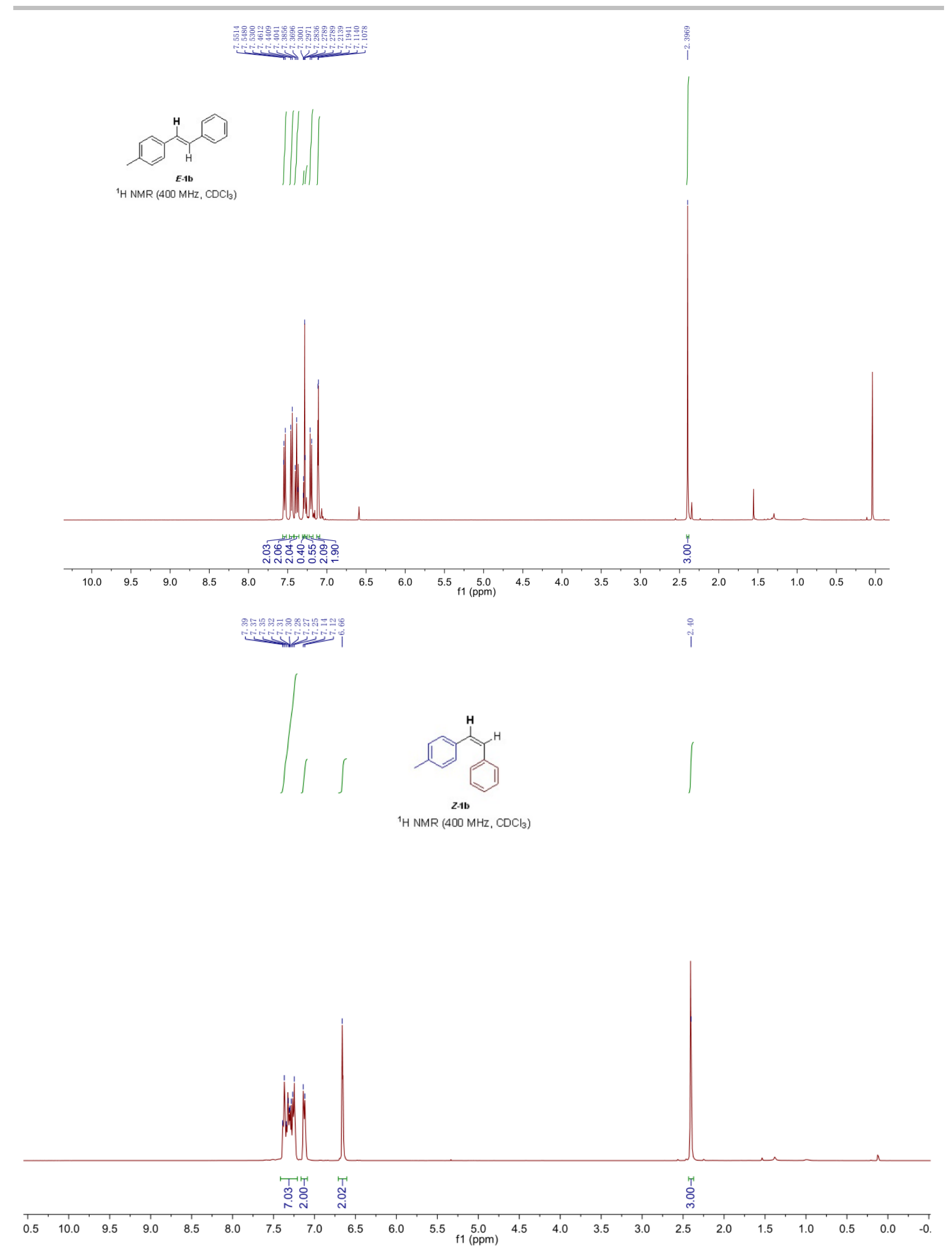




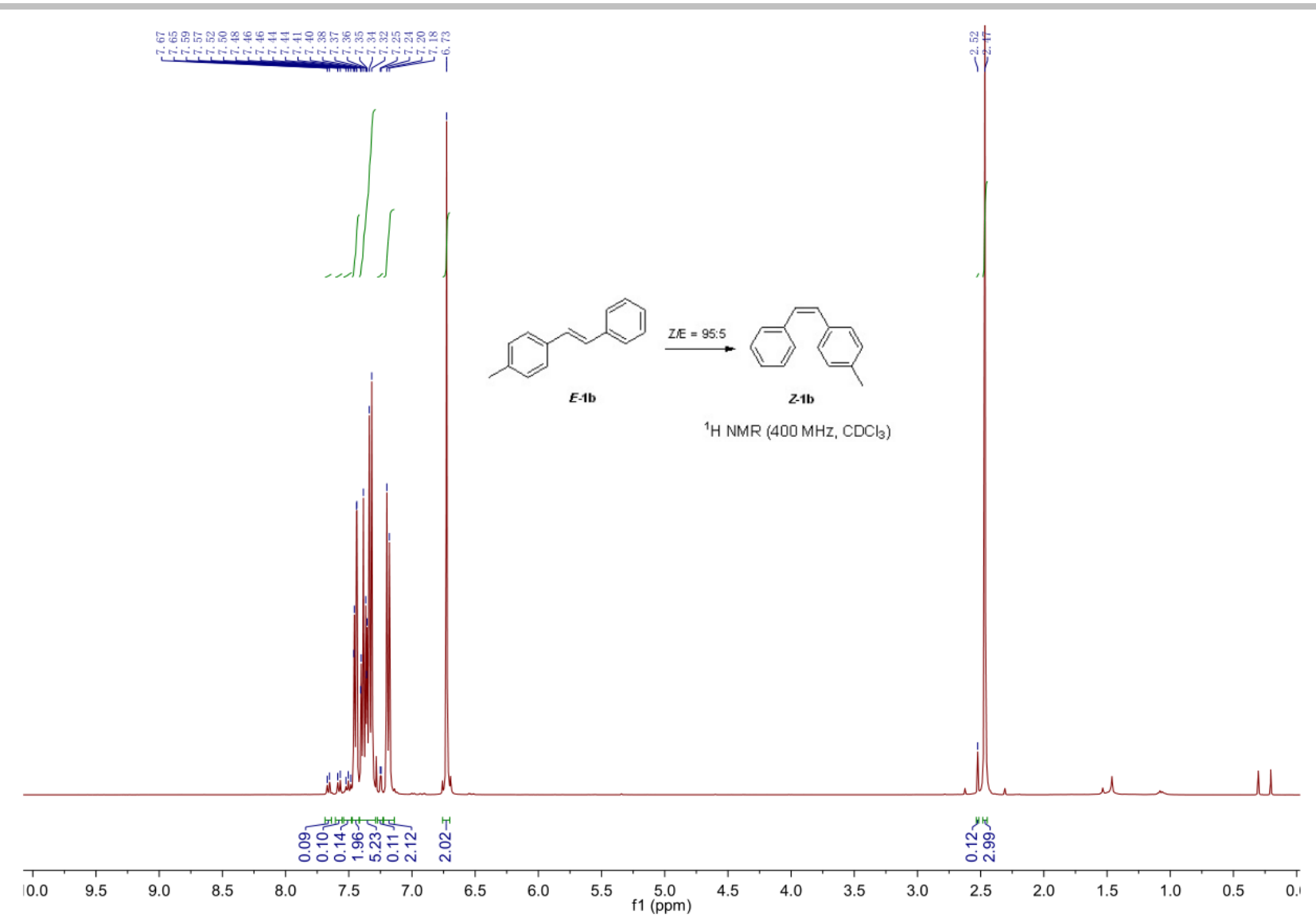

${ }^{1} \mathrm{H}$ NMR of $\boldsymbol{E}$-1c, $\boldsymbol{Z}$-1c and reaction mixture of geometric isomerization of $\boldsymbol{E}$-1c to $\boldsymbol{Z}$-1c

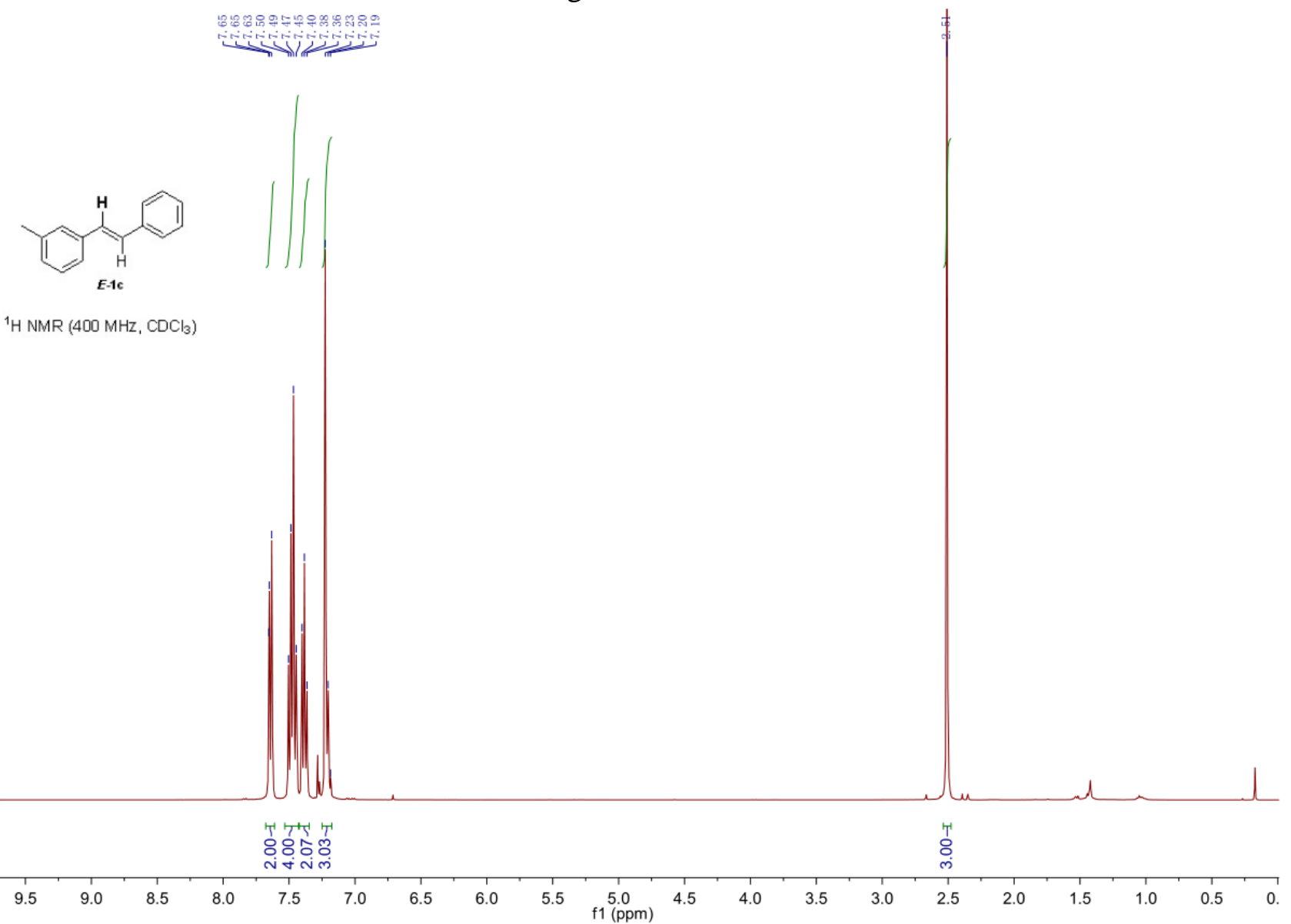




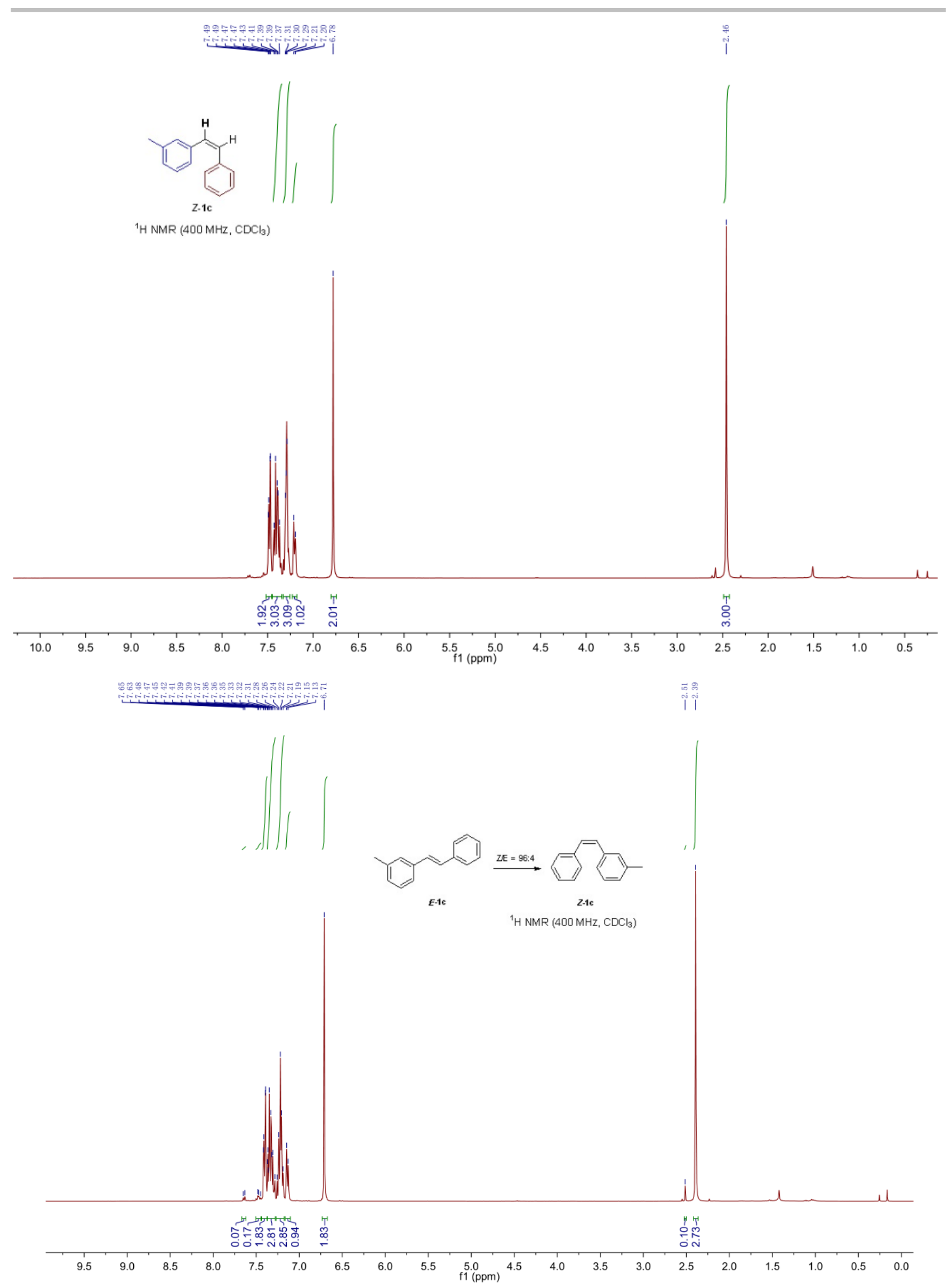


${ }^{1} \mathrm{H}$ NMR of $\boldsymbol{E}$-1d, $\boldsymbol{Z}$-1d and reaction mixture of geometric isomerization of $\boldsymbol{E}$-1d to $\boldsymbol{Z}$-1d :ํㅜㅇㅛ

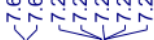

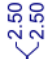
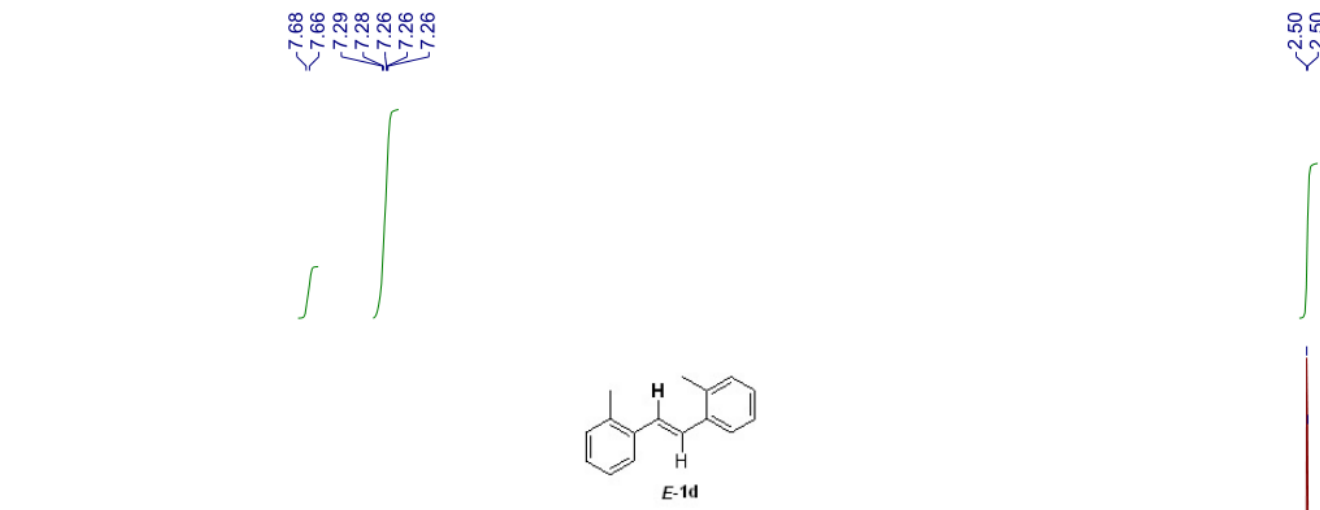

${ }^{1} \mathrm{H} \mathrm{NMR}\left(400 \mathrm{MHz}, \mathrm{CDCl}_{3}\right)$
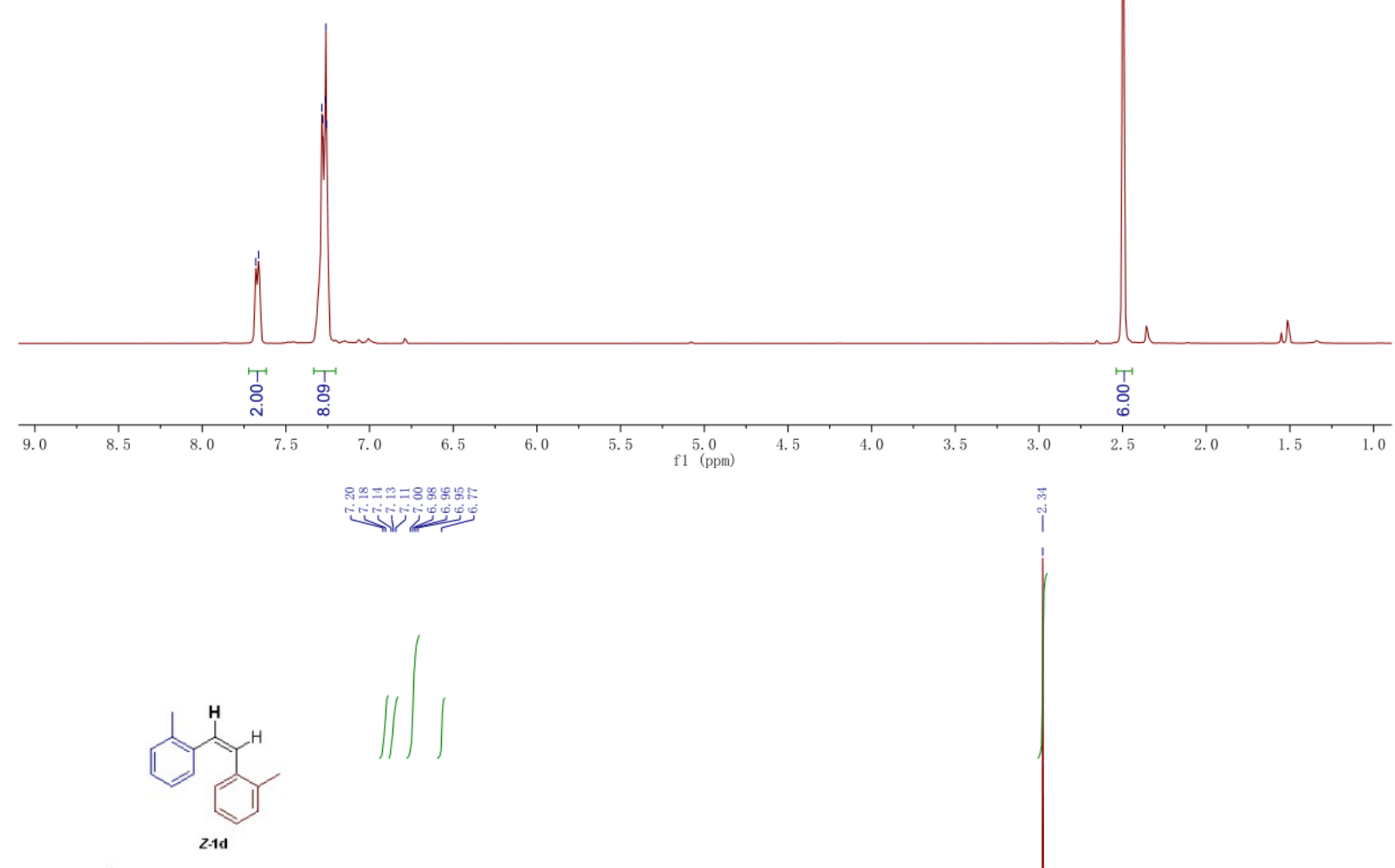

${ }^{1} \mathrm{H} \mathrm{NMR}\left(400 \mathrm{MHz}, \mathrm{CDCl}_{3}\right)$

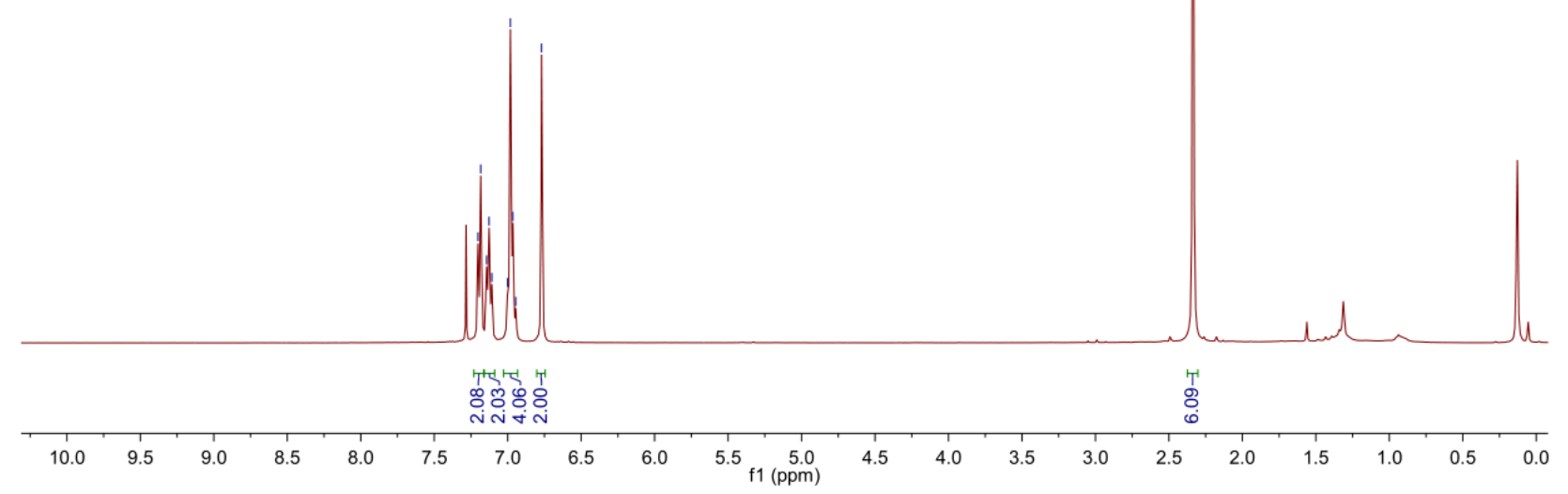




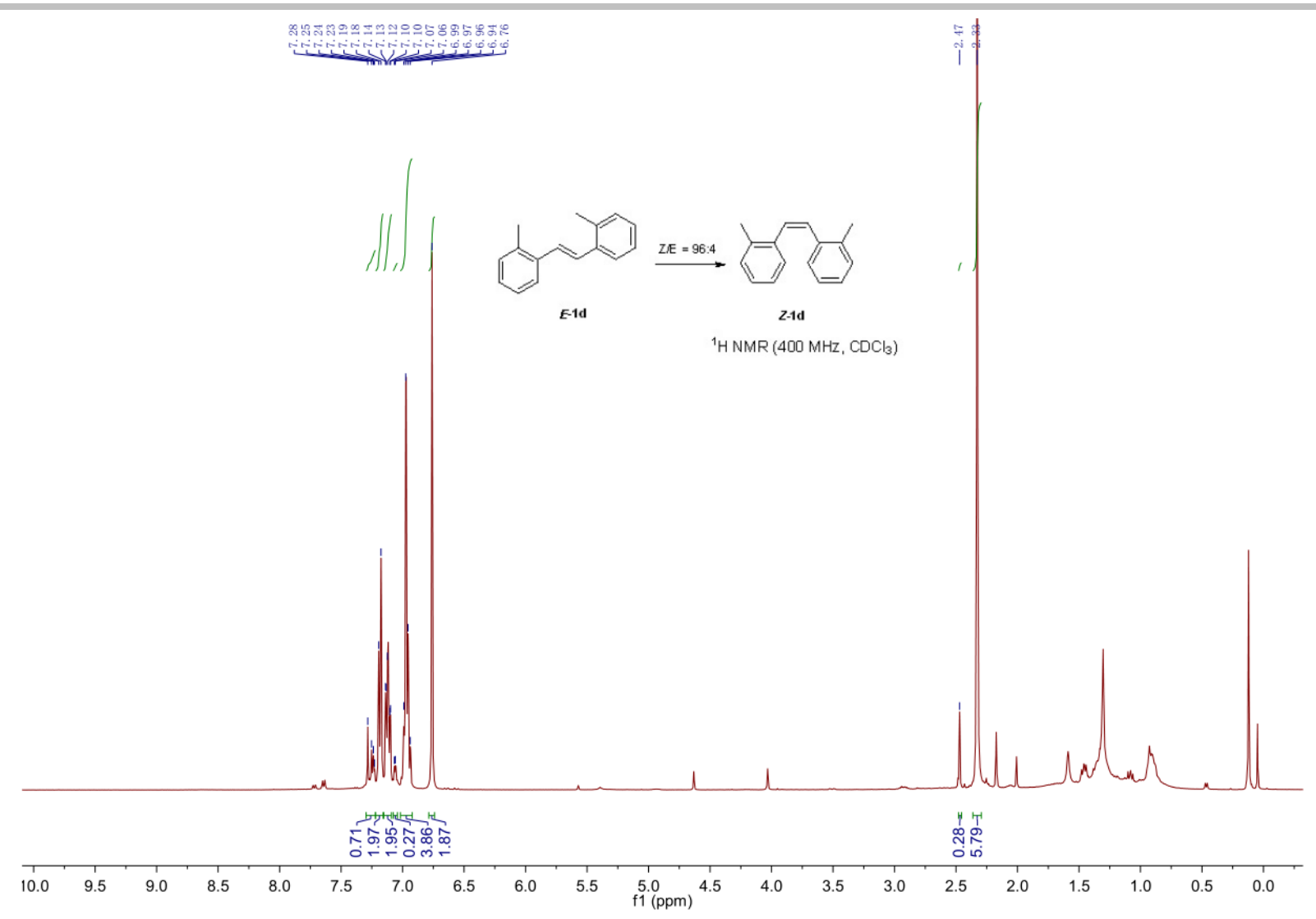

${ }^{1} \mathrm{H}$ NMR of $\boldsymbol{E}$-1e, Z-1e and reaction mixture of geometric isomerization of $\boldsymbol{E}$-1e to $\boldsymbol{Z}$-1e

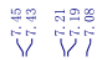
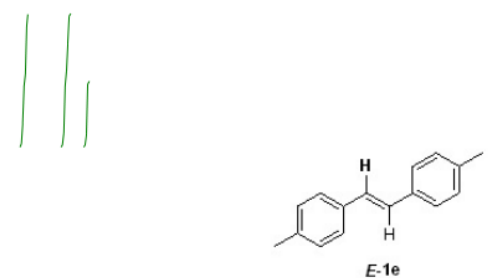

${ }^{1} \mathrm{H} \mathrm{NMR}\left(400 \mathrm{MHz}, \mathrm{CDCl}_{3}\right)$

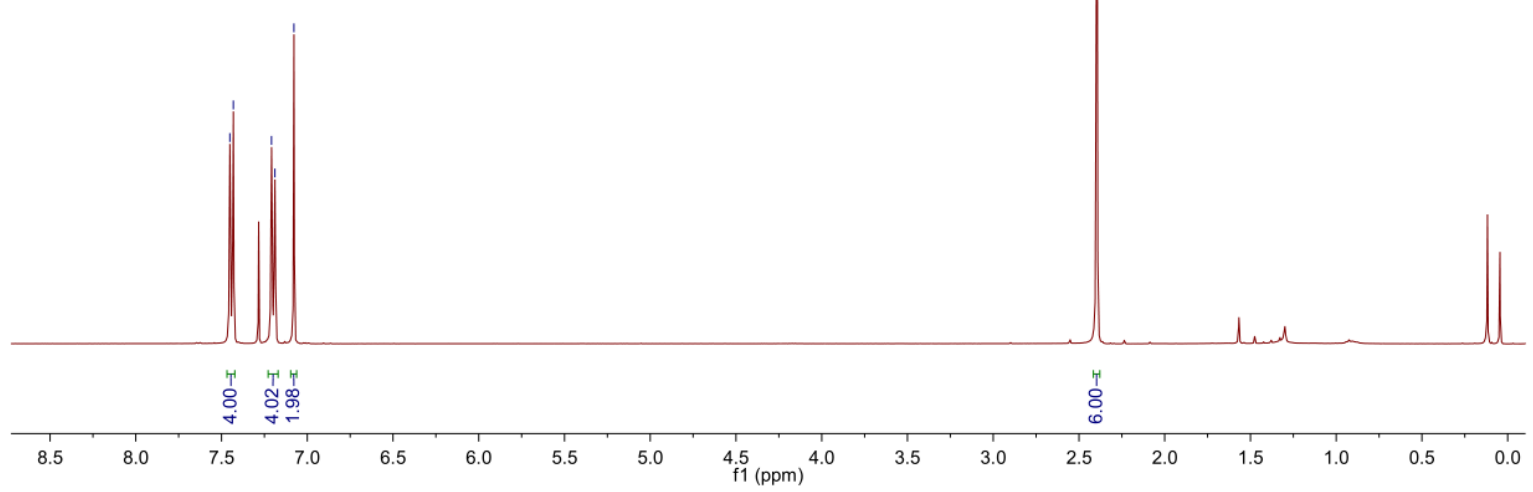




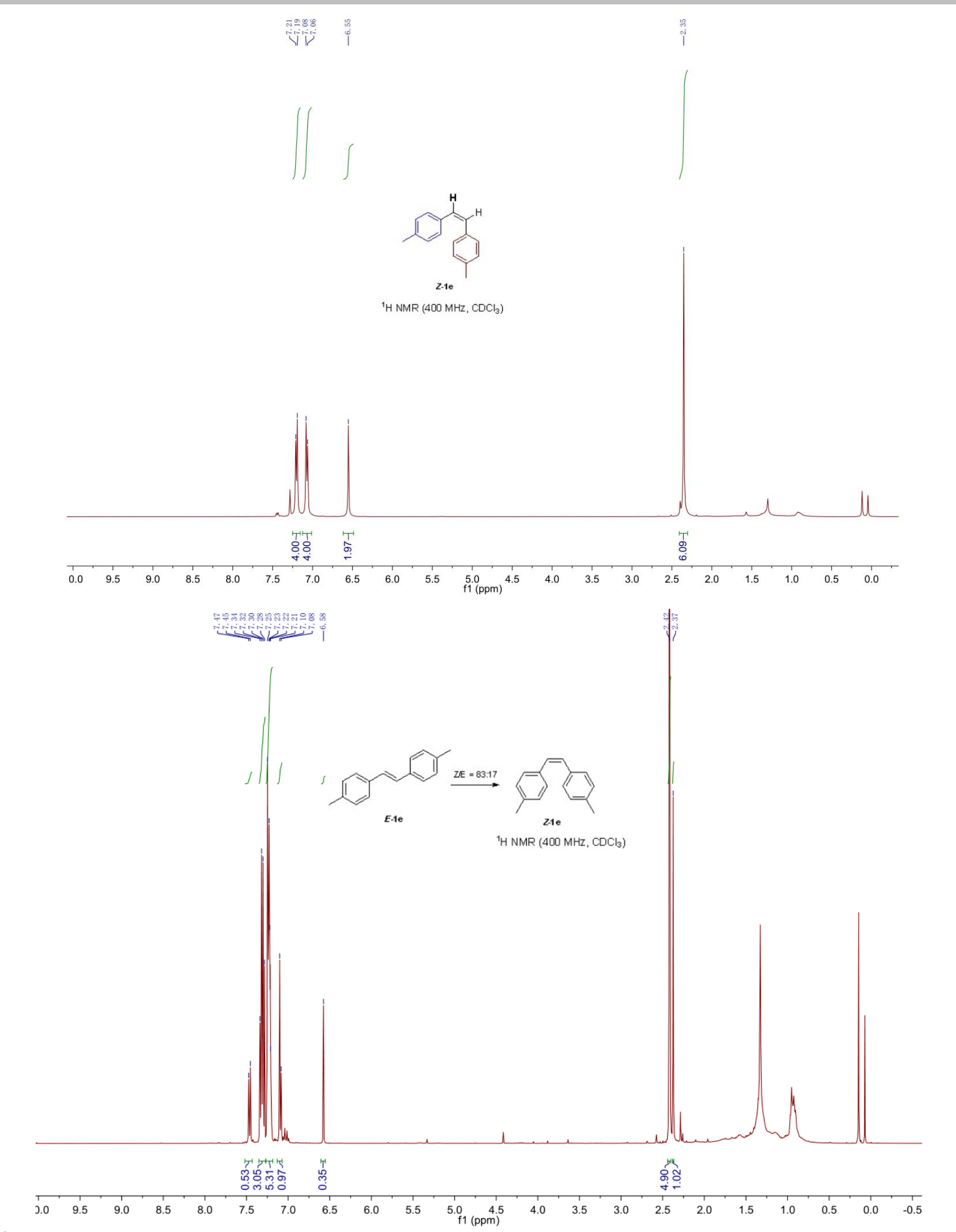

${ }^{1} \mathrm{H}$ NMR of $\boldsymbol{E}$-1f, $\boldsymbol{Z}$-1f and reaction mixture of geometric isomerization of $\boldsymbol{E}$-1f to $\boldsymbol{Z}$-1f 


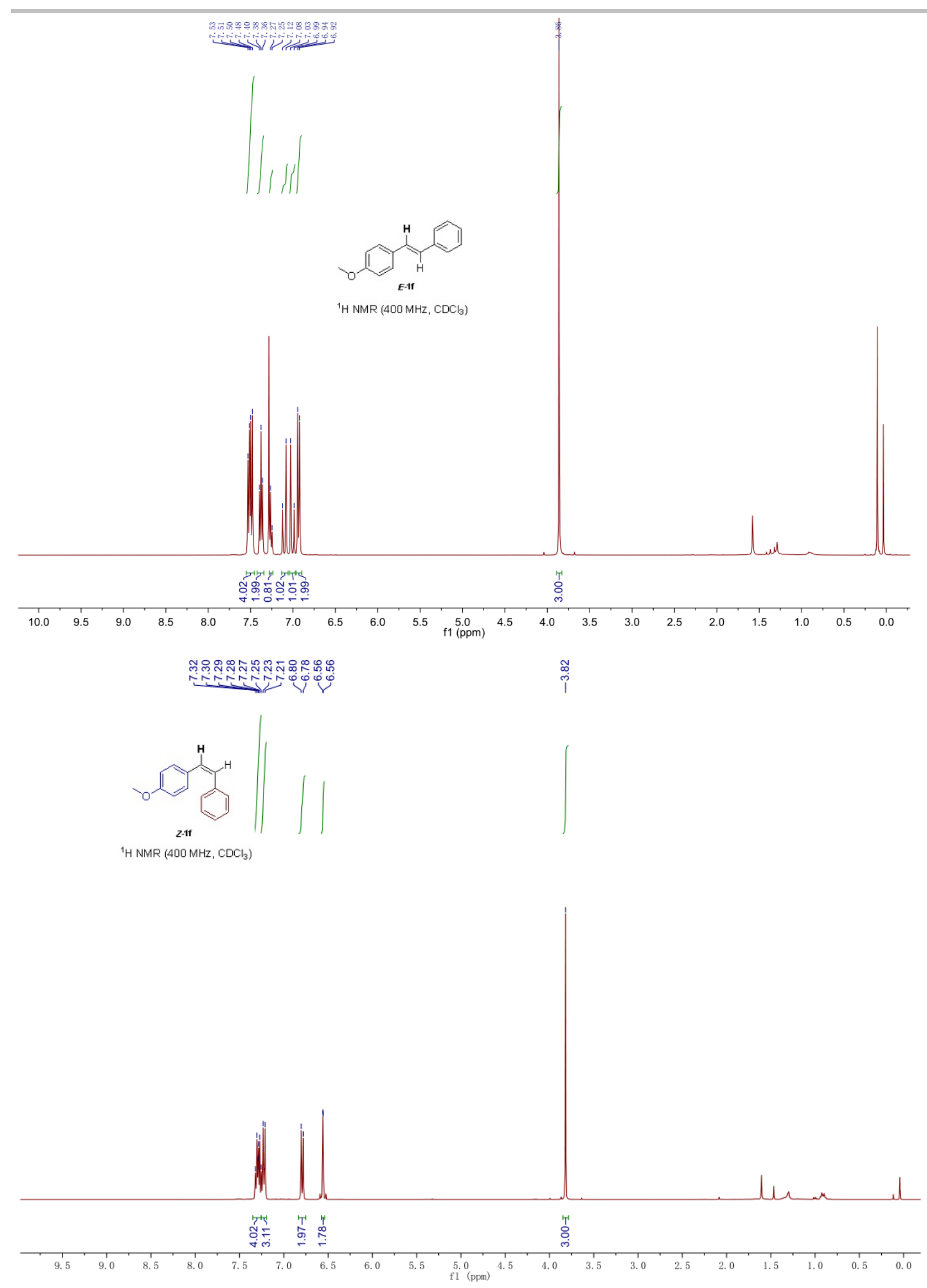




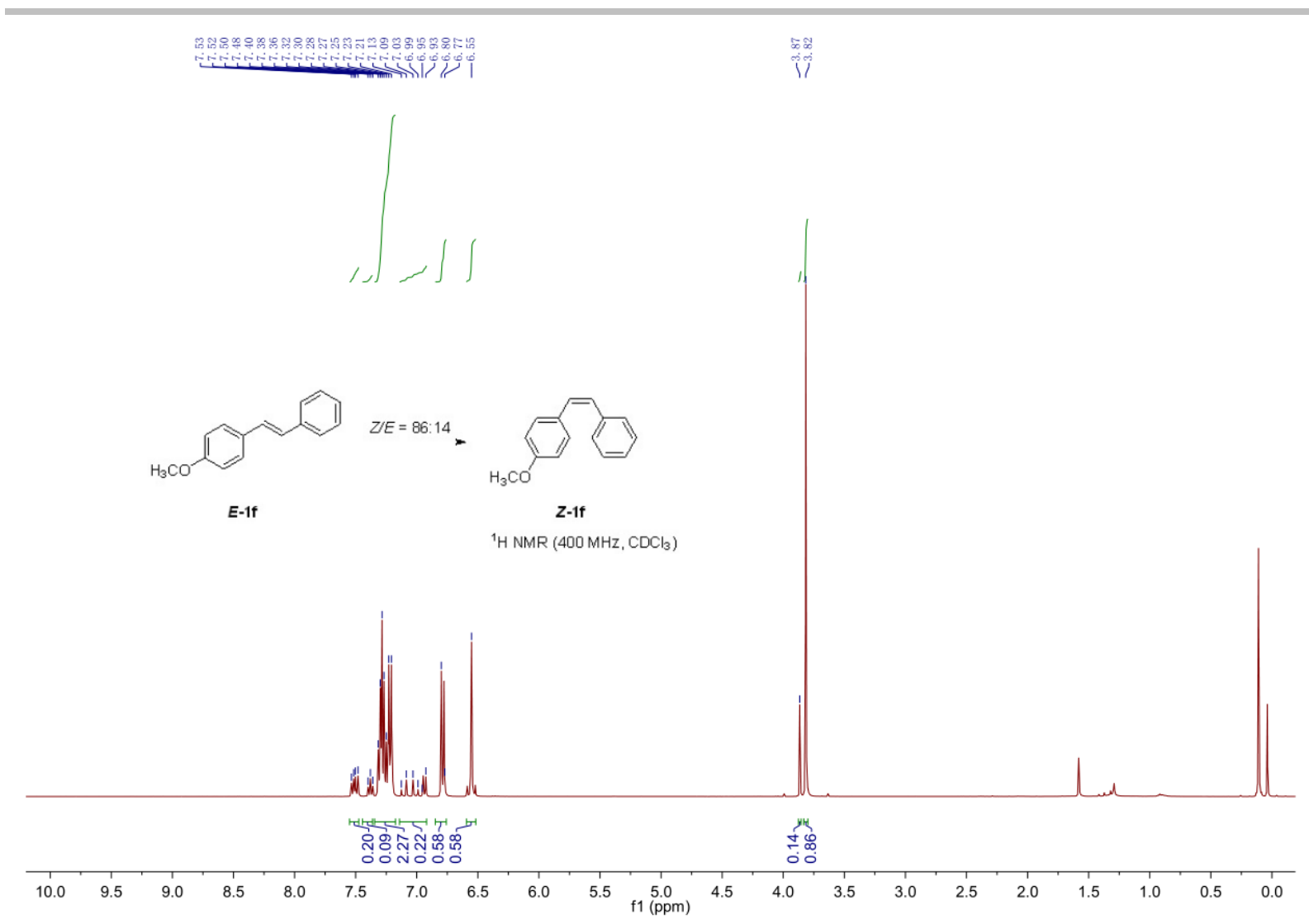

${ }^{1} \mathrm{H}$ NMR of $\boldsymbol{E}-\mathbf{1 g}, \boldsymbol{Z} \mathbf{- 1 g}$ and reaction mixture of geometric isomerization of $\boldsymbol{E} \mathbf{- 1 g}$ to $\boldsymbol{Z} \mathbf{- 1 g}$

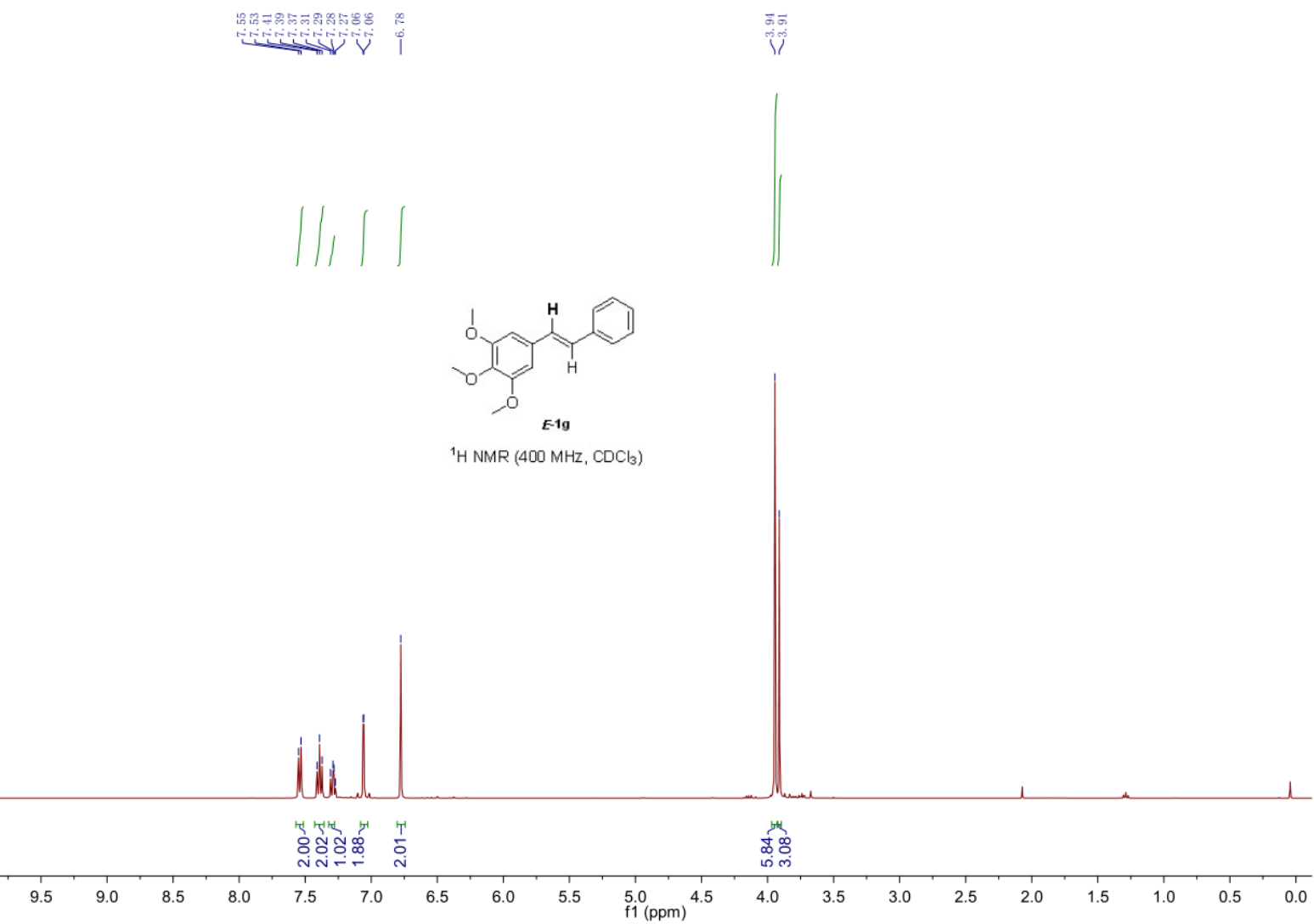




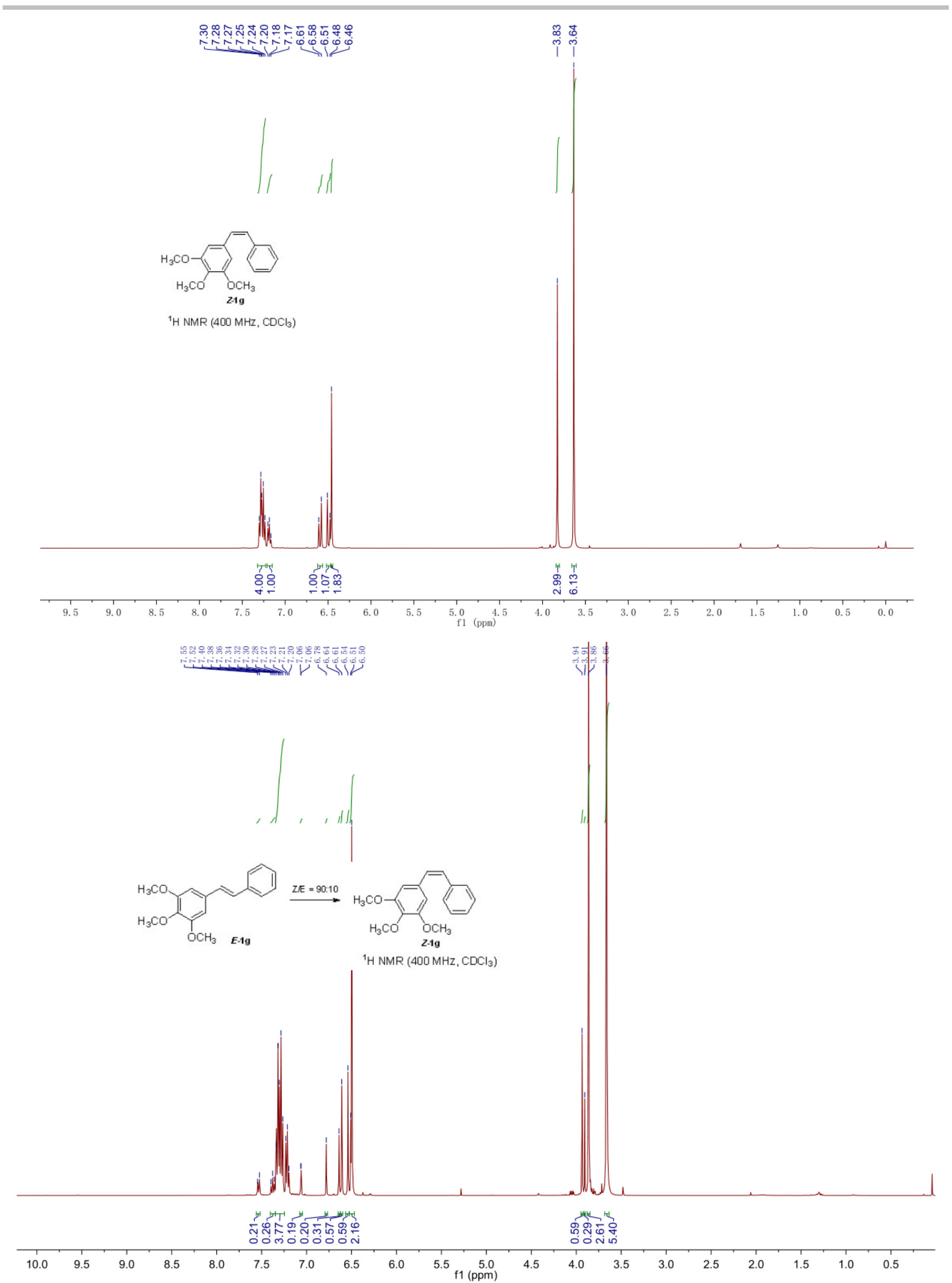

${ }^{1} \mathrm{H}$ NMR of $\boldsymbol{E}-\mathbf{1 h}, \boldsymbol{Z}-\mathbf{1 h}$ and reaction mixture of geometric isomerization of $\boldsymbol{E}-\mathbf{1 h}$ to $\boldsymbol{Z}-\mathbf{1 h}$ 


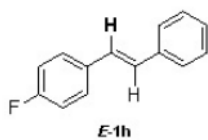

${ }^{1} \mathrm{H} \mathrm{NMR}\left(400 \mathrm{MHz}, \mathrm{CDCl}_{3}\right)$

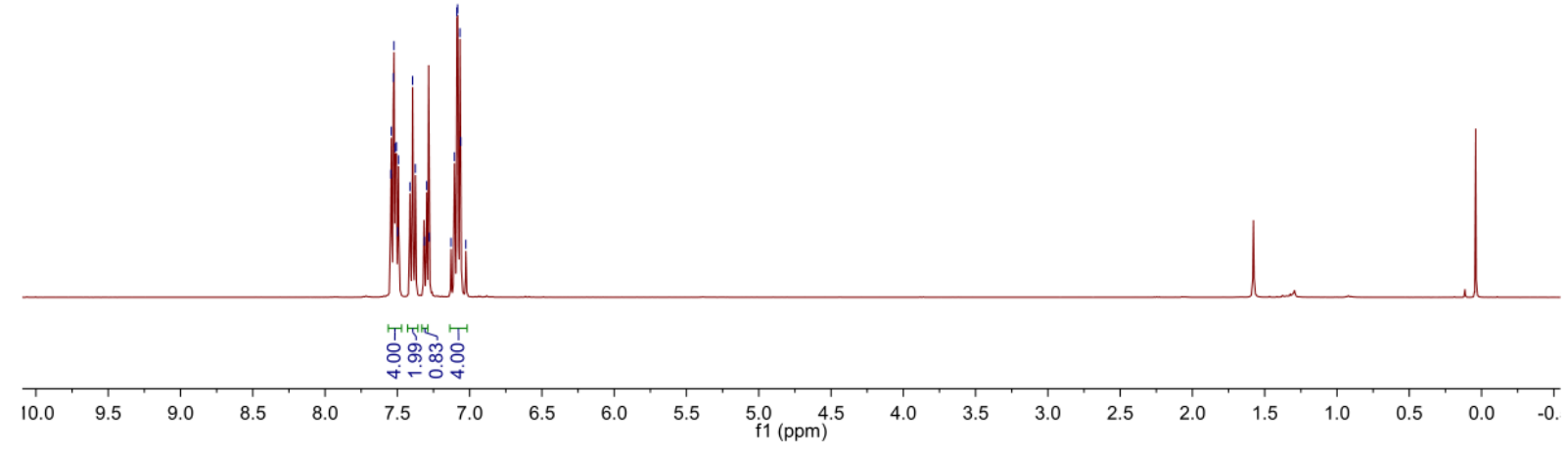

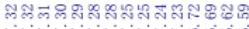

ritivitivitiol

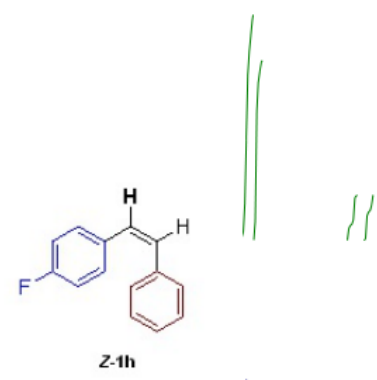

${ }^{1} \mathrm{H} \mathrm{NMR}\left(400 \mathrm{MHz}, \mathrm{CDCl}_{3}\right)$

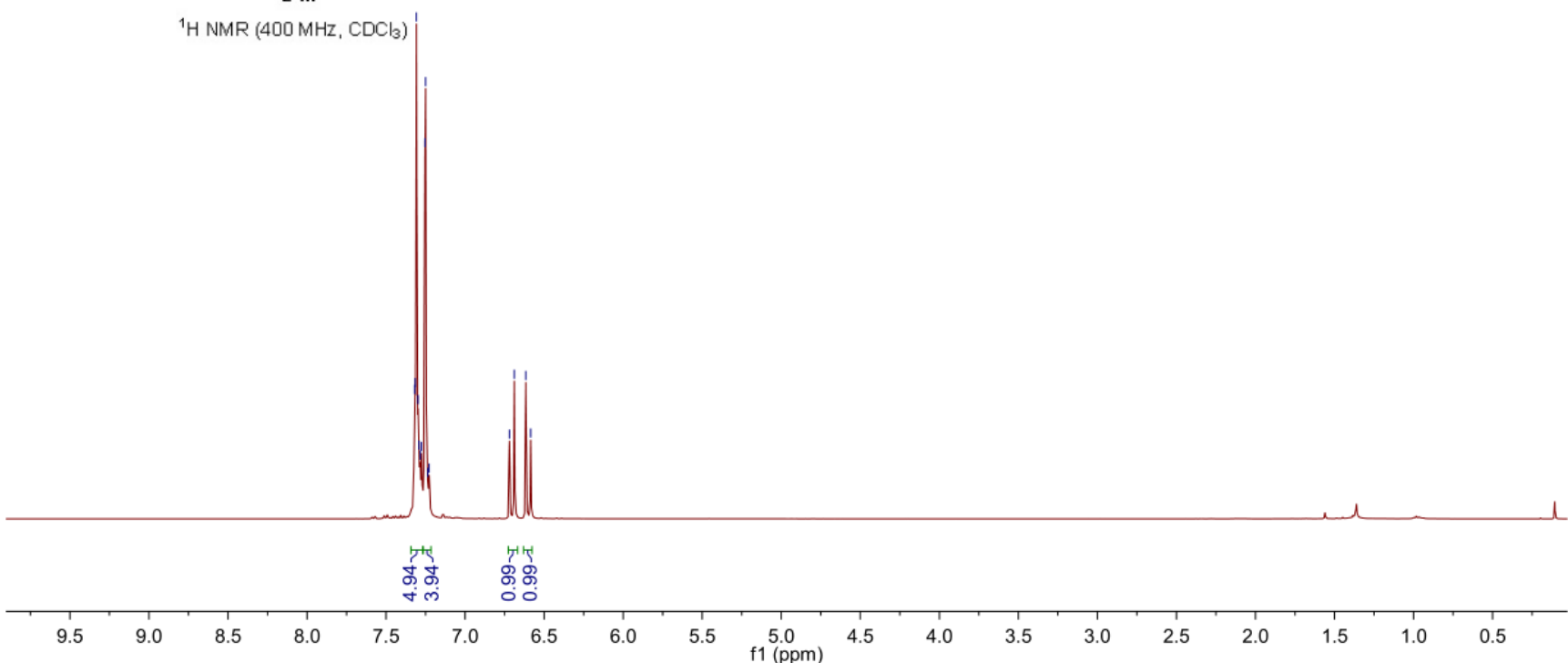




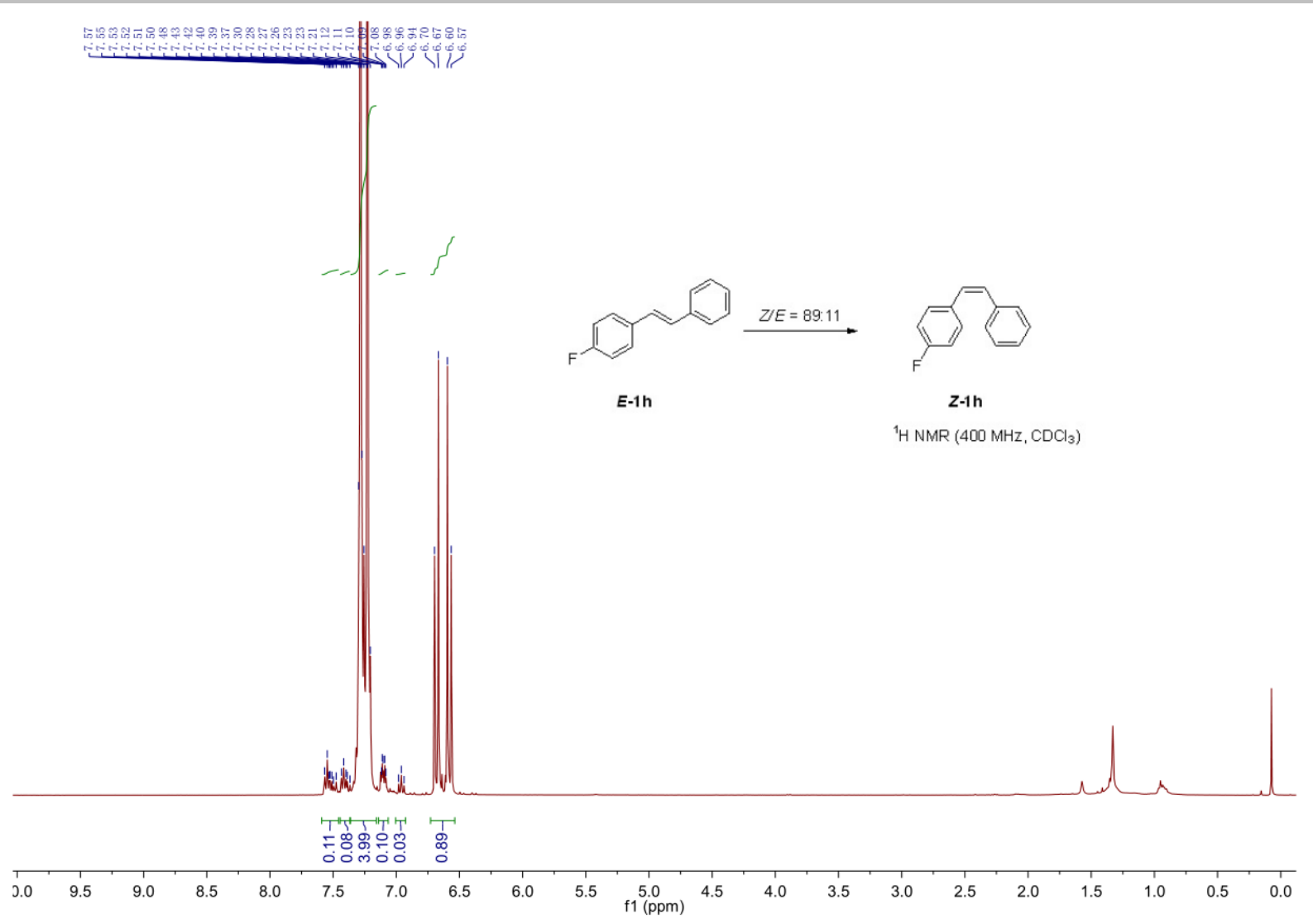

${ }^{1} \mathrm{H}$ NMR of $\boldsymbol{E}-\mathbf{1 i}, \boldsymbol{Z}-\mathbf{1 i}$ and reaction mixture of geometric isomerization of $\boldsymbol{E}-\mathbf{1 i}$ to $\boldsymbol{Z}-\mathbf{1 i}$

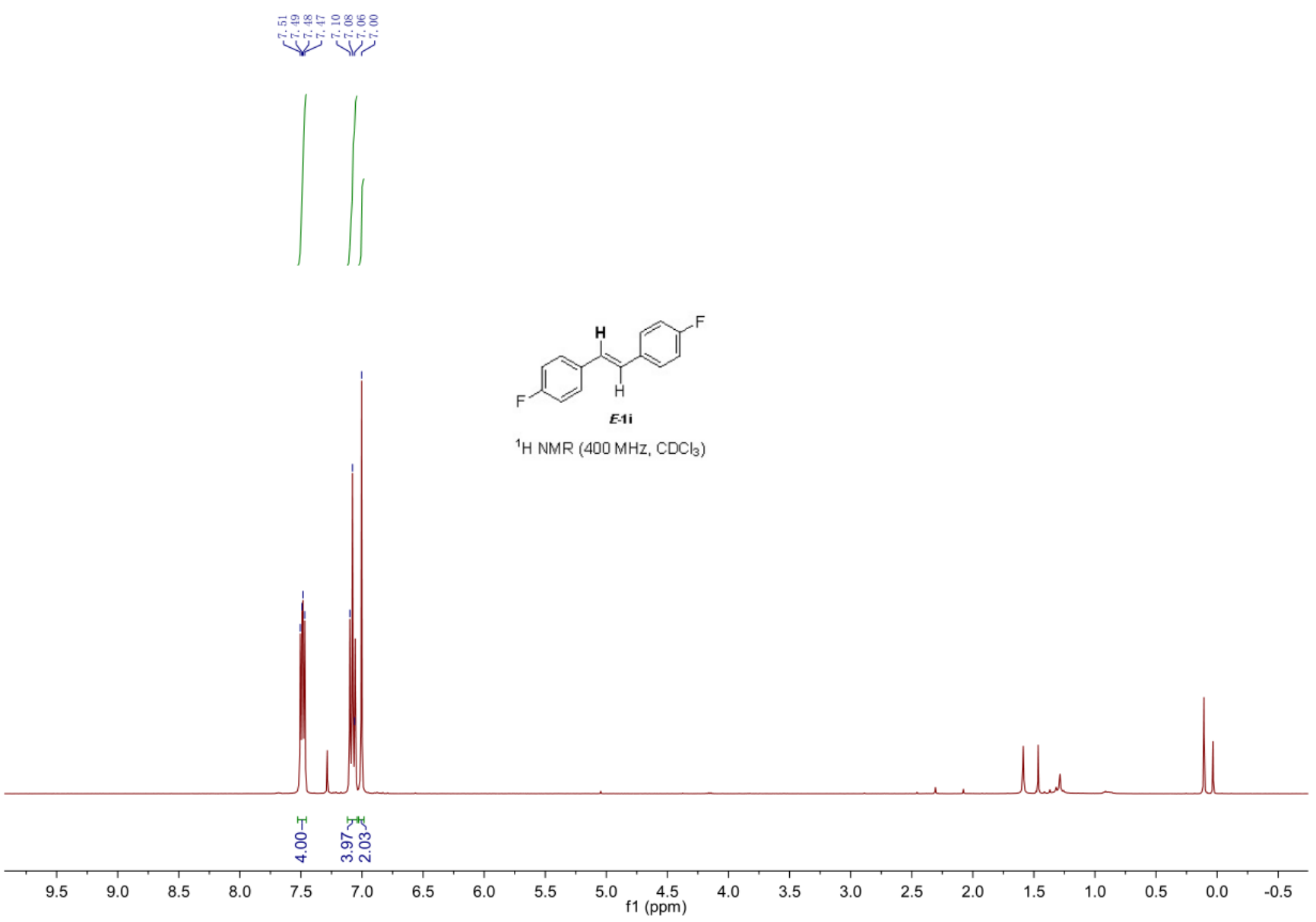



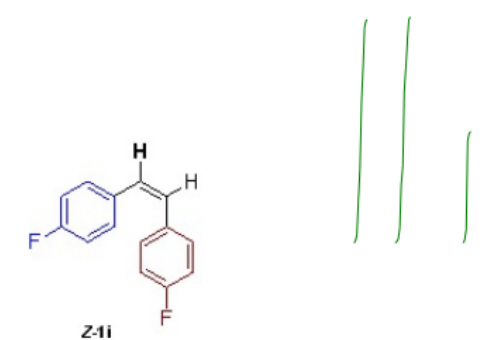

${ }^{1} \mathrm{H}$ NMR $\left(400 \mathrm{MHz}, \mathrm{CDCl}_{3}\right)$
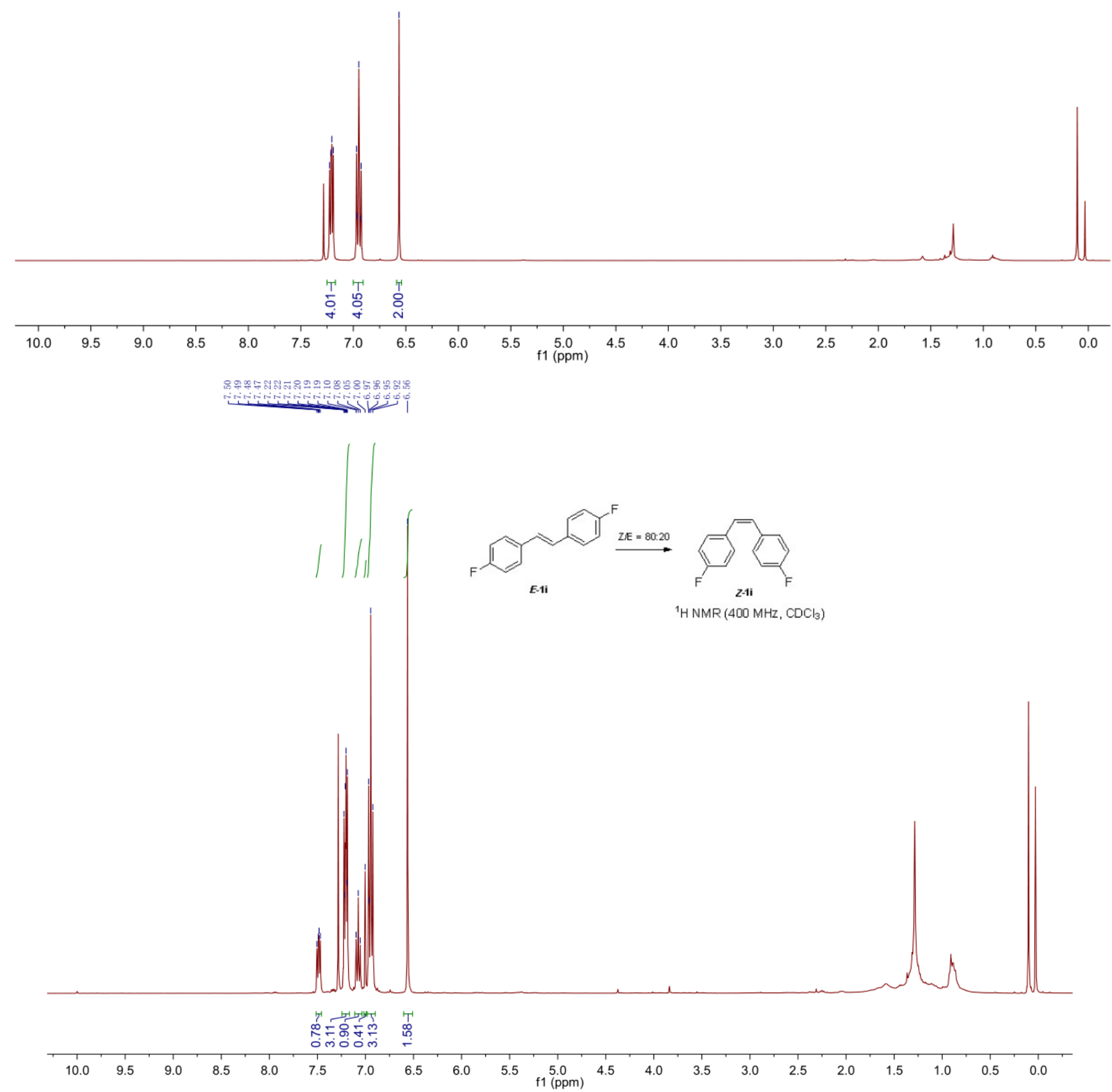

${ }^{1} \mathrm{H} N M R$ of $\boldsymbol{E} \mathbf{- 1 j}, \boldsymbol{Z}-\mathbf{1 j}$ and reaction mixture of geometric isomerization of $\boldsymbol{E} \mathbf{- 1} \mathbf{j}$ to $\boldsymbol{Z}-\mathbf{1 j}$ 


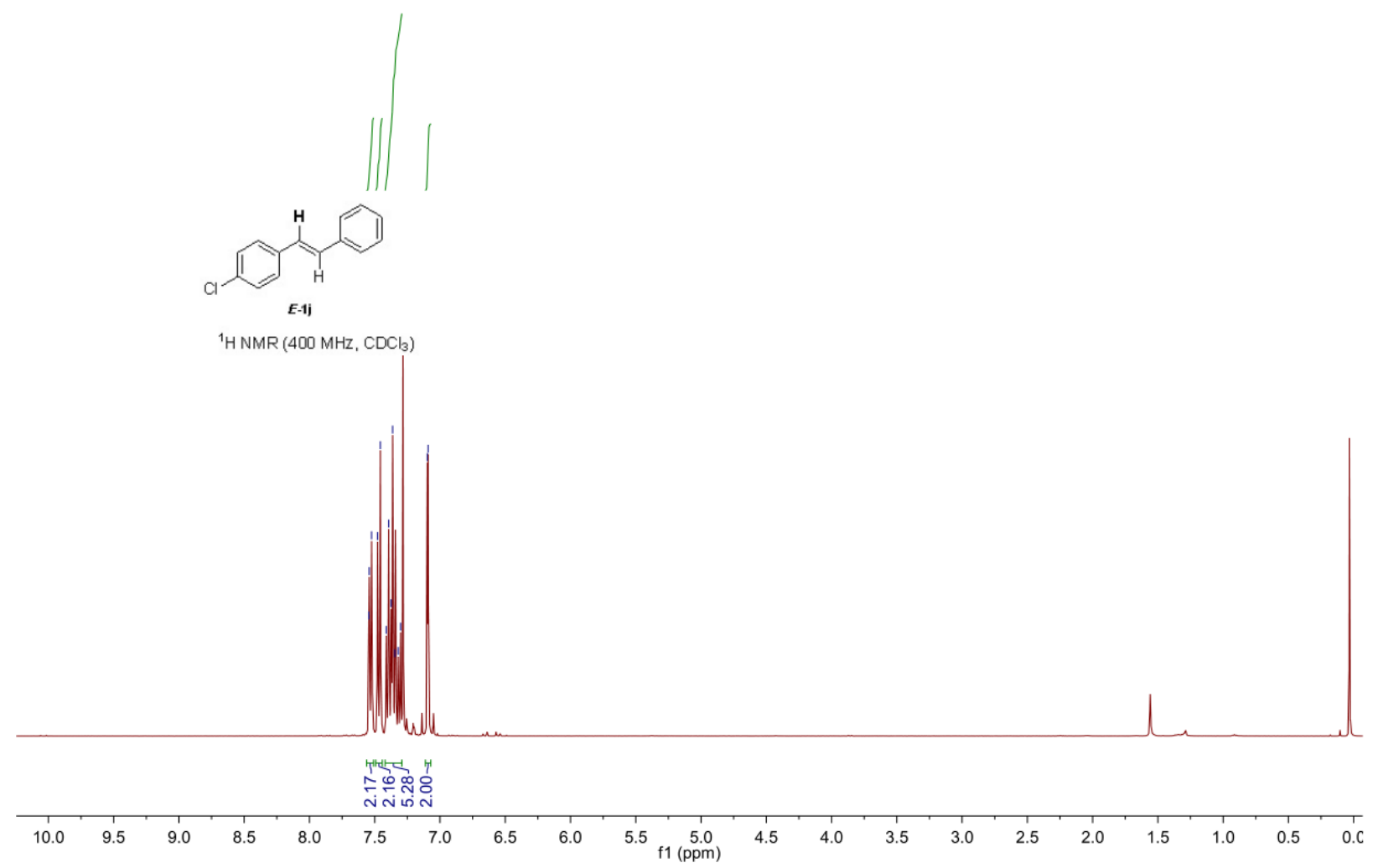

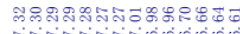

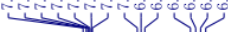

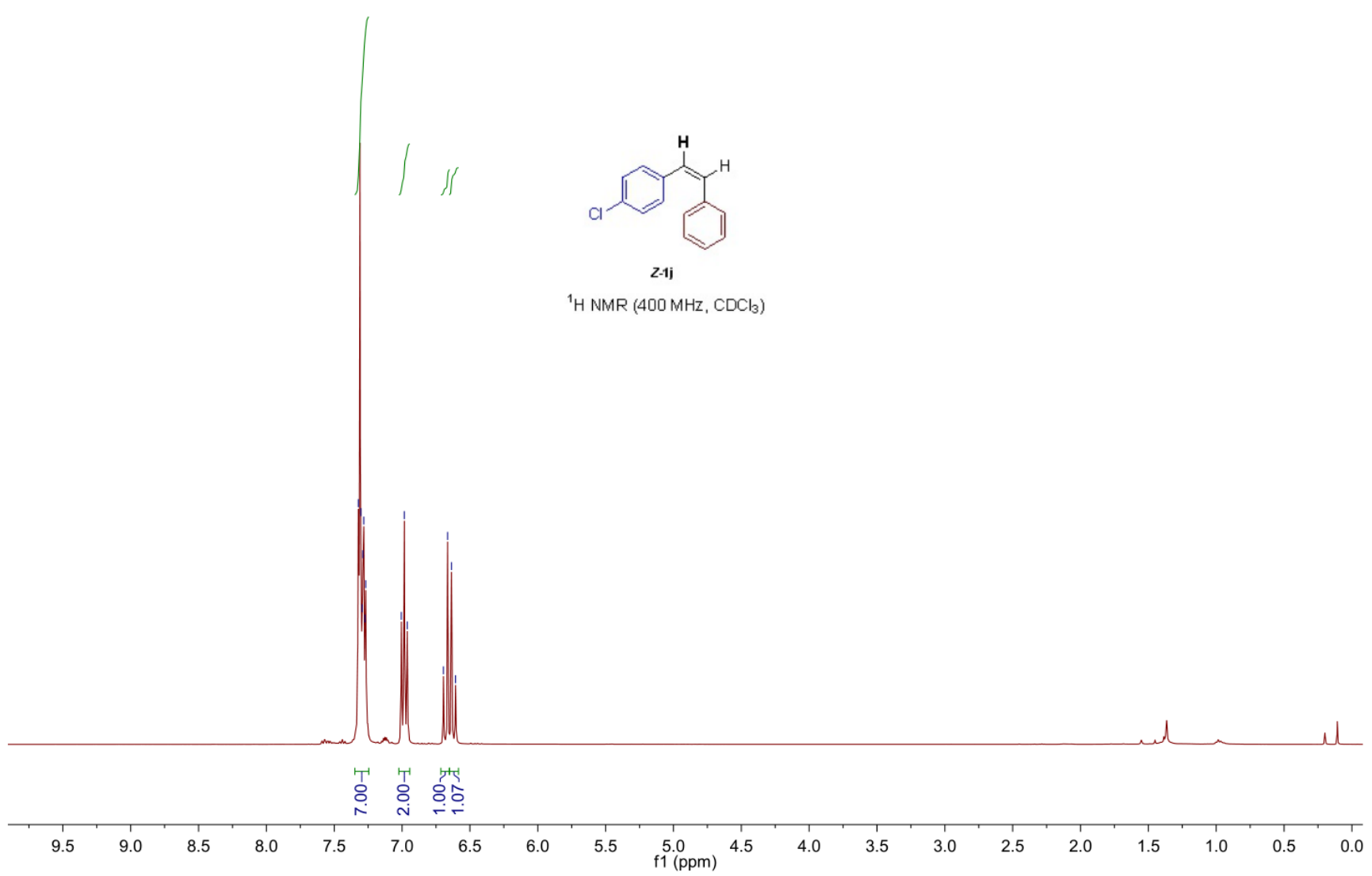




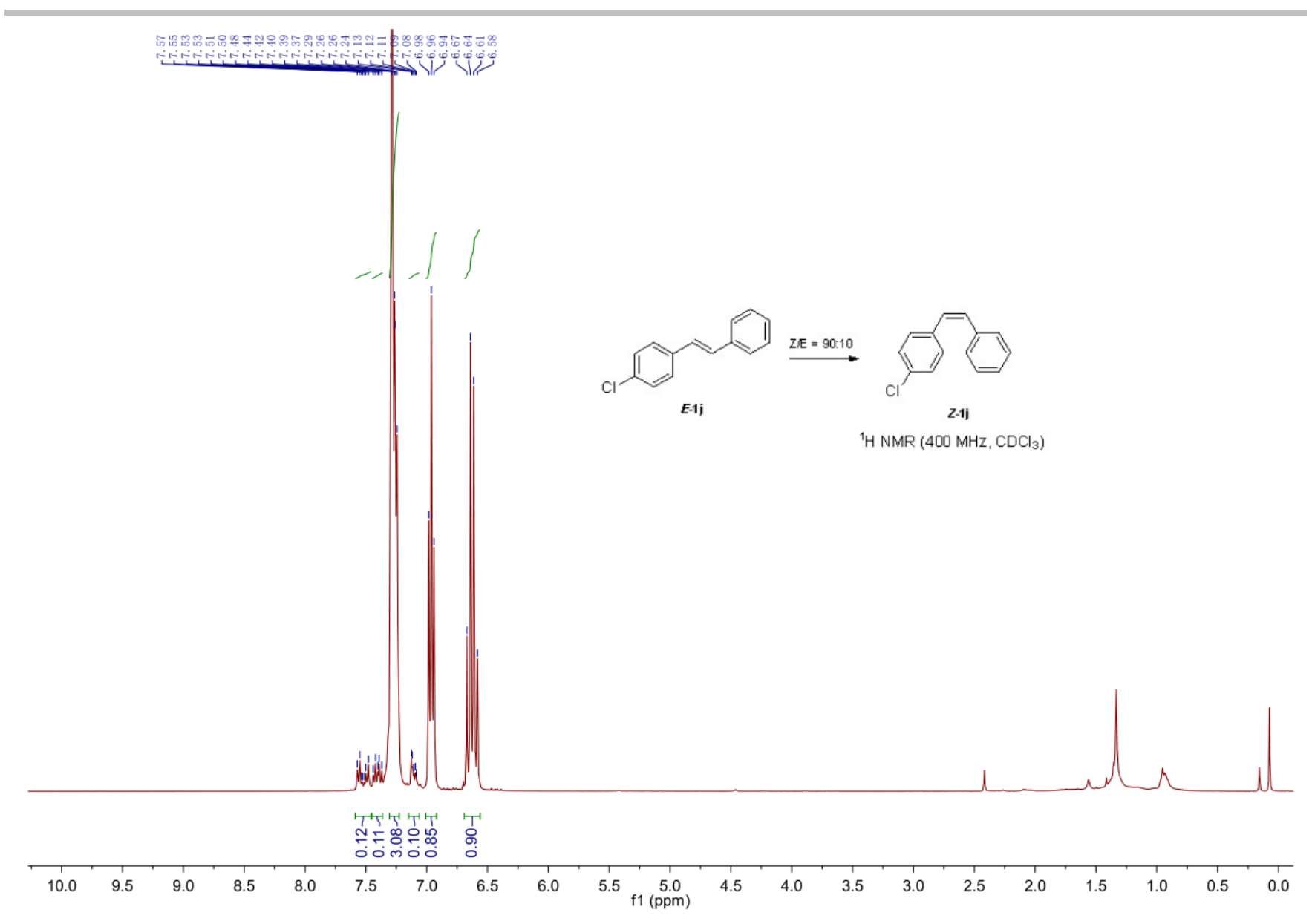

${ }^{1} \mathrm{H}$ NMR of $\boldsymbol{E}-\mathbf{1 k}, \boldsymbol{Z}-\mathbf{1 k}$ and reaction mixture of geometric isomerization of $\boldsymbol{E}-\mathbf{1 k}$ to $\boldsymbol{Z}-\mathbf{1 k}$

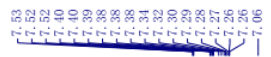
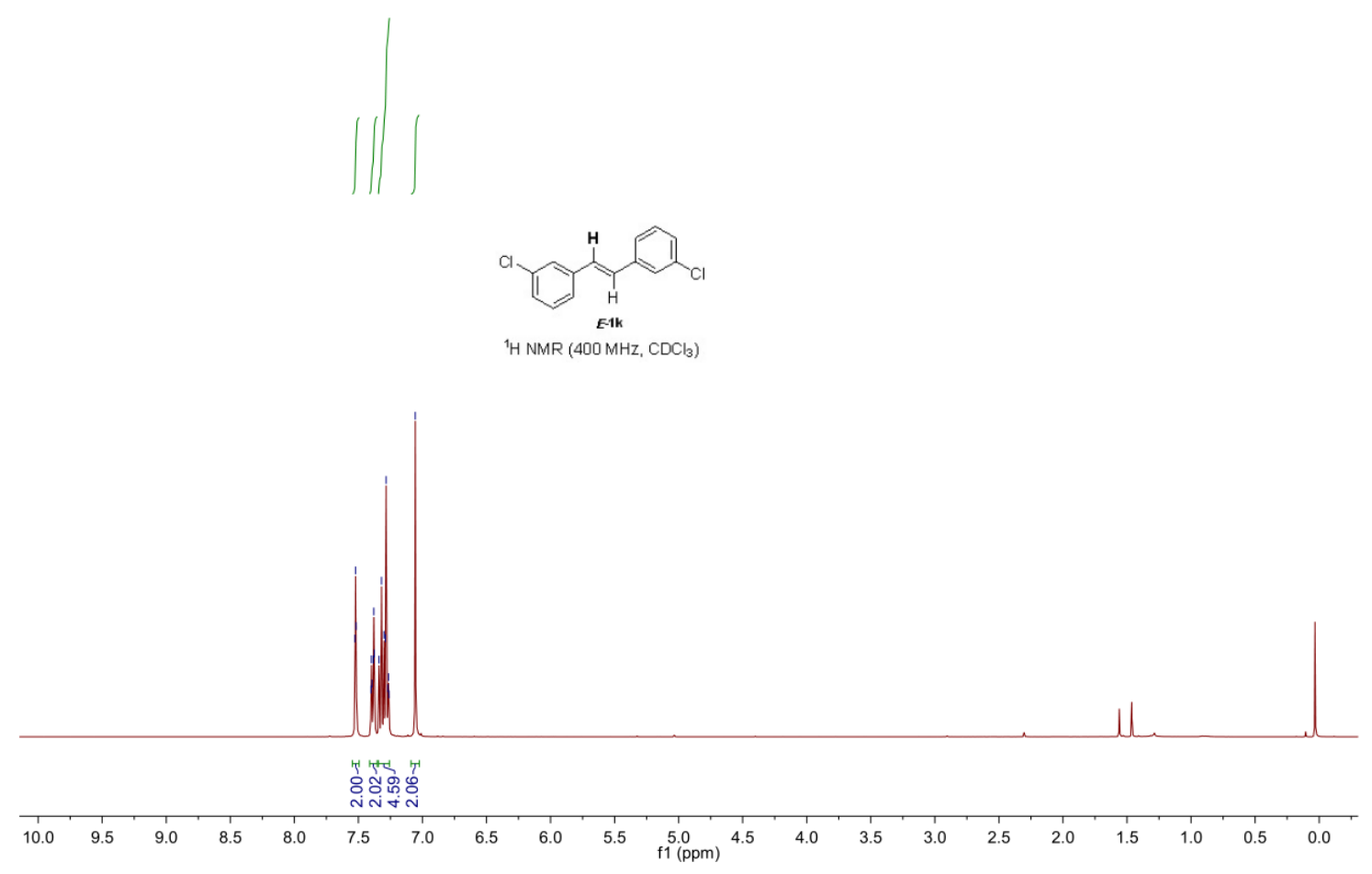


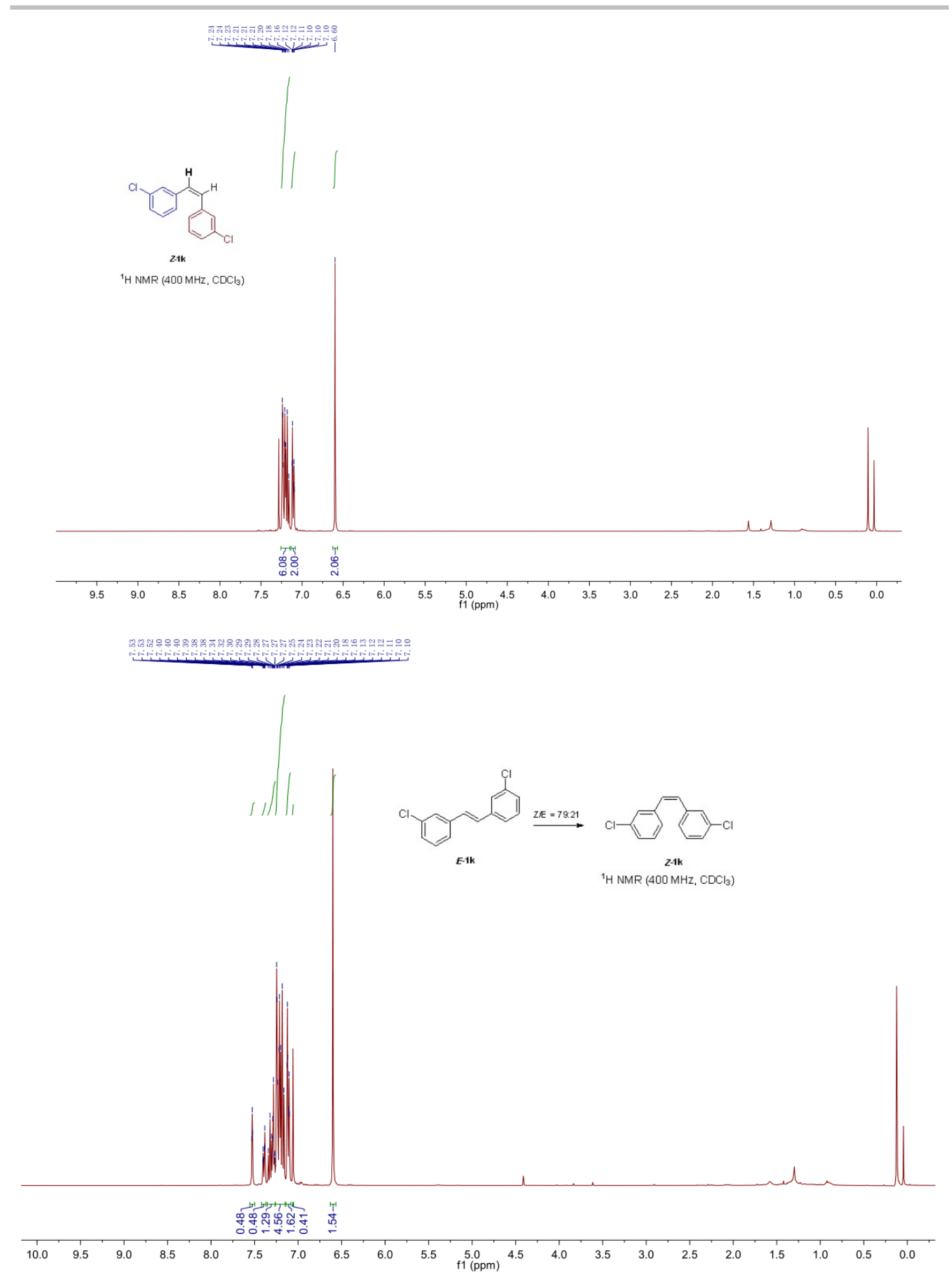

${ }^{1} \mathrm{H}$ NMR of $\boldsymbol{E}-\mathbf{1 1}, \boldsymbol{Z}-\mathbf{1 l}$ and reaction mixture of geometric isomerization of $\boldsymbol{E}-\mathbf{1 l}$ to $\boldsymbol{Z}-\mathbf{1 1}$ 


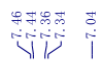
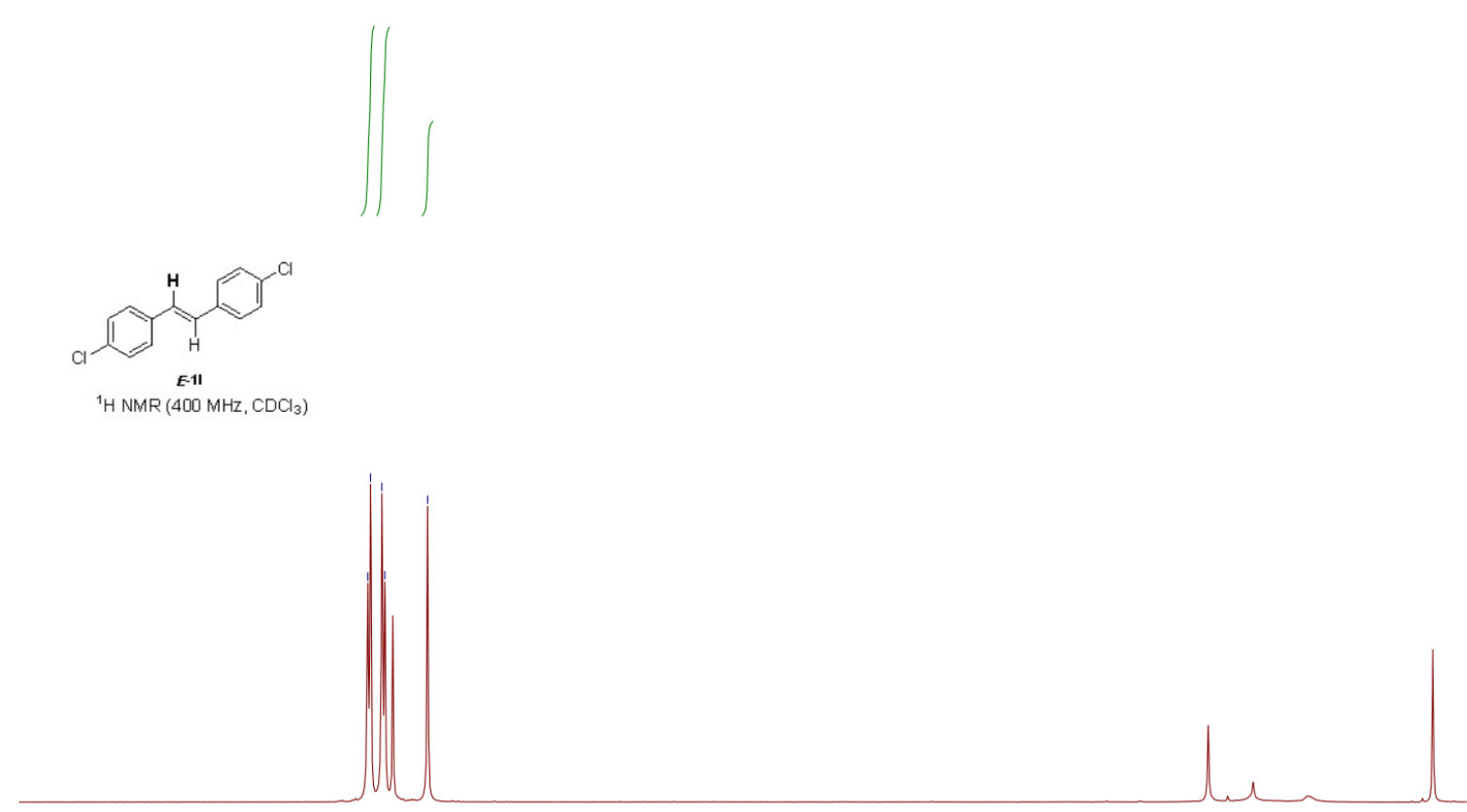

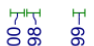

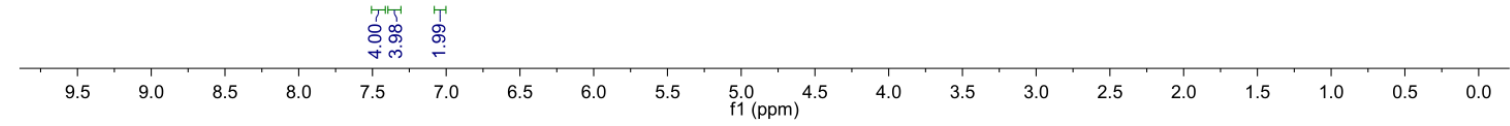

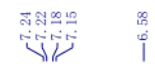
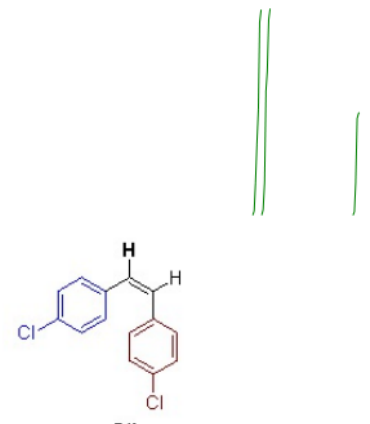

2-11

${ }^{1} \mathrm{H}$ NMR $\left(400 \mathrm{MHz}, \mathrm{CDCl}_{3}\right)$

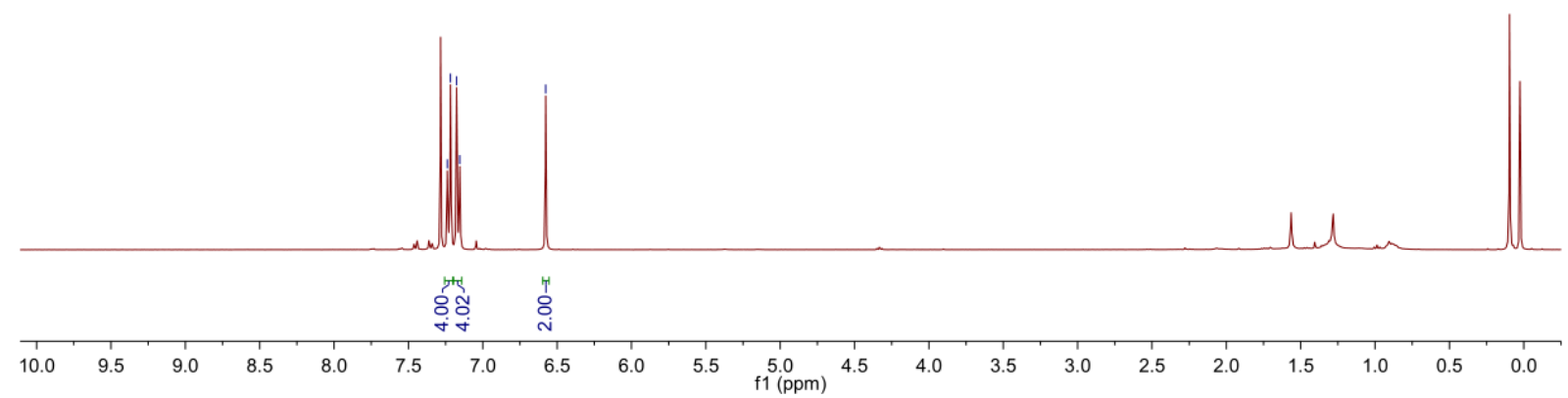




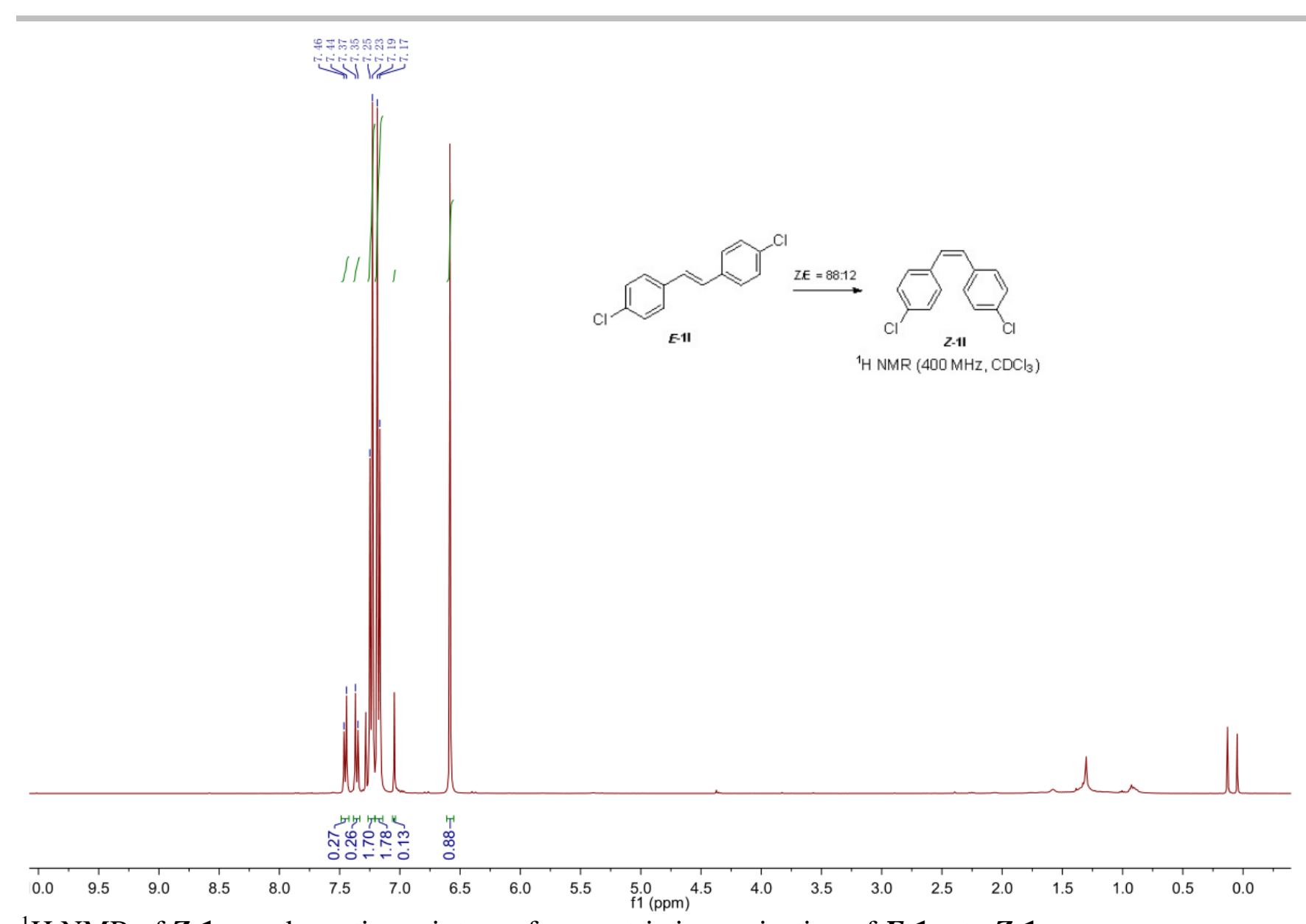

${ }^{1} \mathrm{H}$ NMR of $\boldsymbol{Z}-\mathbf{1 m}$ and reaction mixture of geometric isomerization of $\boldsymbol{E}-\mathbf{1 m}$ to $\boldsymbol{Z}-\mathbf{1 m}$

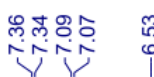
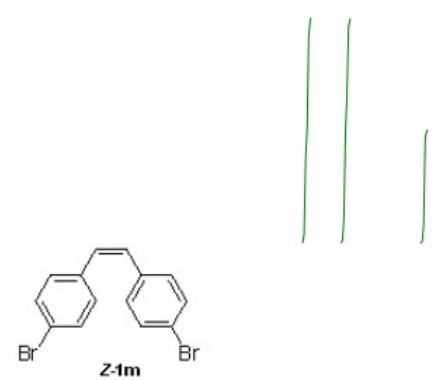

${ }^{1} \mathrm{H} \mathrm{NMR}\left(400 \mathrm{MHz}, \mathrm{CDCl}_{3}\right)$

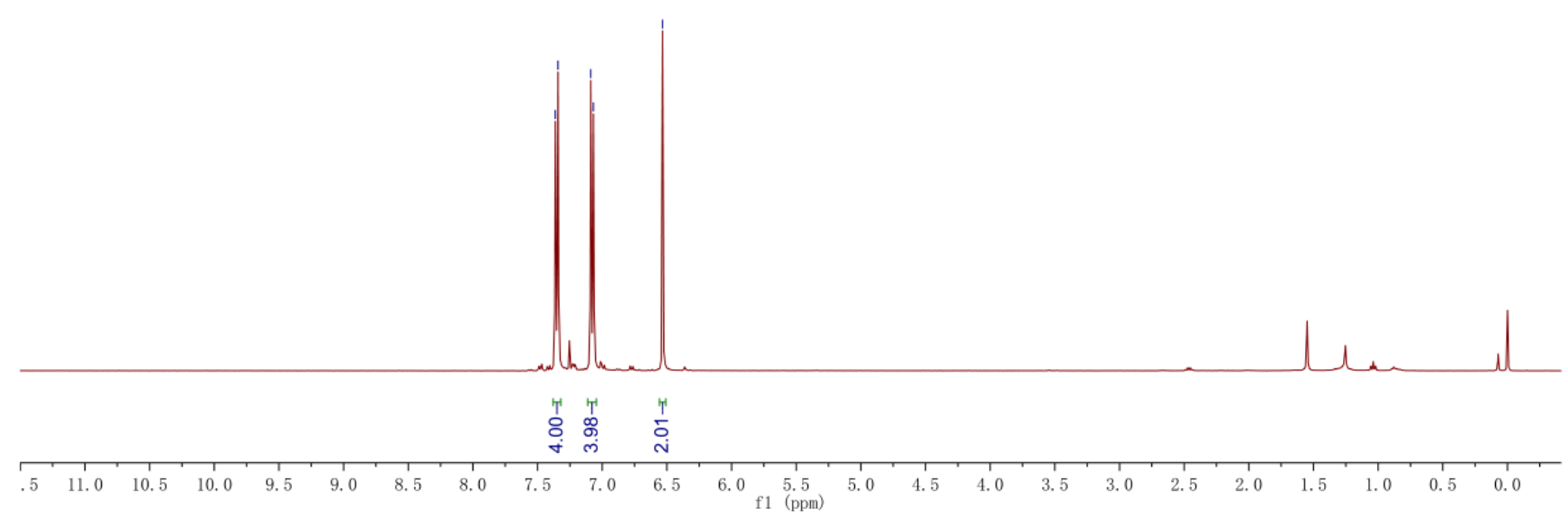




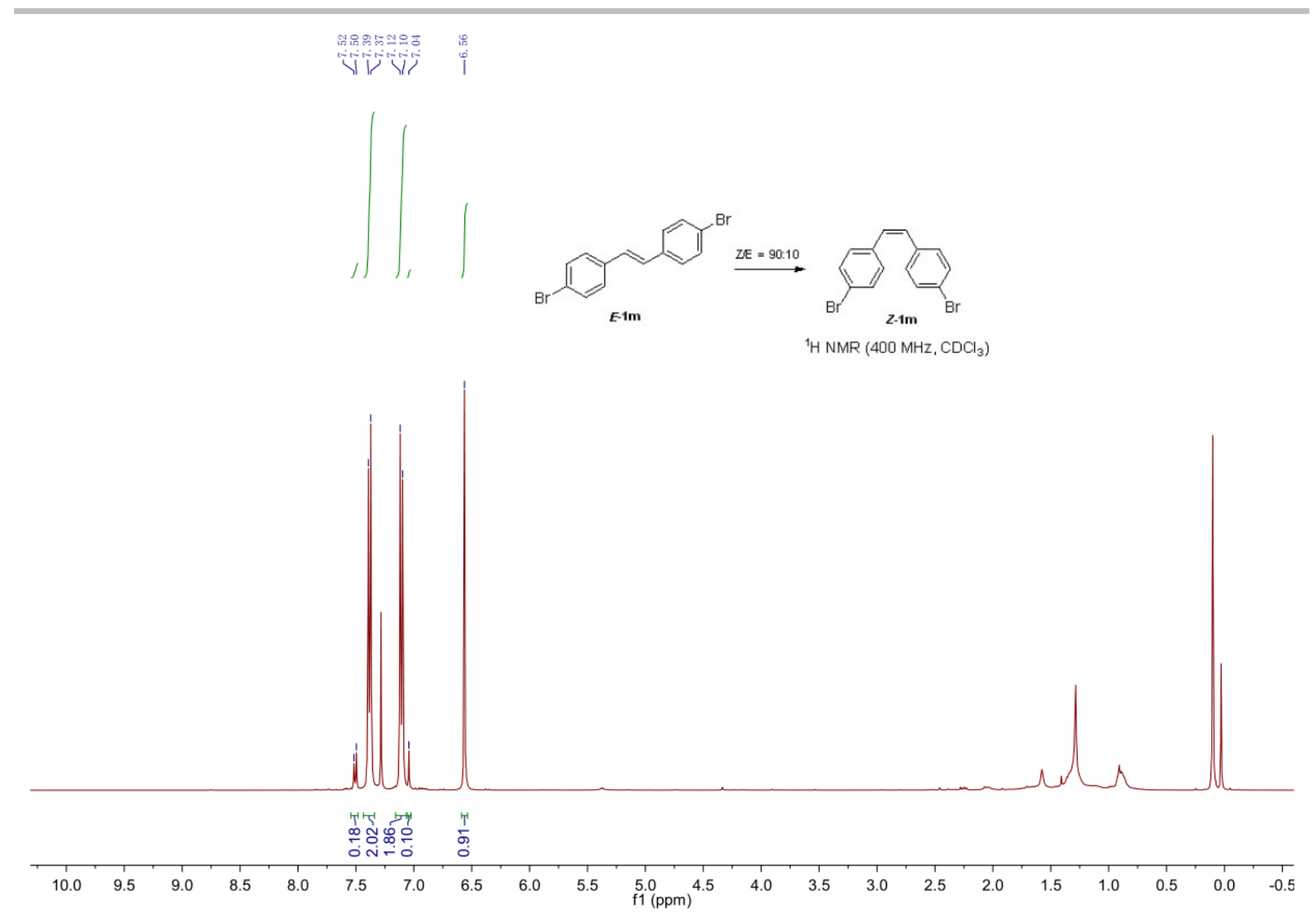

${ }^{1} \mathrm{H}$ NMR of $\boldsymbol{E}-\mathbf{1 n}, \boldsymbol{Z}-\mathbf{1 n}$ and reaction mixture of geometric isomerization of $\boldsymbol{E}-\mathbf{1 n}$ to $\boldsymbol{Z}-\mathbf{1 n}$

8.

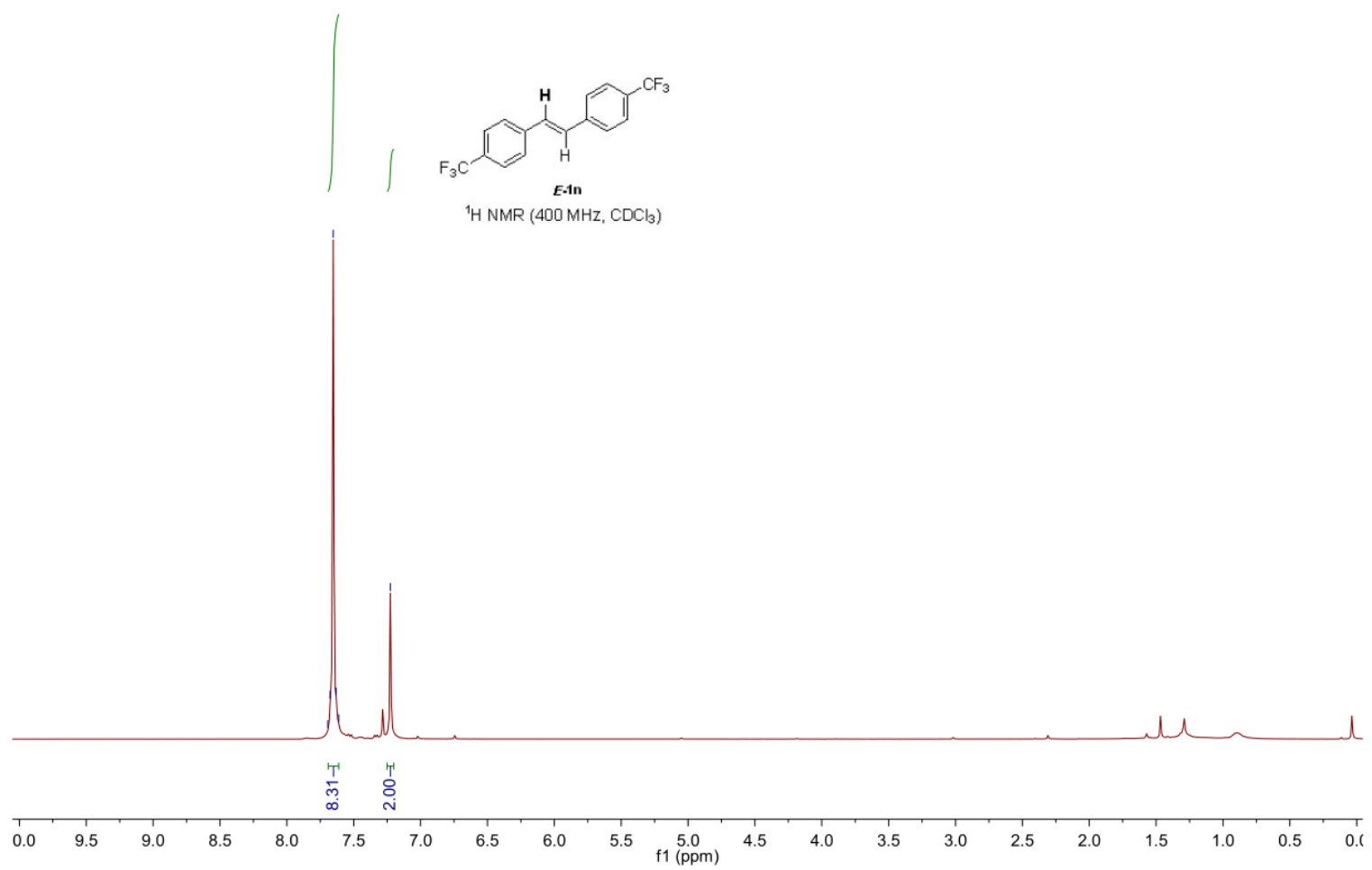




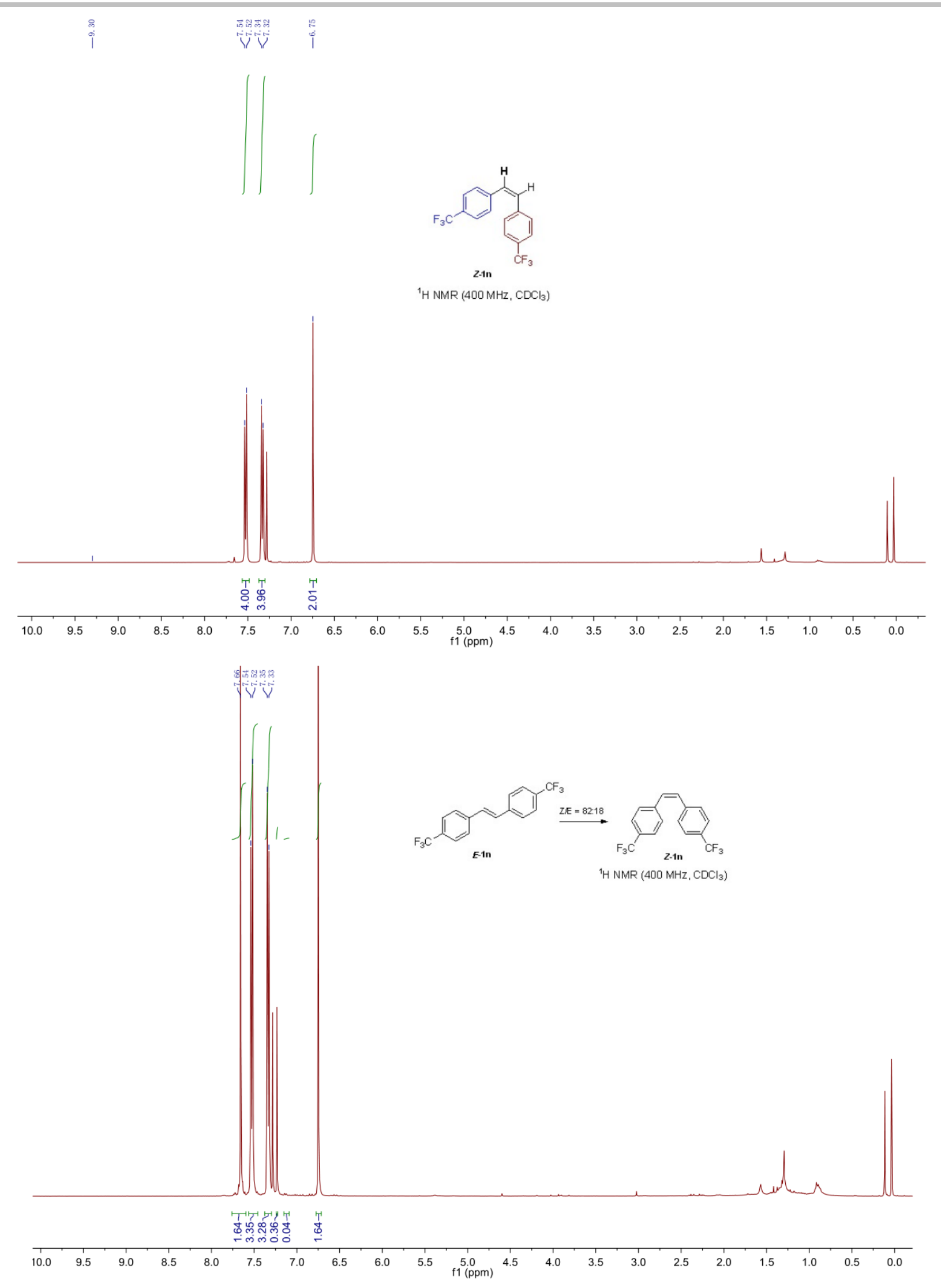

${ }^{1} \mathrm{H}$ NMR of $\boldsymbol{Z}$-10 and reaction mixture of geometric isomerization of $\boldsymbol{E}-10$ to $\boldsymbol{Z}$-10 


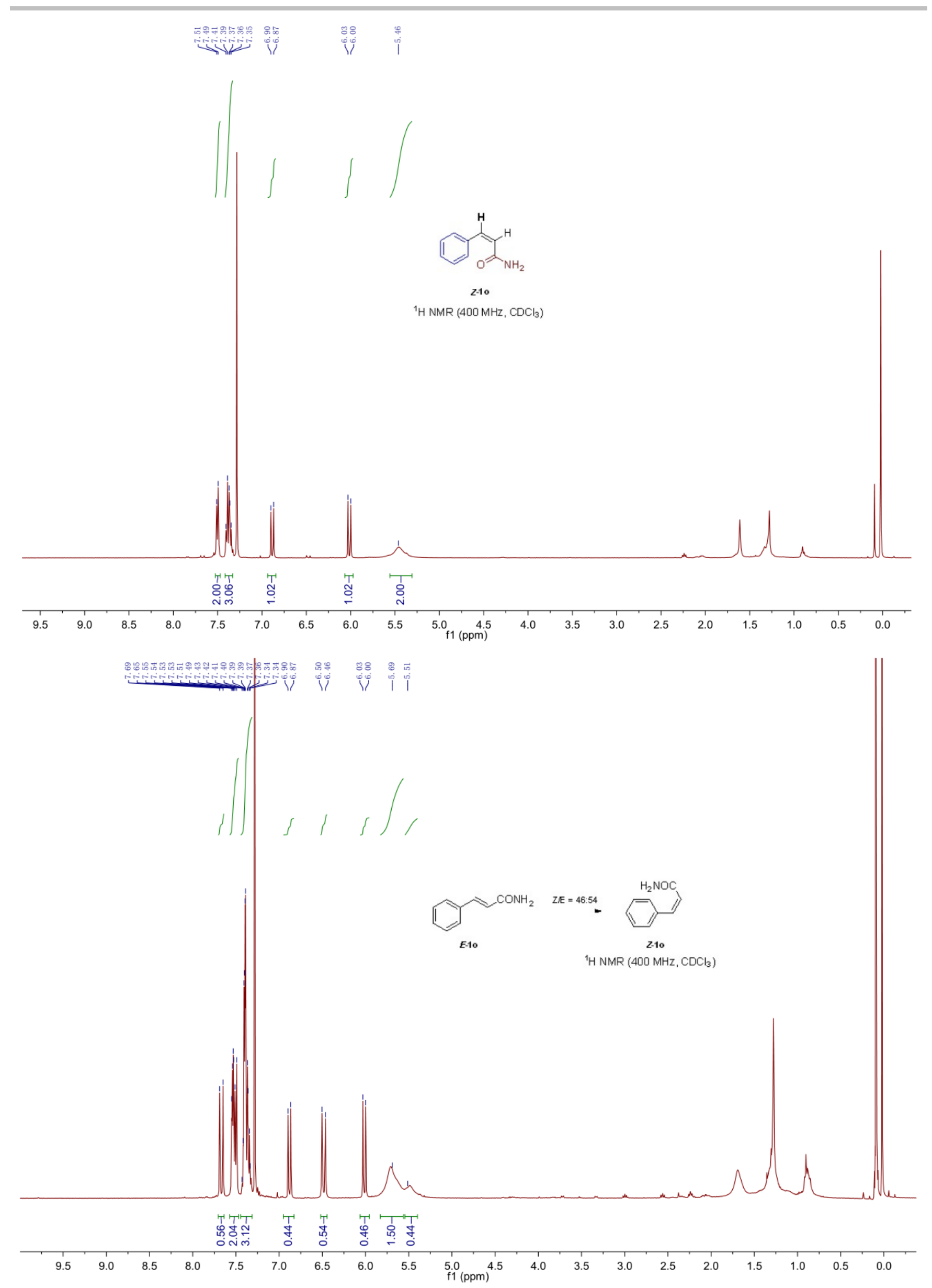


${ }^{1} \mathrm{H}$ NMR of $\boldsymbol{E}-\mathbf{1 p}, \boldsymbol{Z}-\mathbf{1 p}$ and reaction mixture of geometric isomerization of $\boldsymbol{E}-\mathbf{1 p}$ to $\boldsymbol{Z}-\mathbf{1 p}$

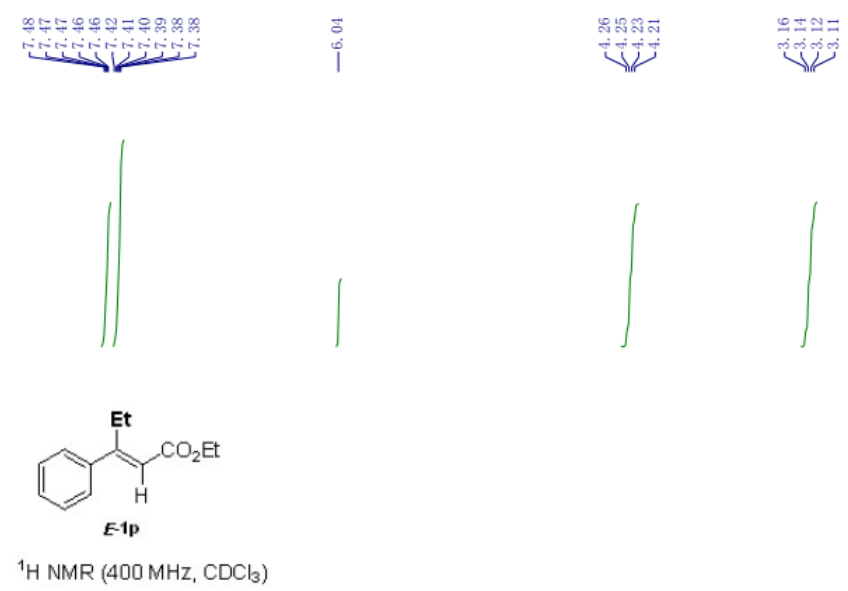

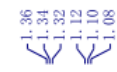
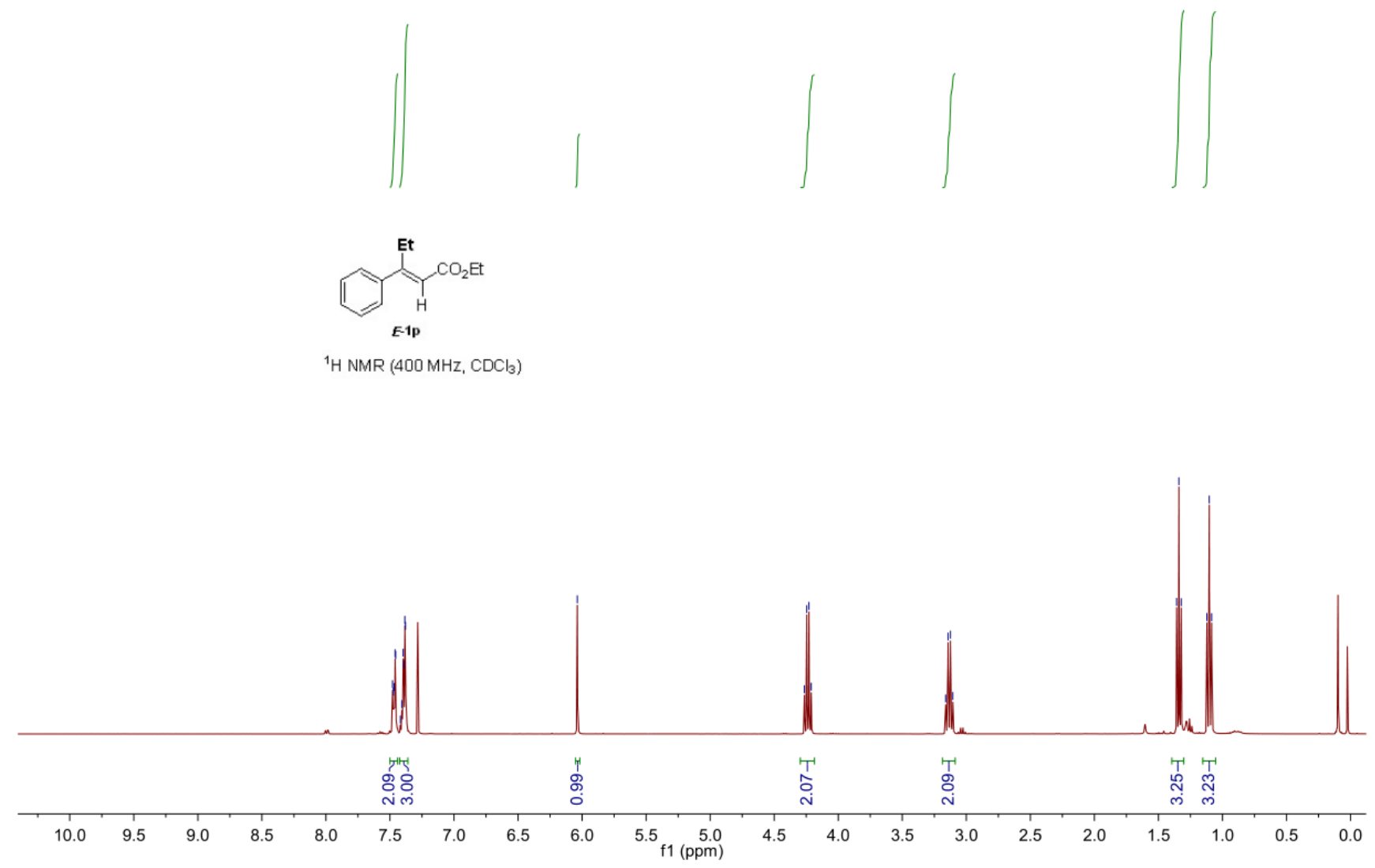

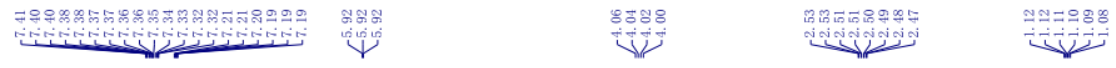

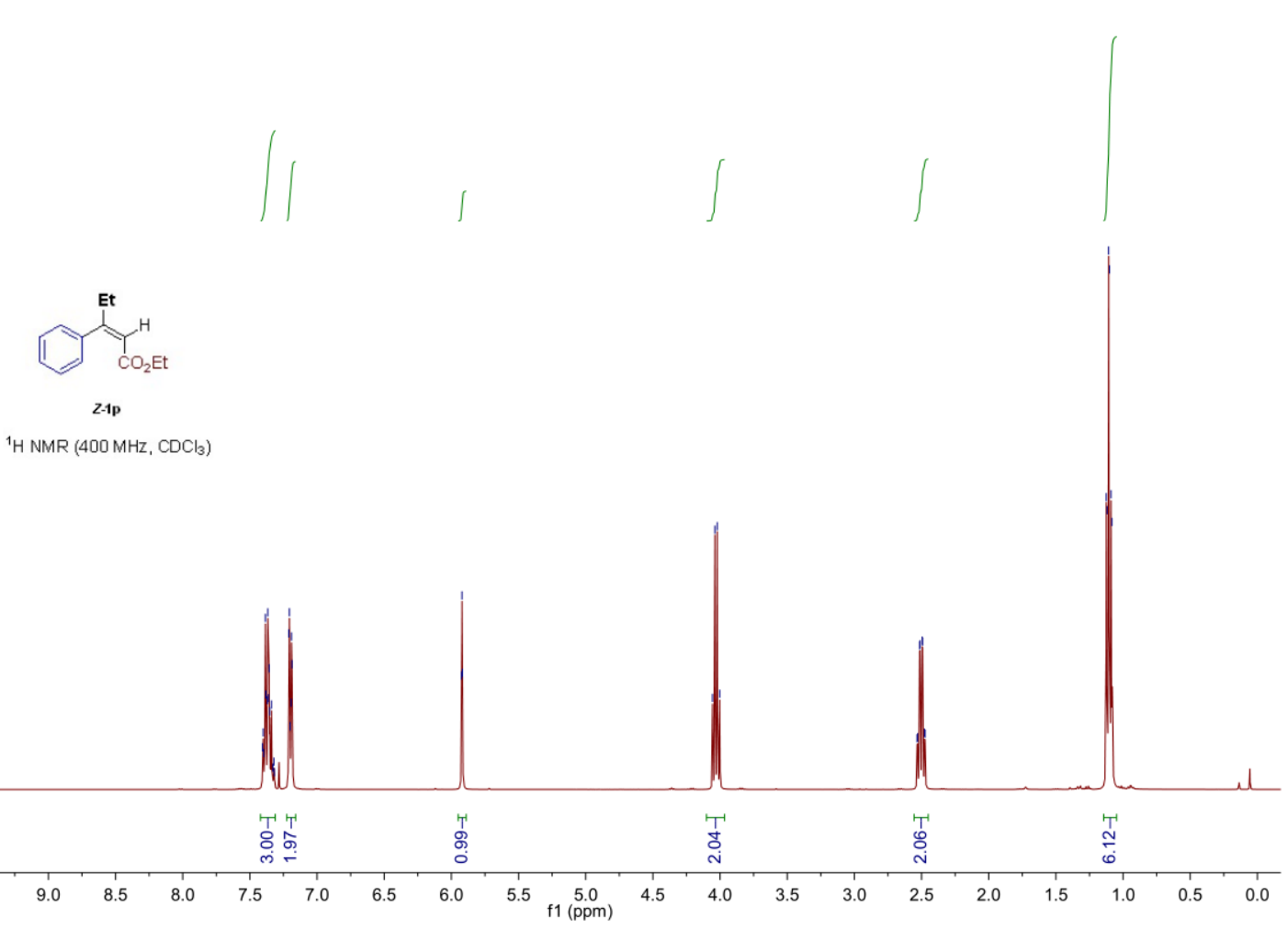




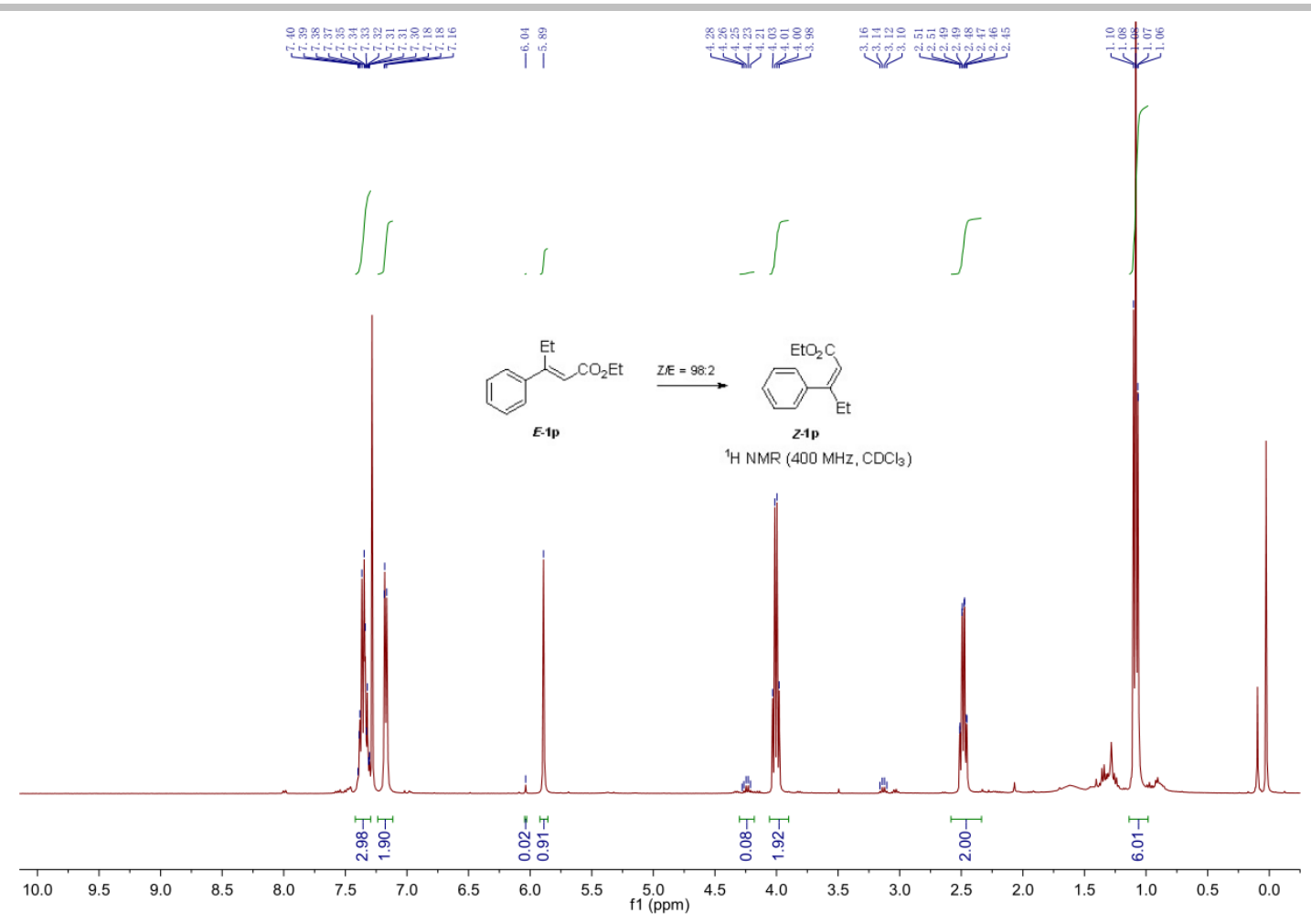

NMR of $\boldsymbol{E}-1 q, Z$-1q and reaction mixture of geometric isomerization of $\boldsymbol{E}$-1q to $Z$-1q
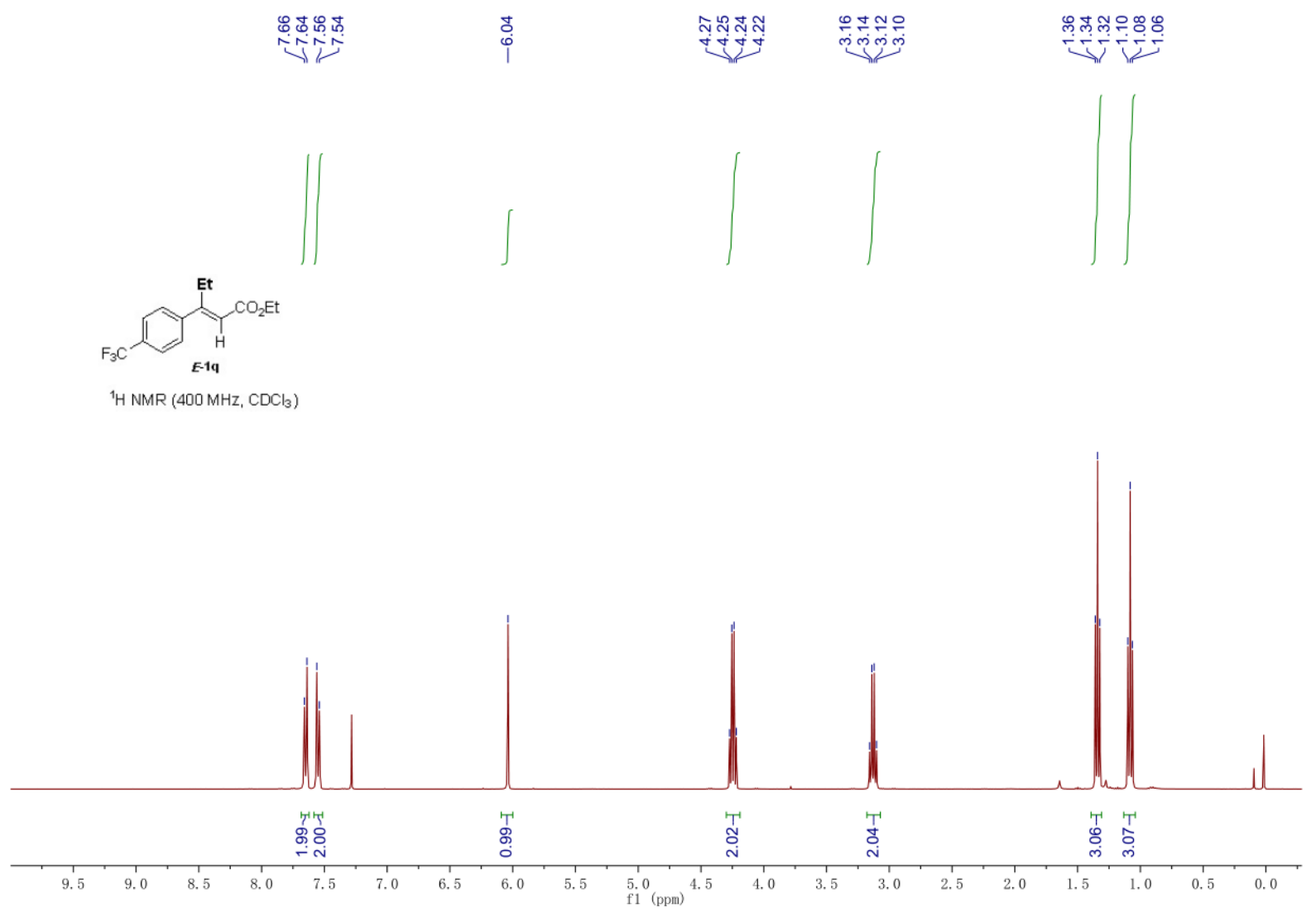

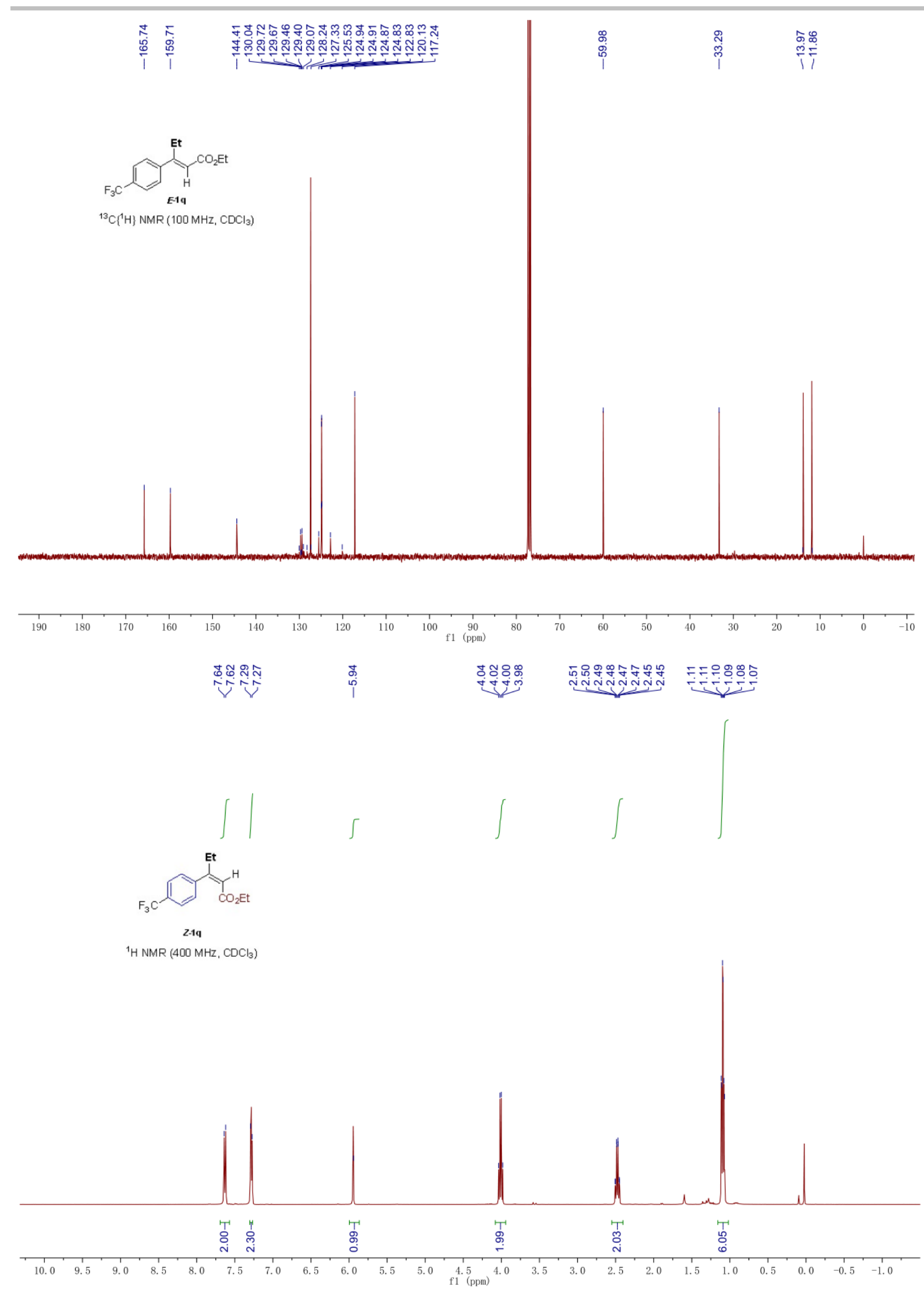


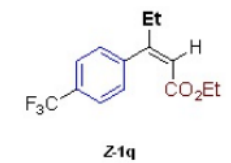

${ }^{13} \mathrm{C}\left({ }^{1} \mathrm{H}\right\} \mathrm{NMR}\left(100 \mathrm{MHz}, \mathrm{CDCl}_{3}\right)$
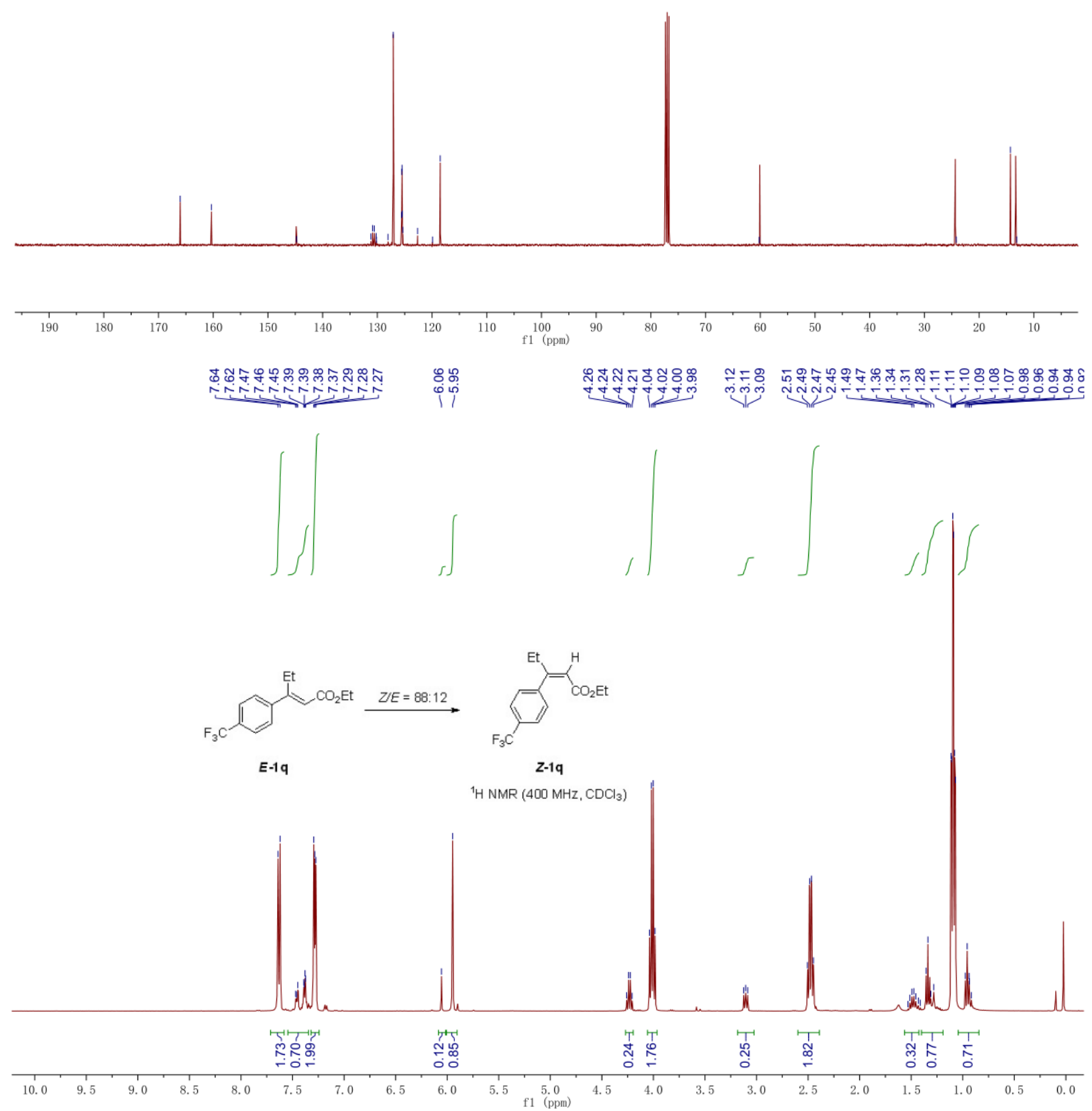

${ }^{1} \mathrm{H}$ NMR of $\boldsymbol{E}-\mathbf{1 r}, \boldsymbol{Z}-\mathbf{1 r}$ and reaction mixture of geometric isomerization of $\boldsymbol{E}-\mathbf{1 r}$ to $\boldsymbol{Z}$-1r 


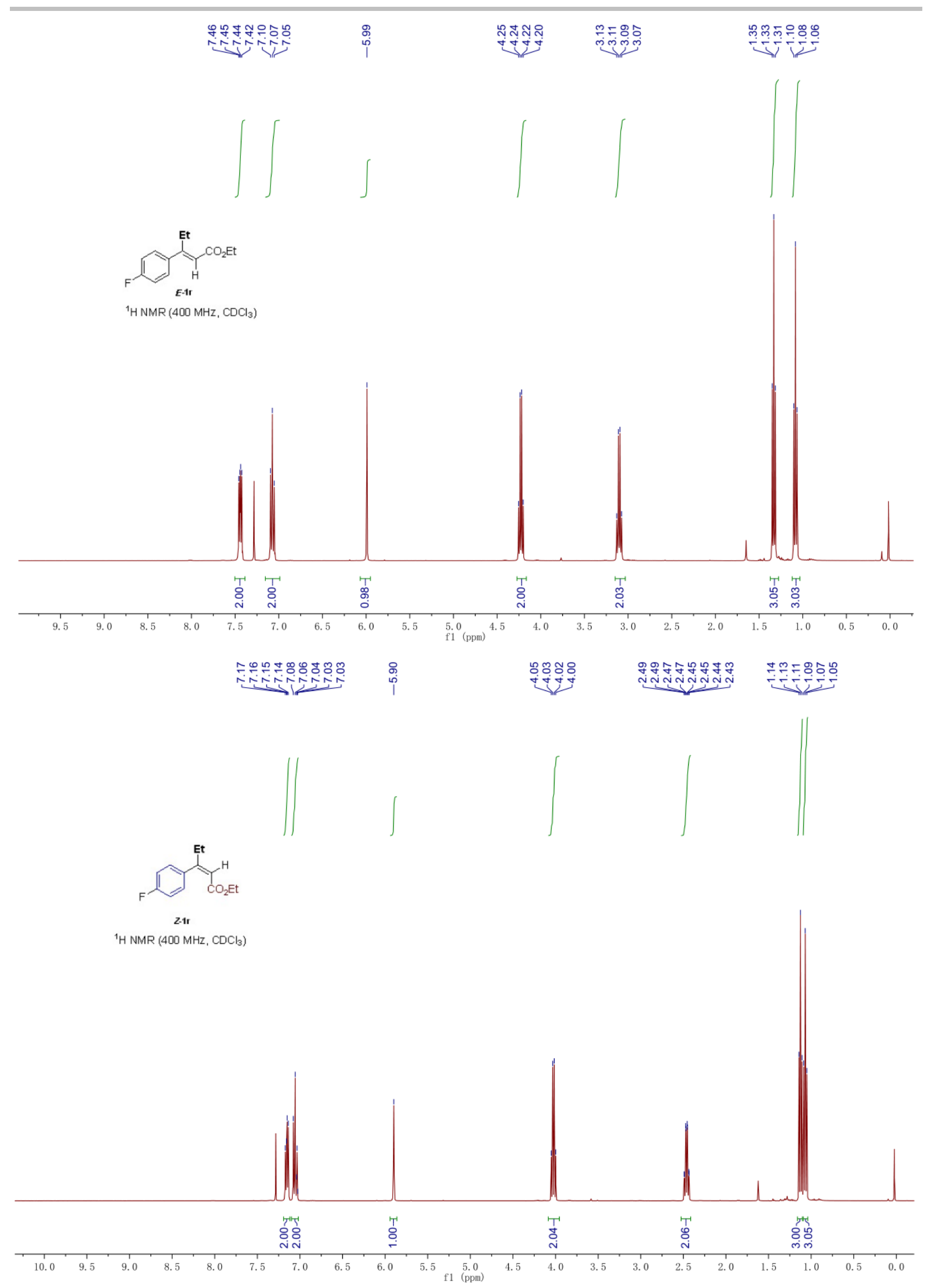




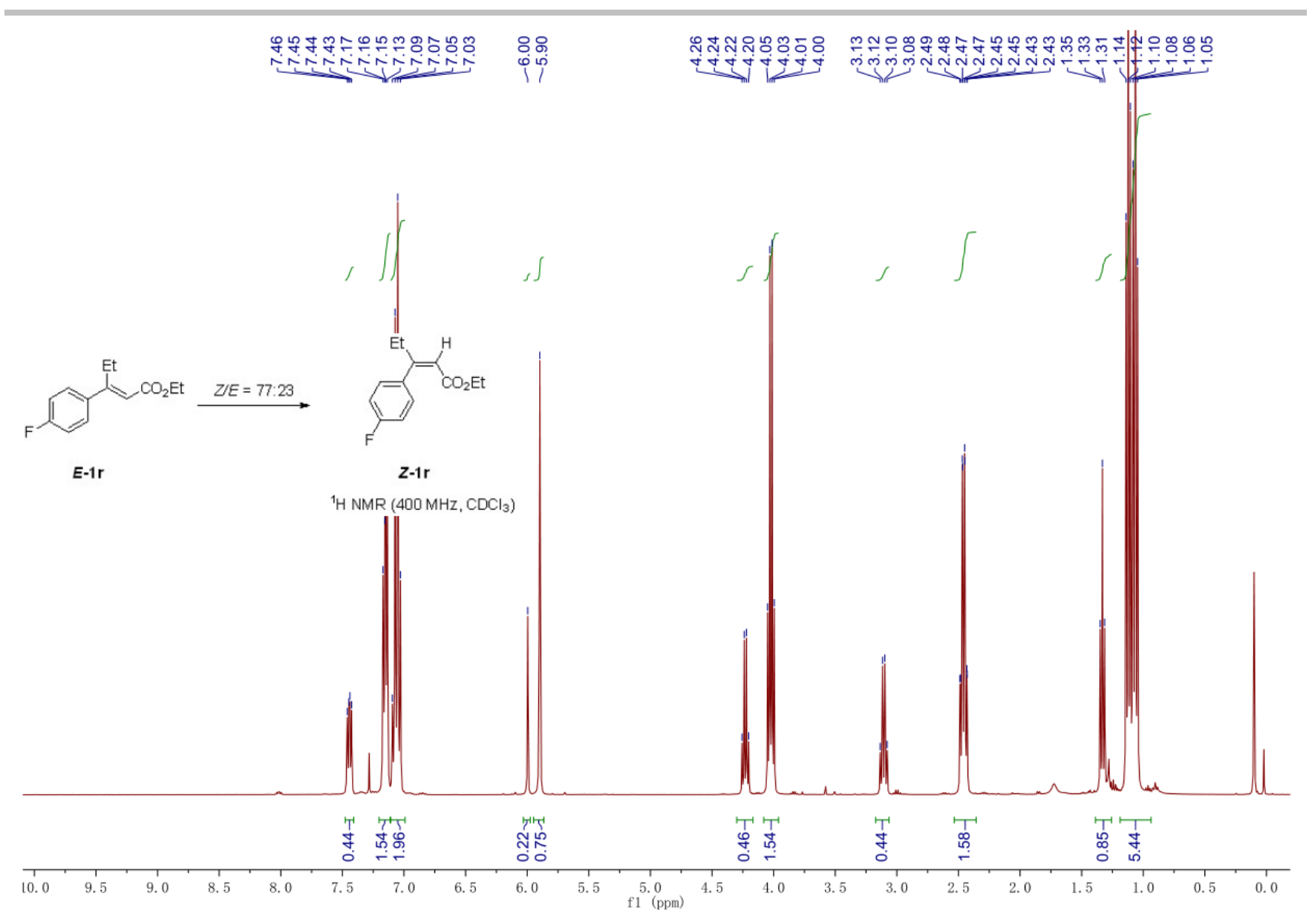

${ }^{1} \mathrm{H}$ NMR of $\boldsymbol{E}-\mathbf{1 s}, \boldsymbol{Z}-1 \mathrm{~s}$ and reaction mixture of geometric isomerization of $\boldsymbol{E}$-1s to $\boldsymbol{Z}$-1s
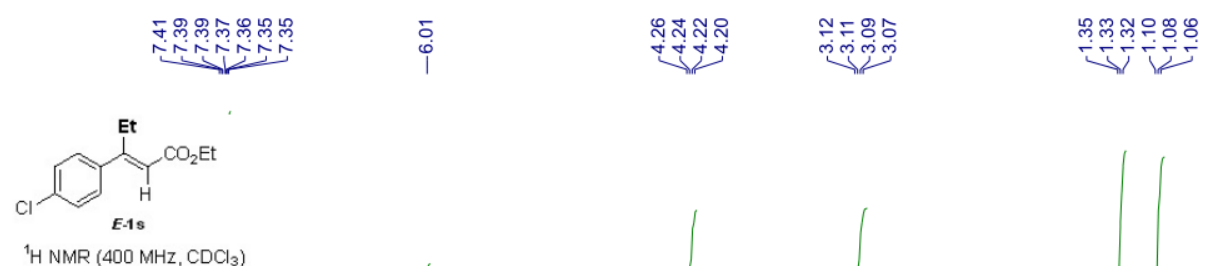

${ }^{1} \mathrm{H}$ NMR $\left(400 \mathrm{MHz}, \mathrm{CDCl}_{3}\right)$
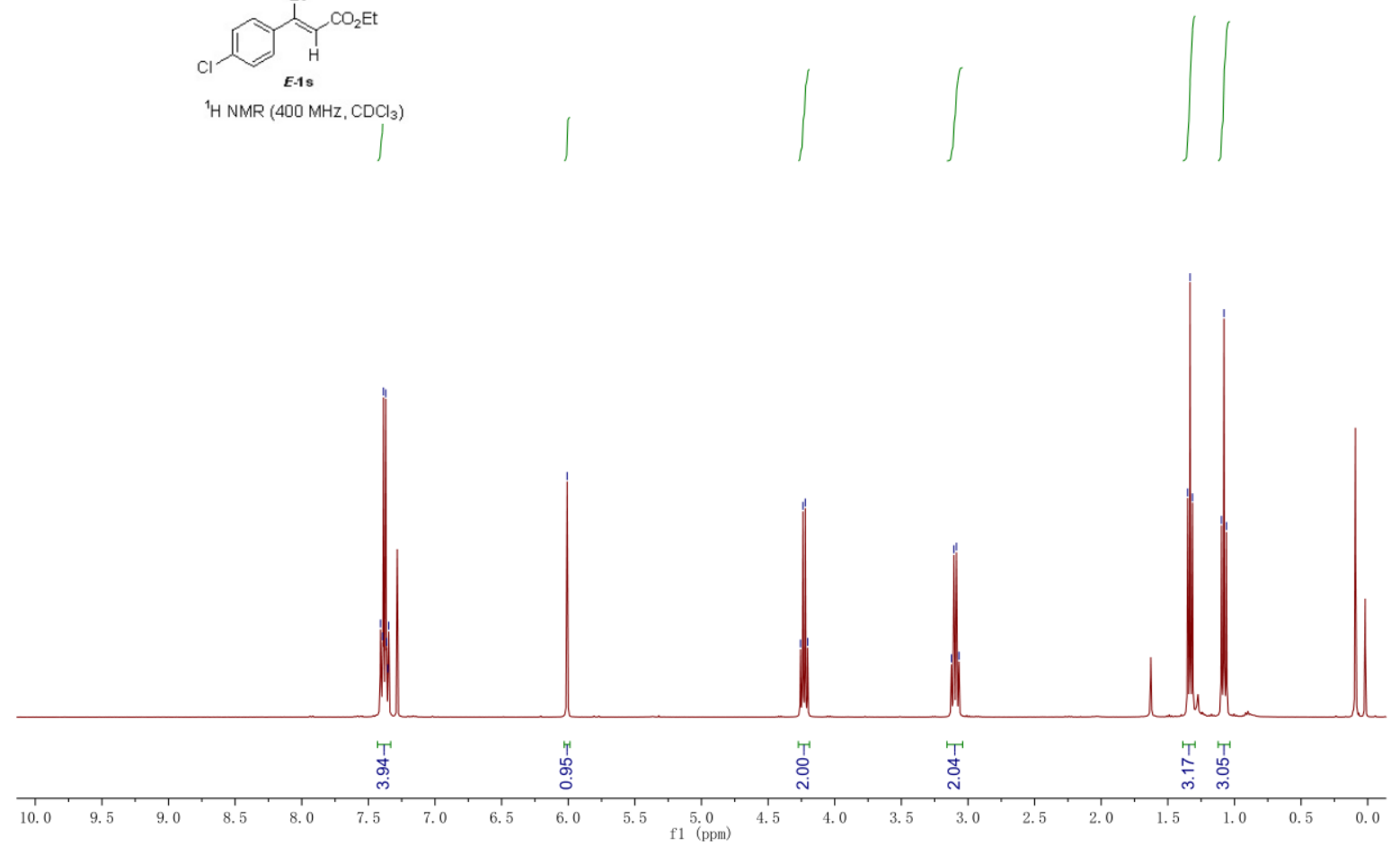


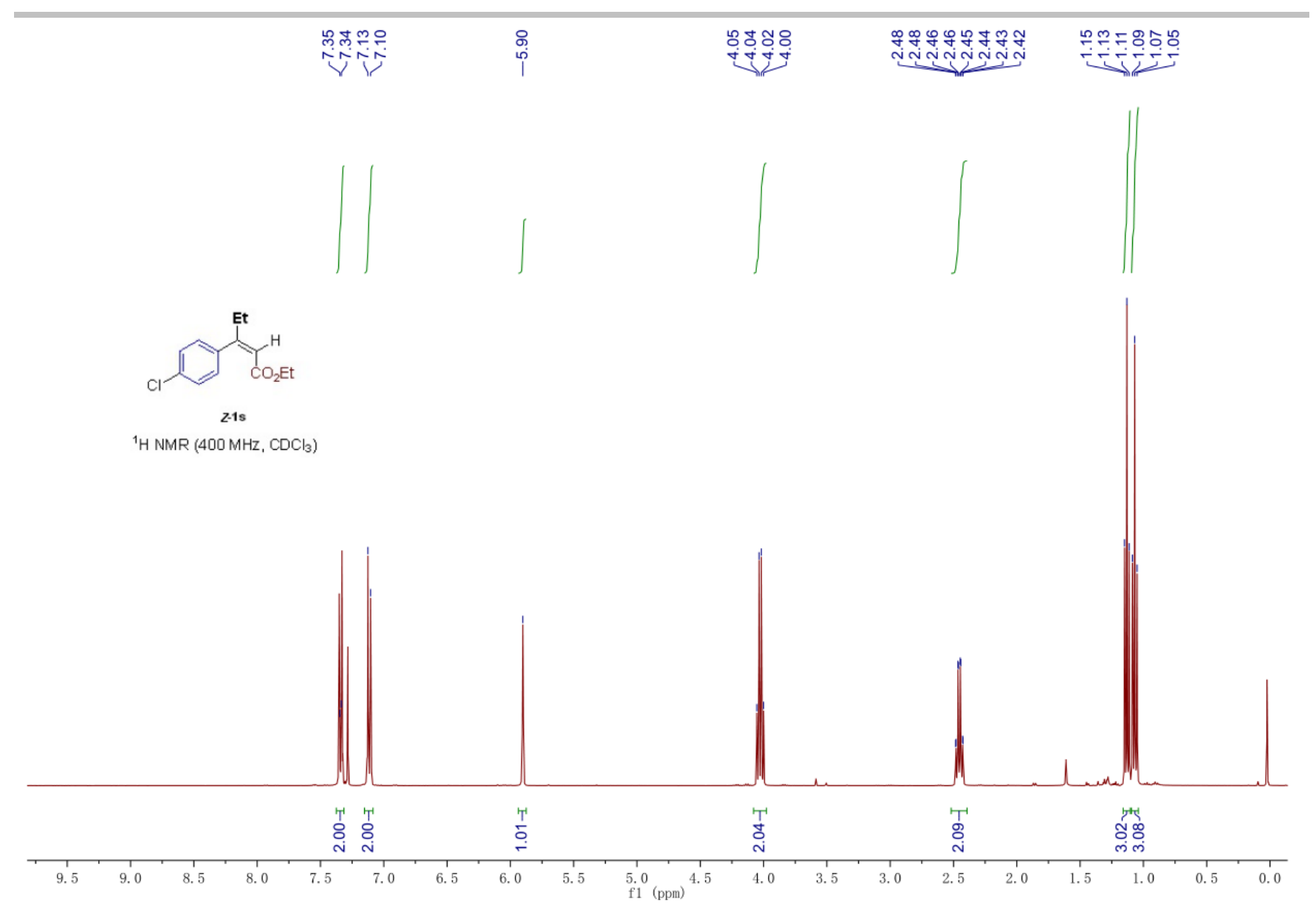

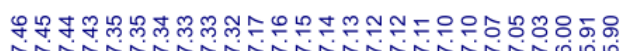

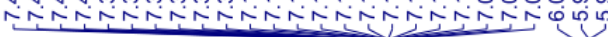

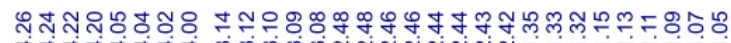

ن

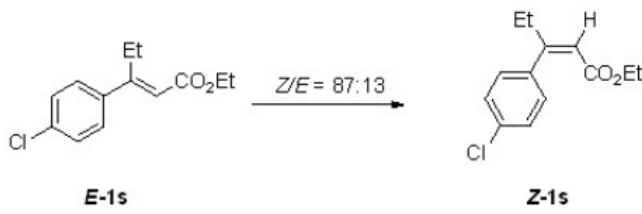

${ }^{1} \mathrm{H} \mathrm{NMR}\left(400 \mathrm{MHz}, \mathrm{CDCl}_{3}\right)$
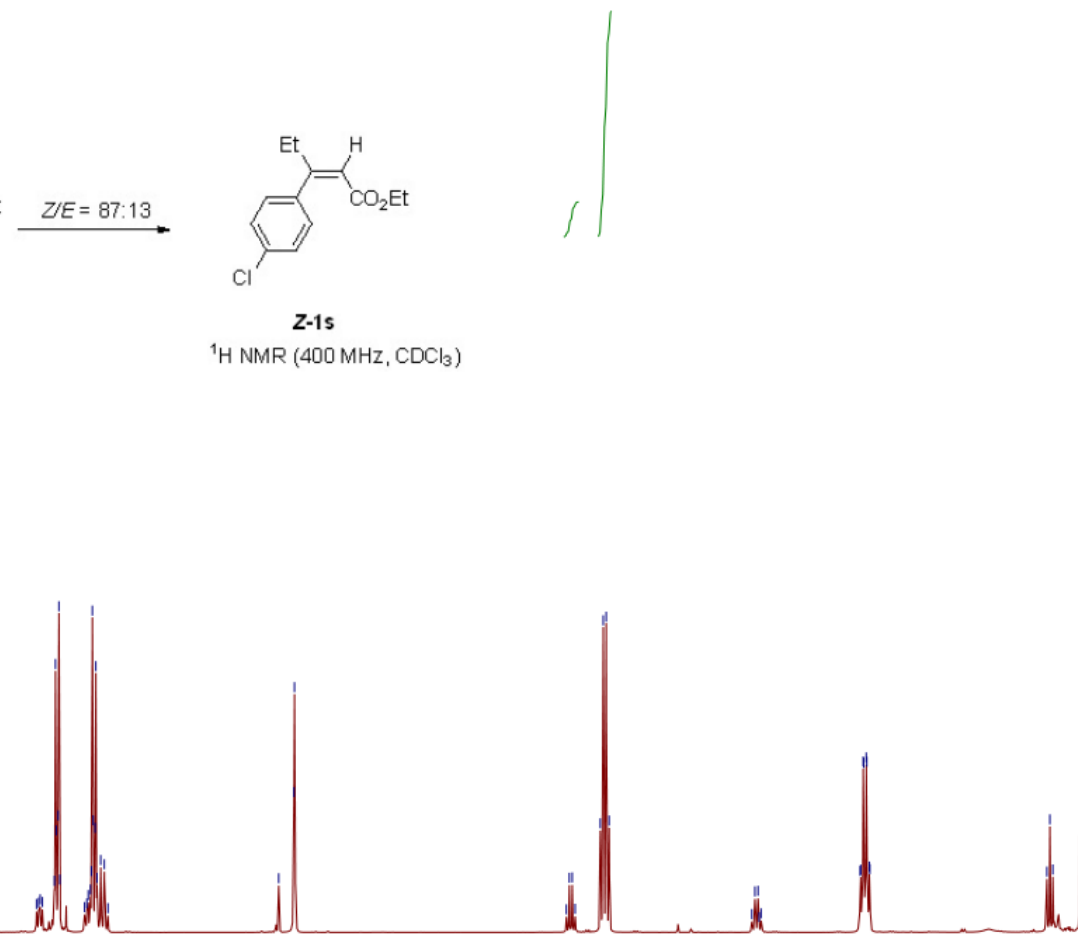

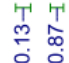

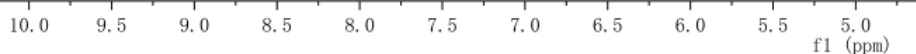

4. 


\section{NMR of $E-1 t, Z-1 t$ and reaction mixture of geometric isomerization of $E$-1t to $Z$-1t}
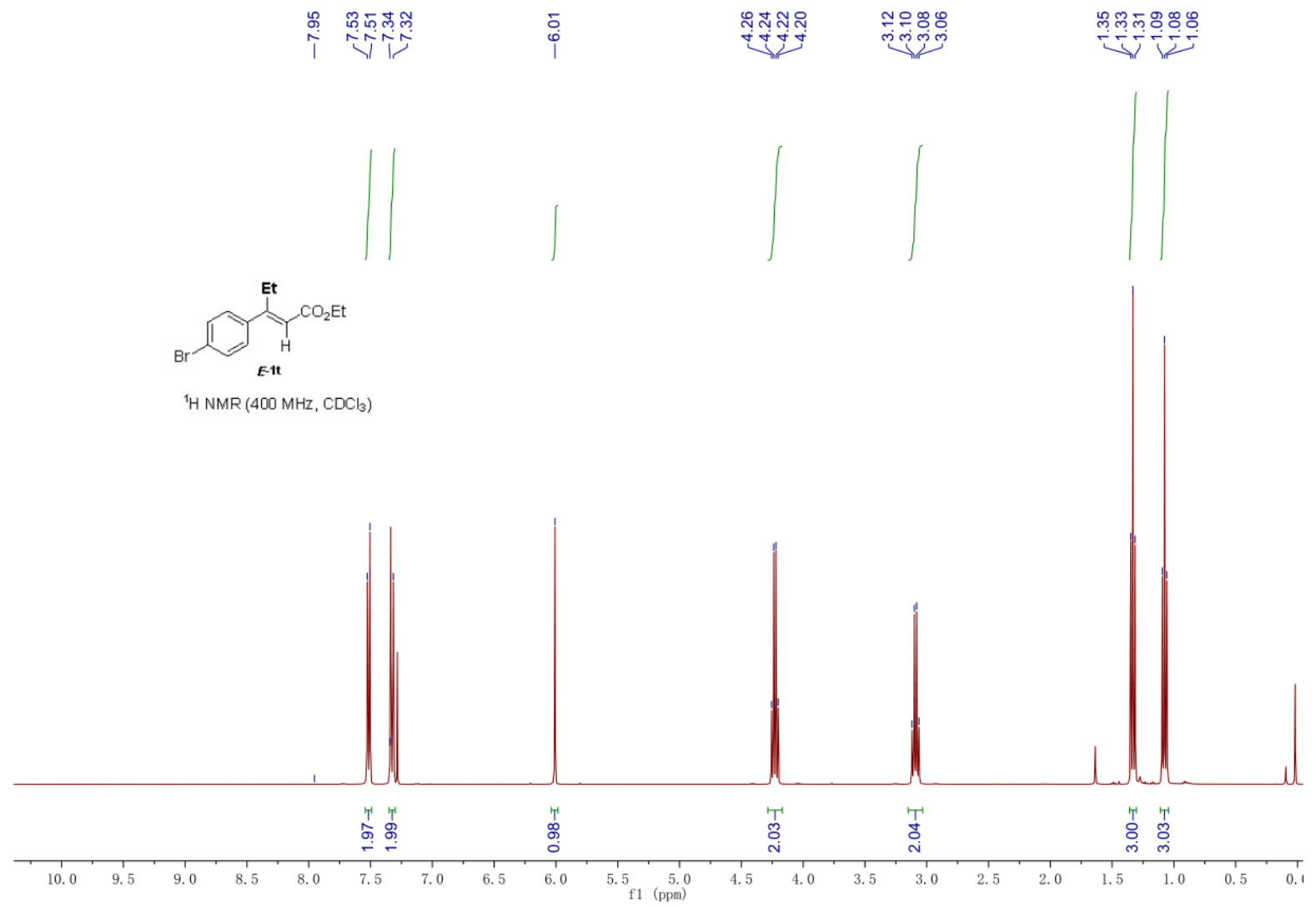

${ }^{1} \mathrm{H}$ NMR (400 MHz, $\left.\mathrm{CDCl}_{3}\right)$

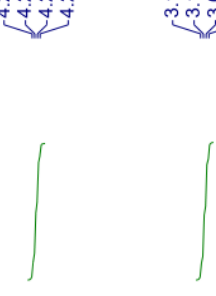

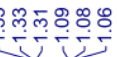

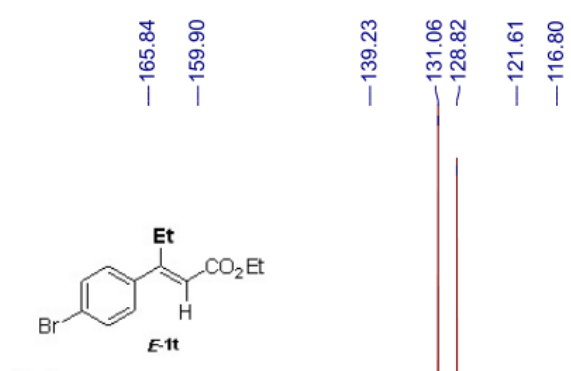

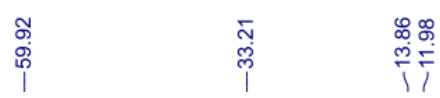

${ }^{13} \mathrm{C}\left({ }^{1} \mathrm{H}\right\}$ NMR $\left(100 \mathrm{MHz}, \mathrm{CDCl}_{3}\right)$

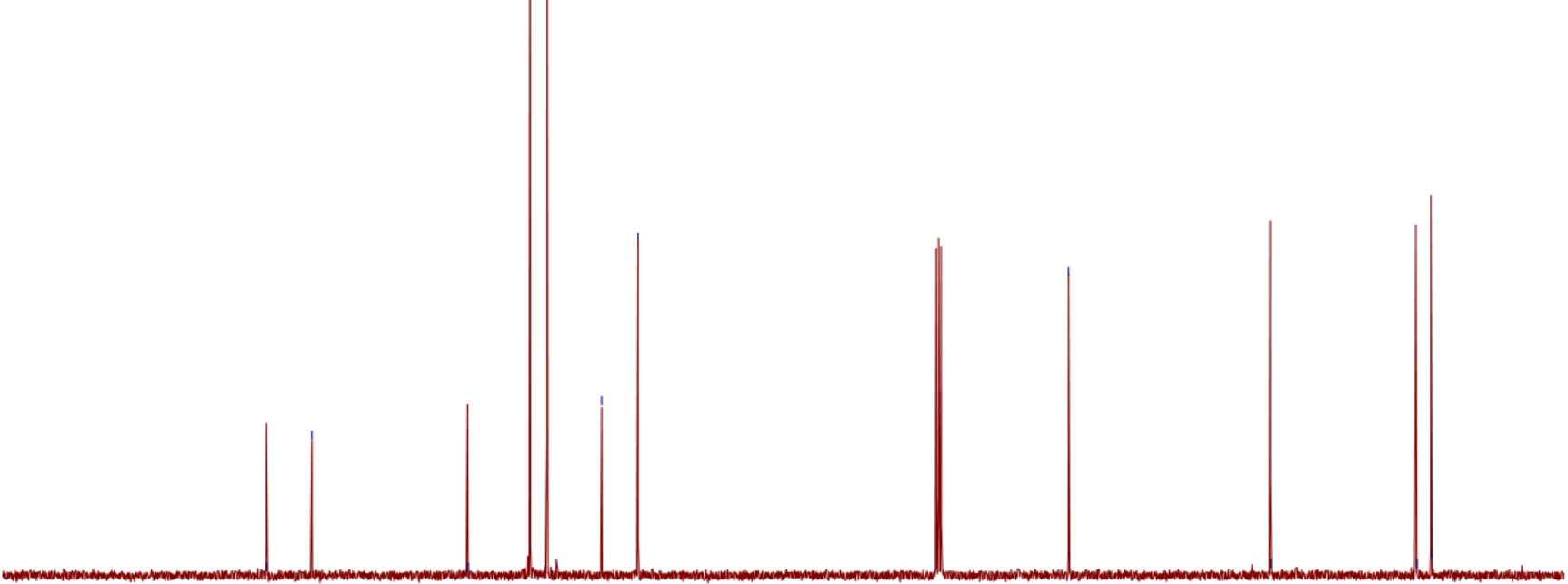

To
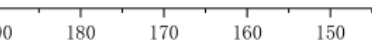

140

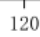

100
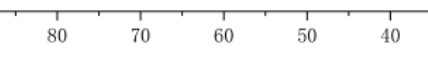


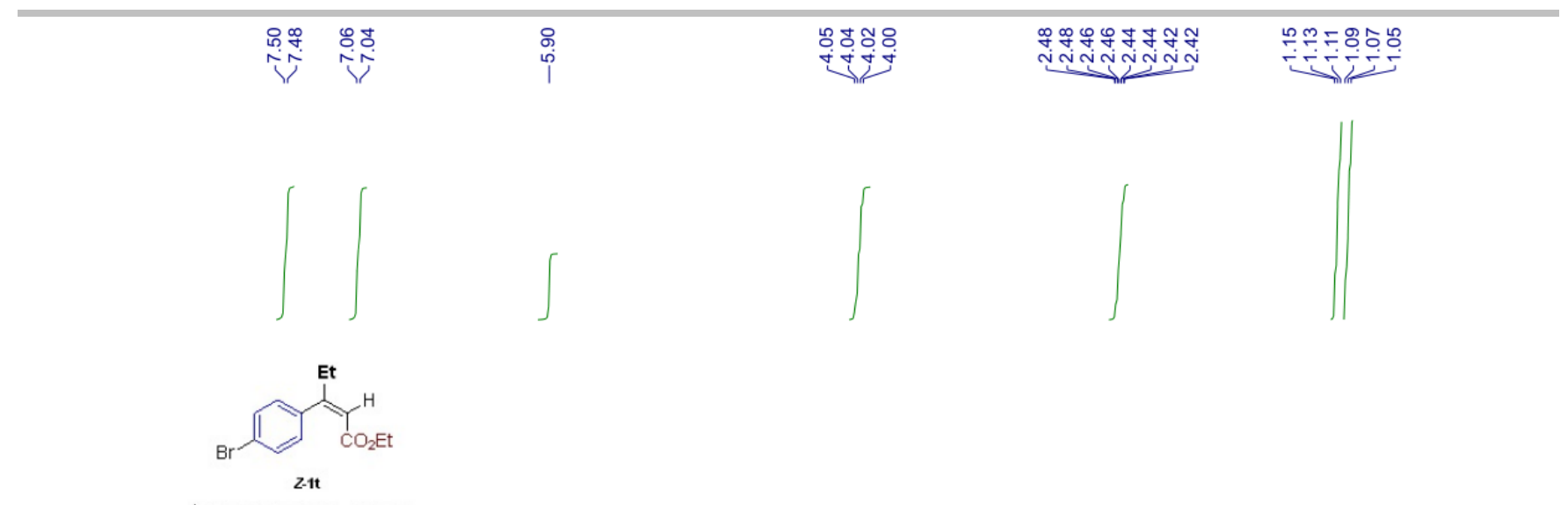

${ }^{1} \mathrm{H} \mathrm{NMR}\left(400 \mathrm{MHz}, \mathrm{CDCl}_{3}\right)$
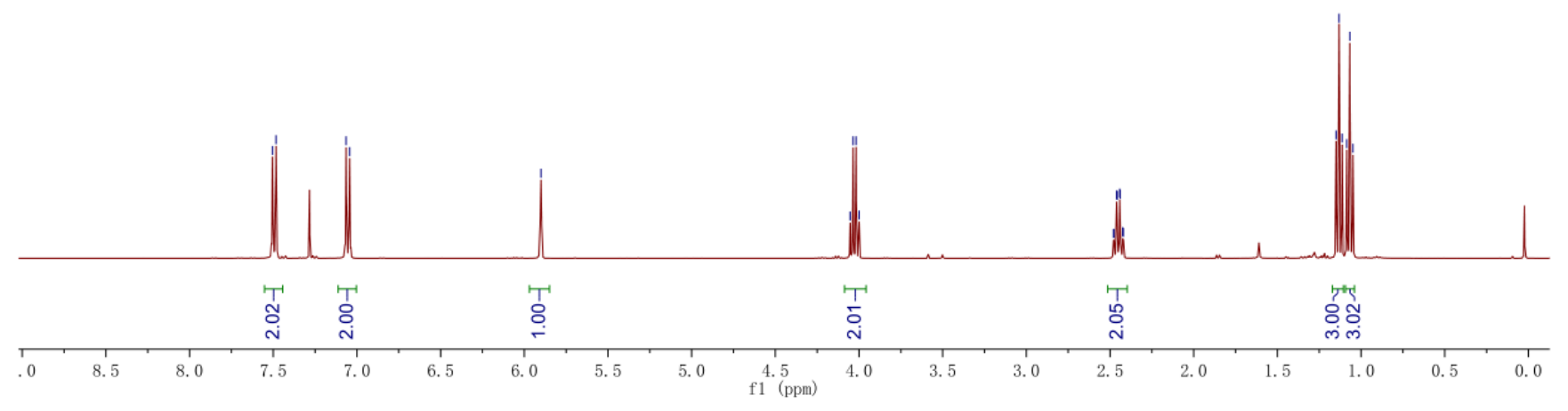

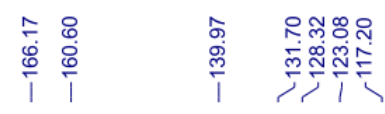
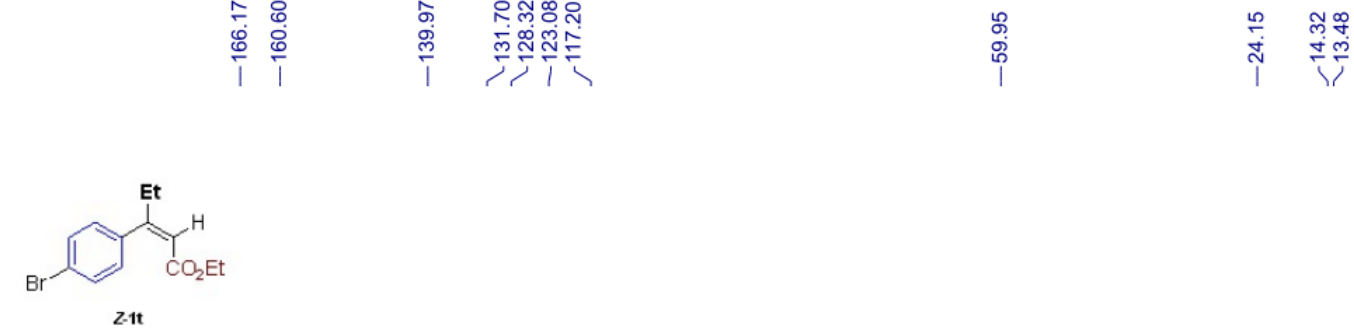

${ }^{13} \mathrm{C}\left\{{ }^{1} \mathrm{H}\right\} \mathrm{NMR}\left(100 \mathrm{MHz}, \mathrm{CDCl}_{3}\right)$

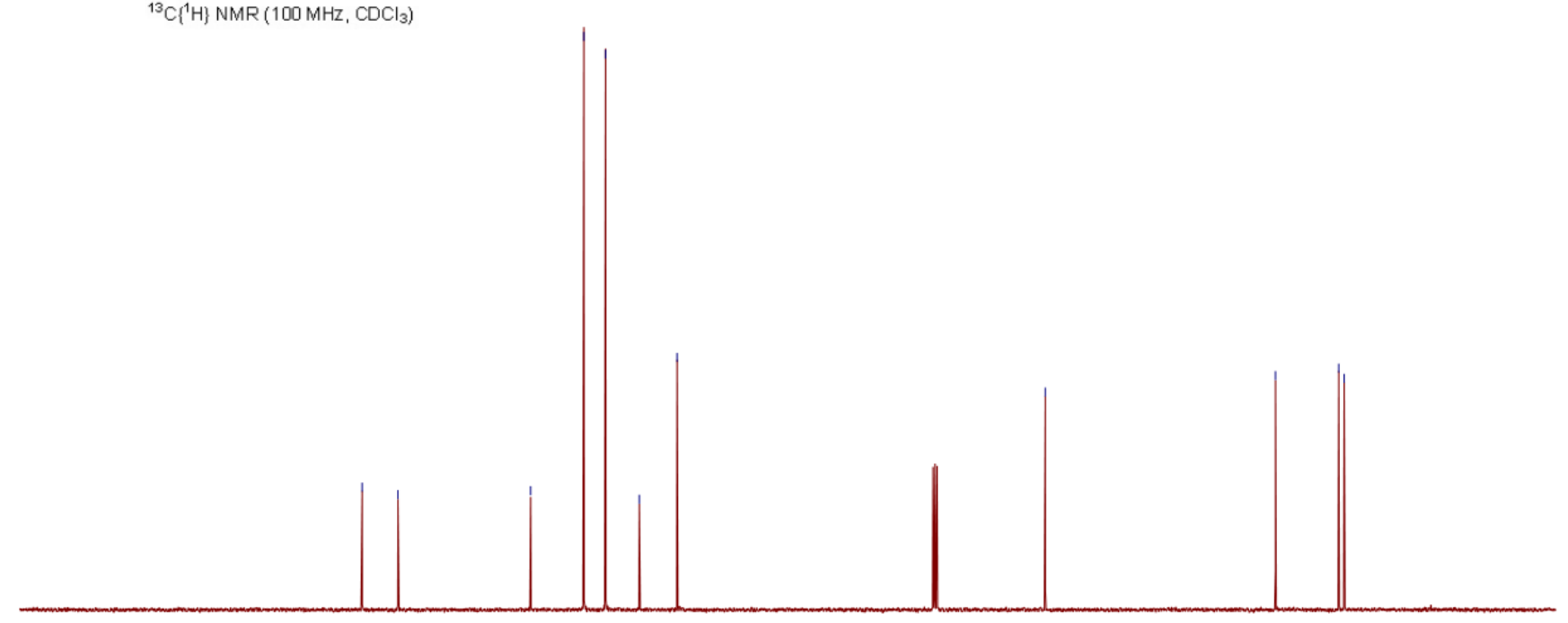




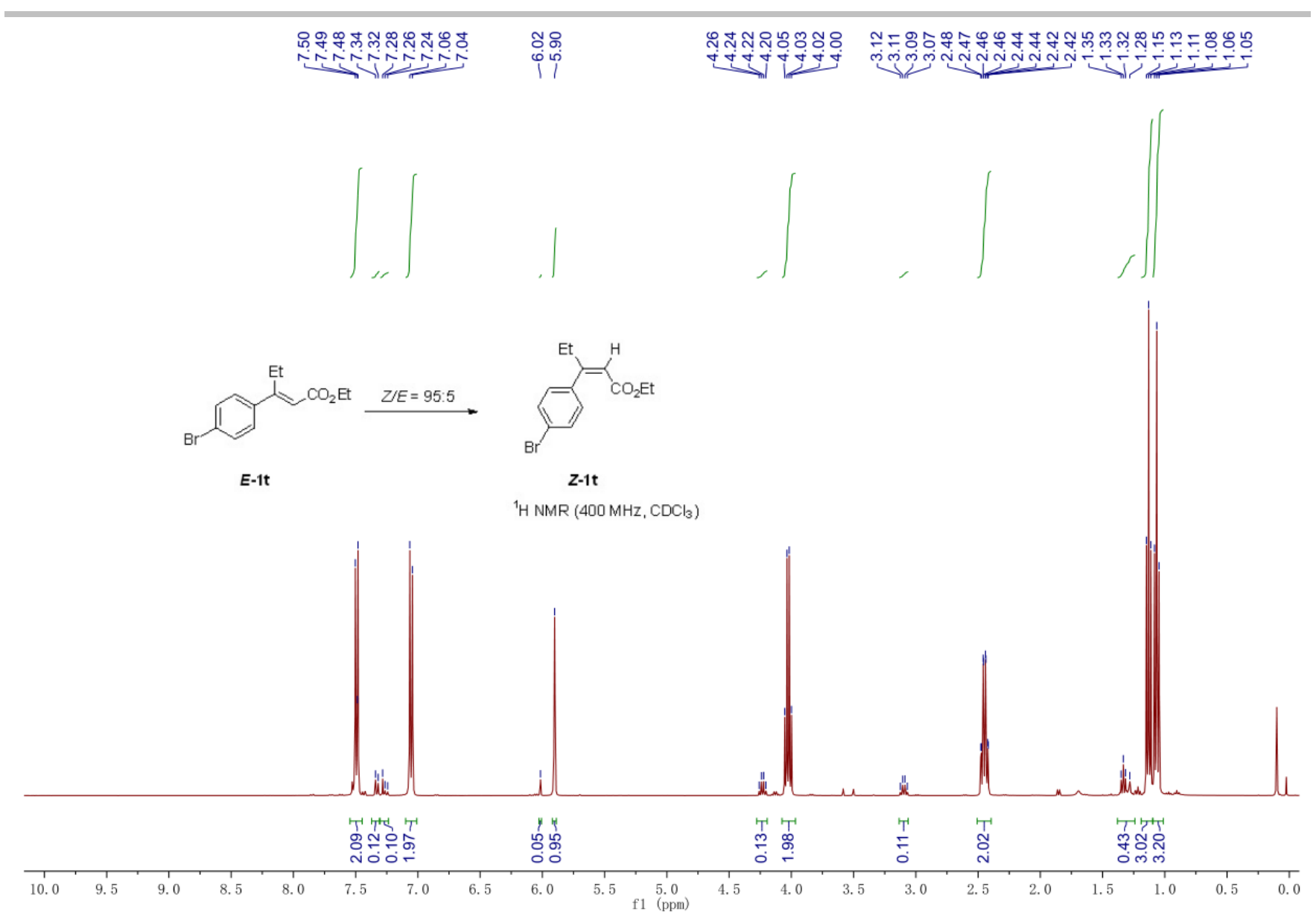

${ }^{1} \mathrm{H}$ NMR of $\boldsymbol{E}-\mathbf{1 u}, \boldsymbol{Z}-\mathbf{1 u}$ and reaction mixture of geometric isomerization of $\boldsymbol{E}-\mathbf{1 u}$ to $\boldsymbol{Z}-\mathbf{1 u}$

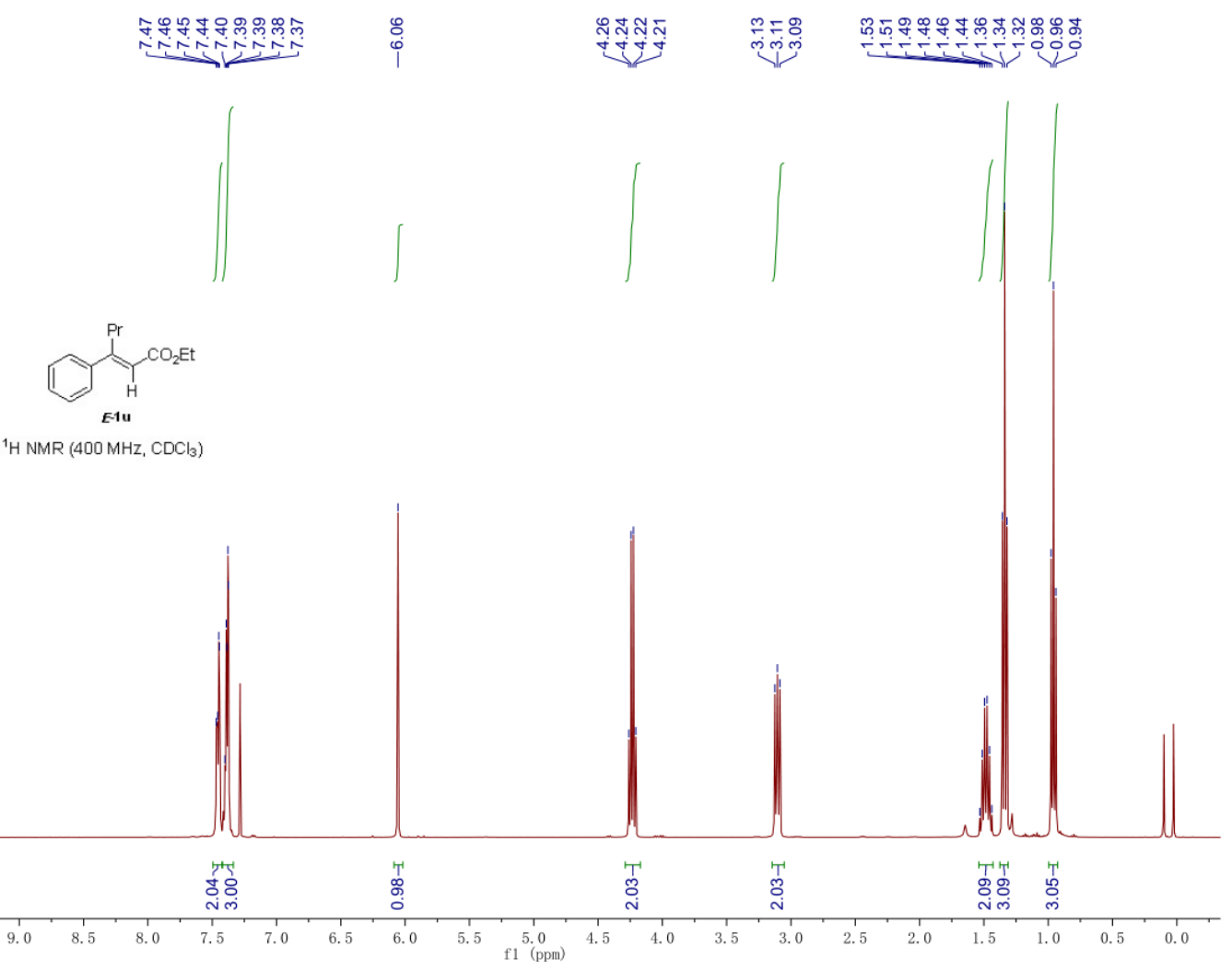




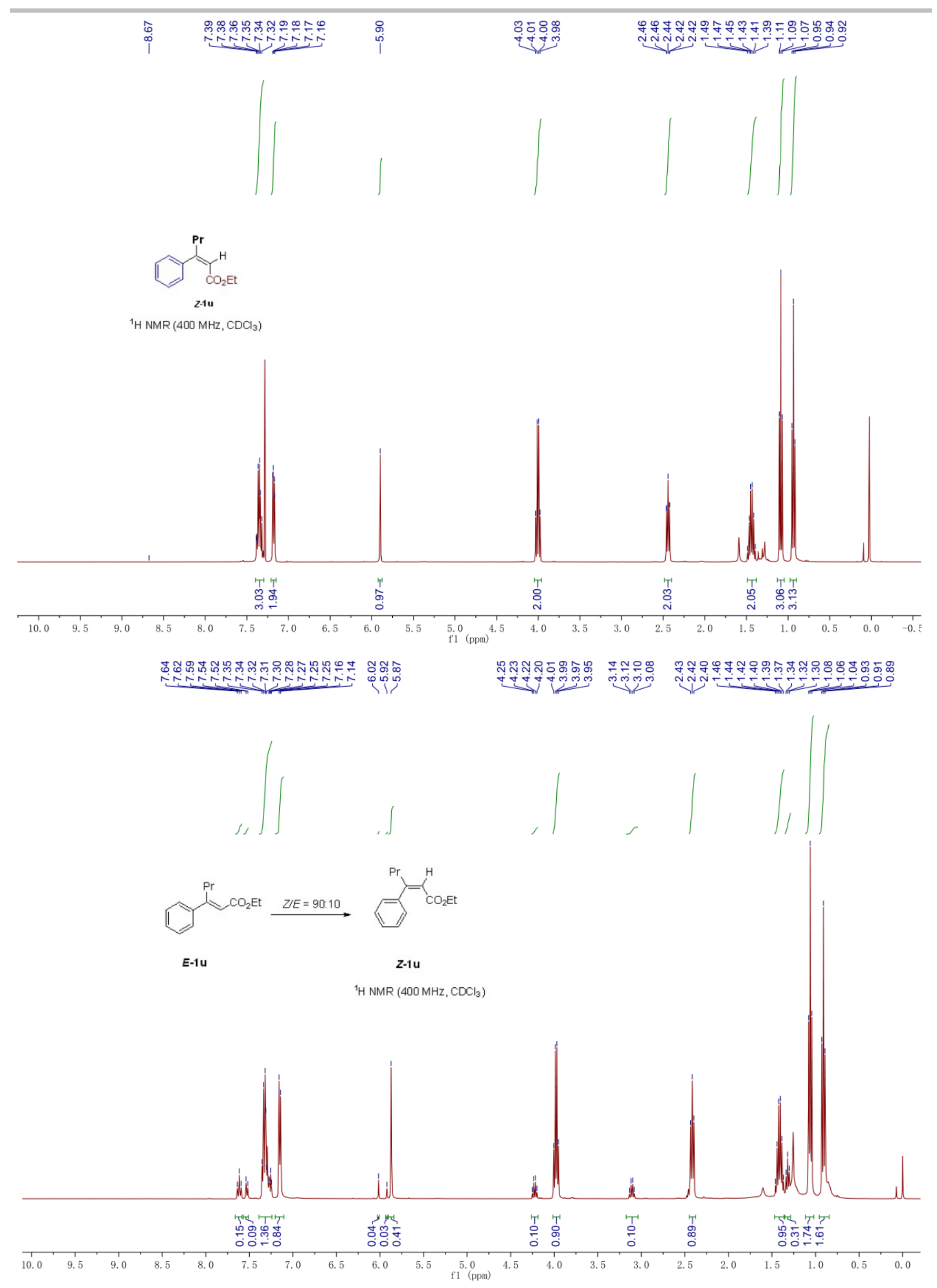




\section{Characterizations of EnT-mediated organometallic catalysis}

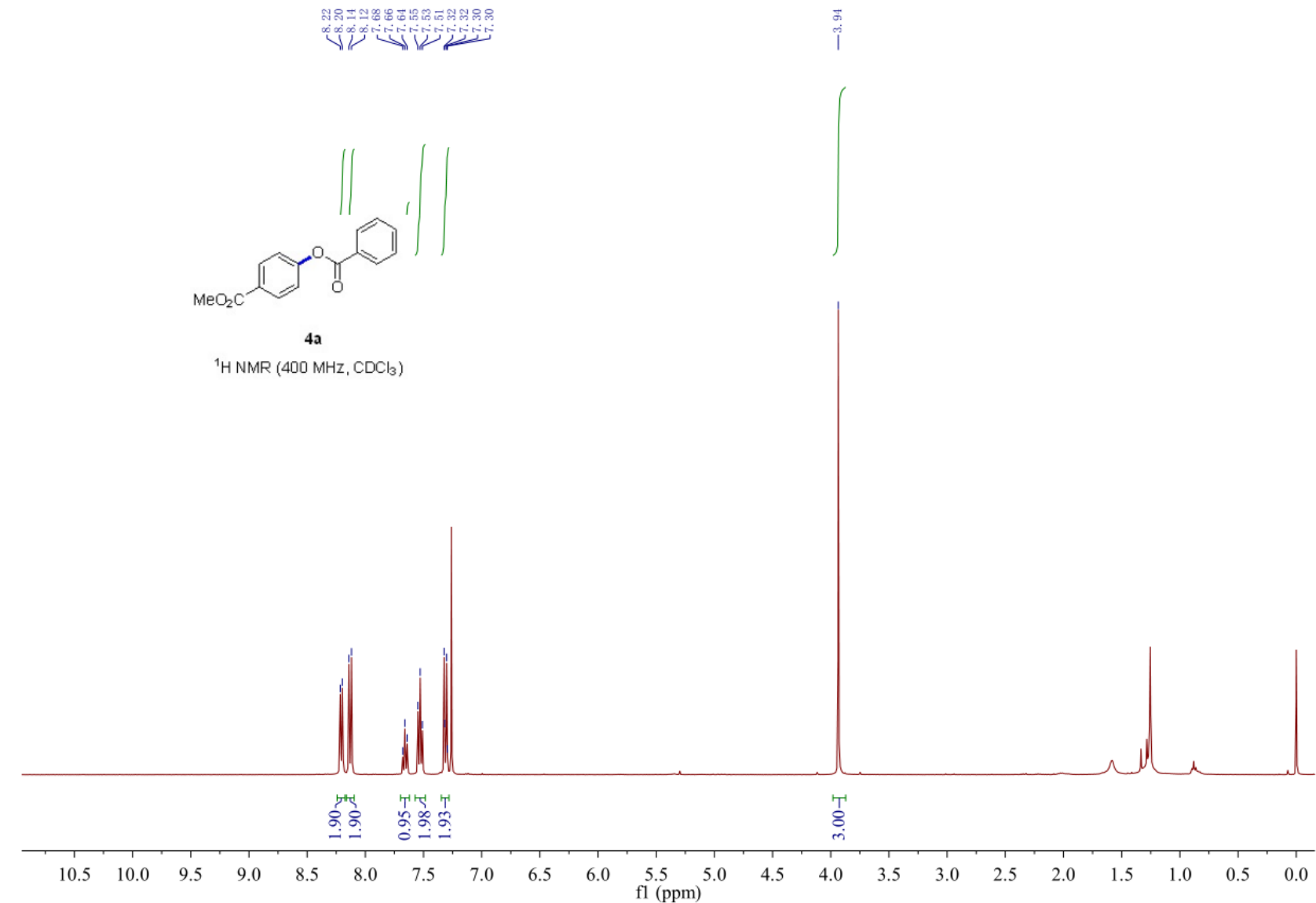

我四
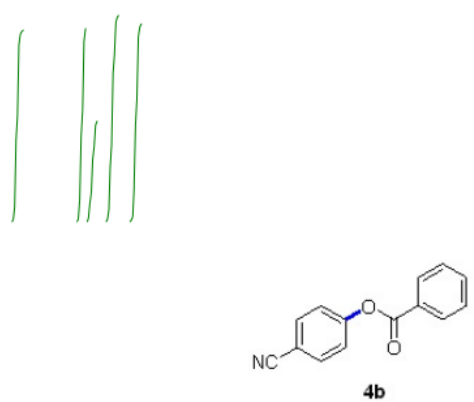

${ }^{1} \mathrm{H} \mathrm{NMR}\left(400 \mathrm{MHz}, \mathrm{CDCl}_{3}\right)$

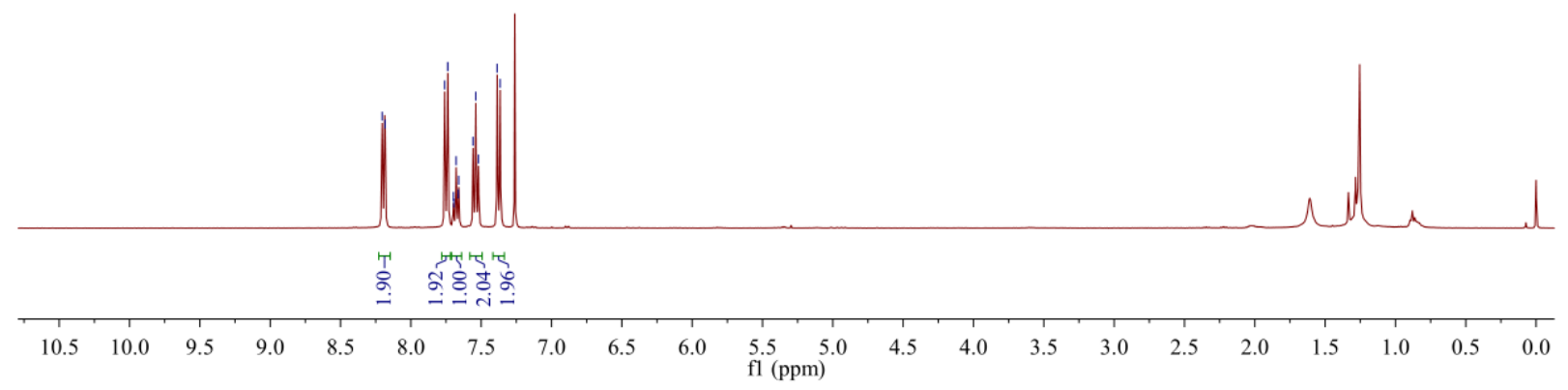




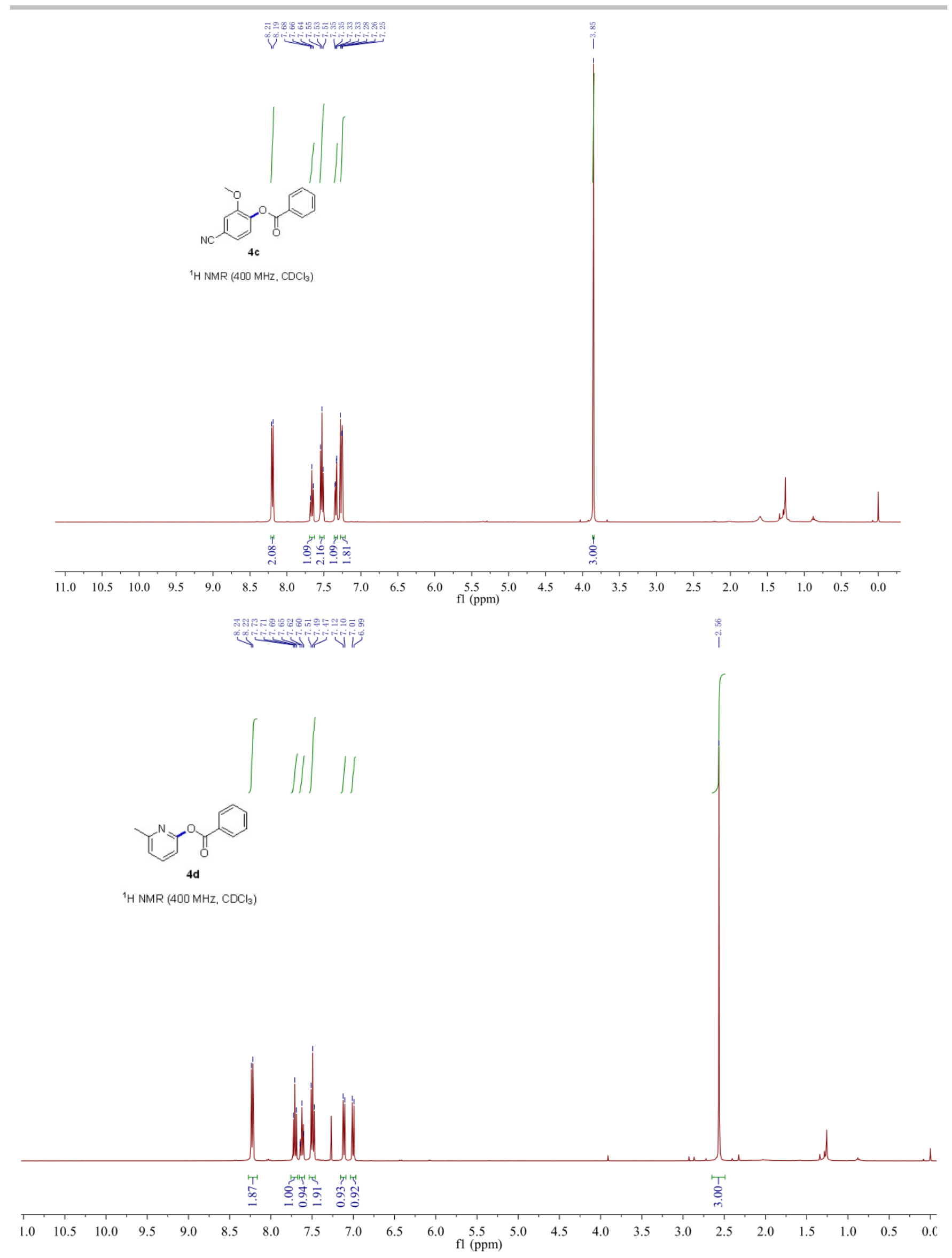



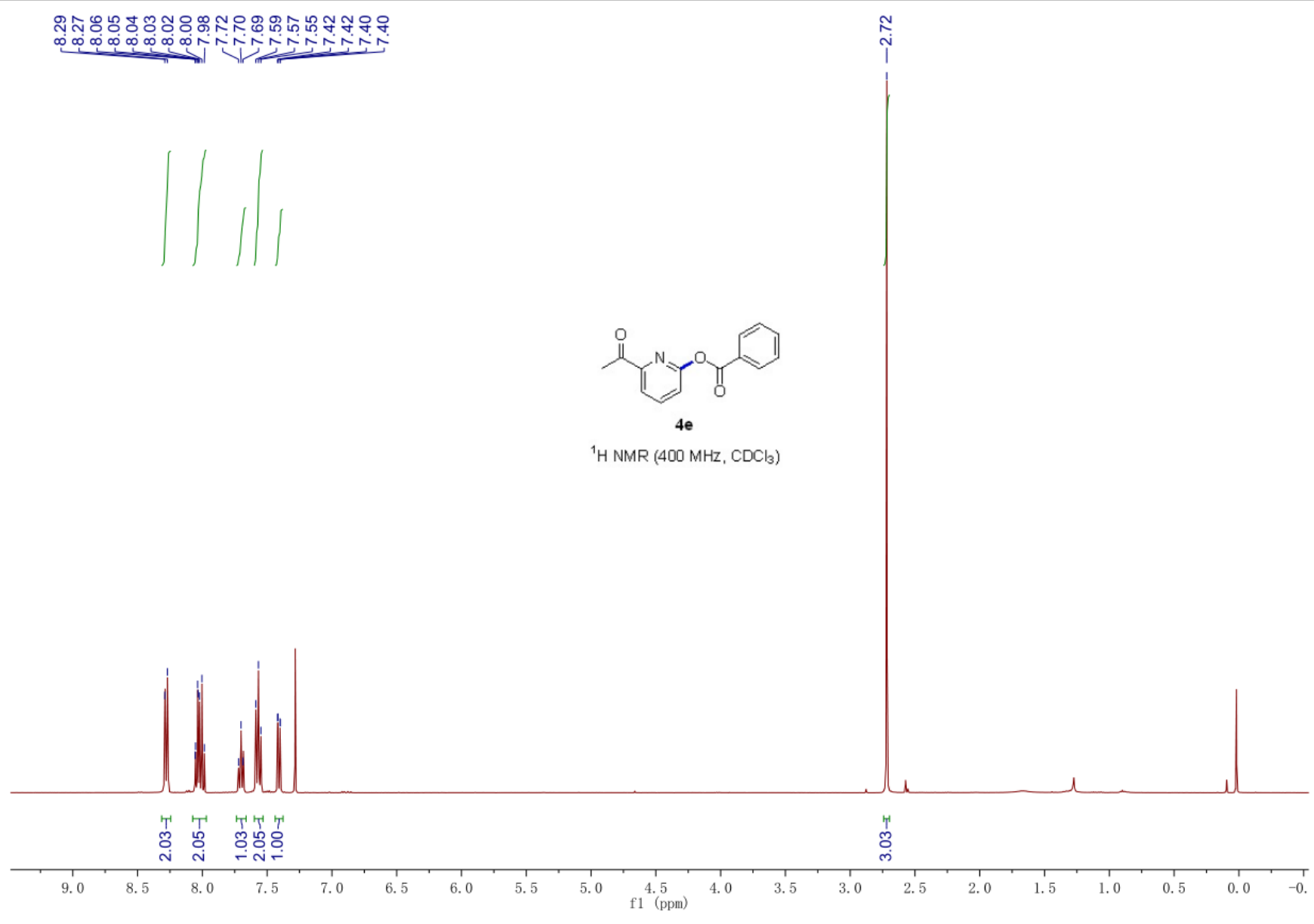

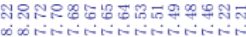

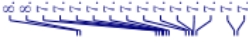

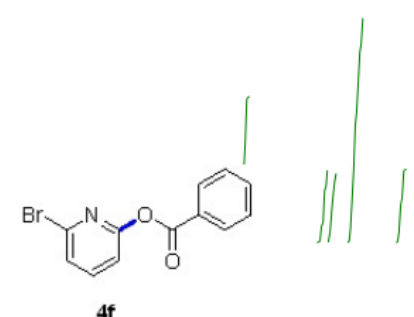

${ }^{1} \mathrm{H}$ NMR $\left(400 \mathrm{MHz}_{1} \mathrm{CDCl}_{3}\right)$

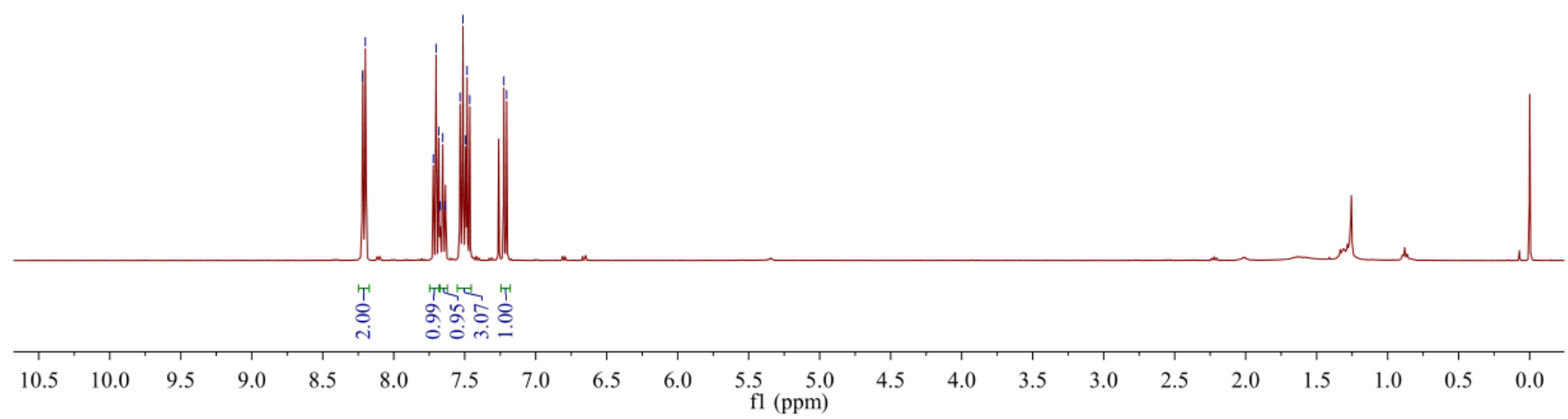




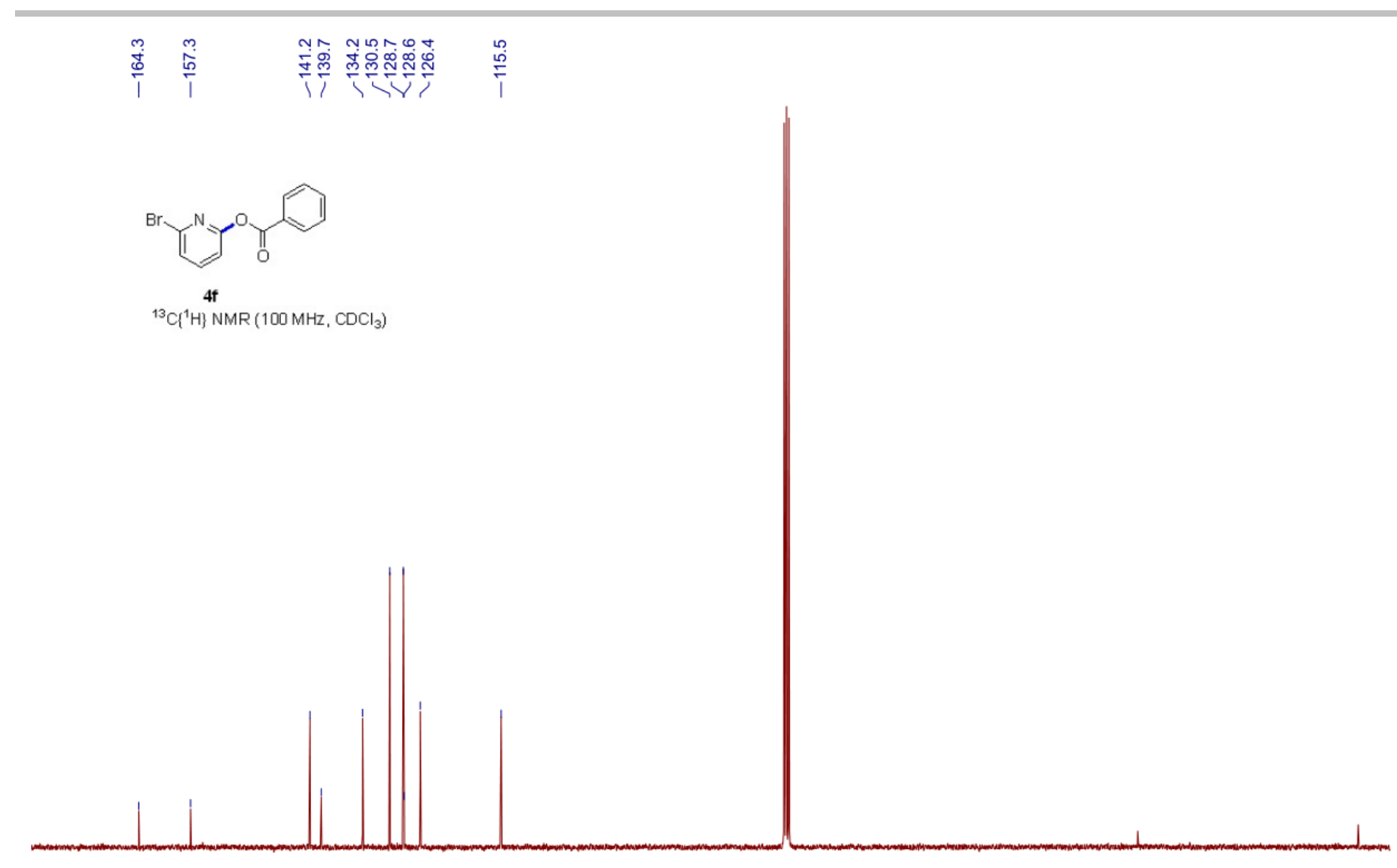

\begin{tabular}{|c|c|c|c|c|c|c|c|c|c|c|c|c|c|c|c|c|c|}
\hline 170 & 160 & 150 & 140 & 130 & 120 & 110 & 100 & $\begin{array}{l}90 \\
\text { f1 (ppm) }\end{array}$ & 80 & 70 & 60 & 50 & 40 & 30 & 20 & 10 & 0 \\
\hline
\end{tabular}

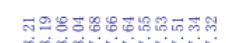

il

ช
I
|

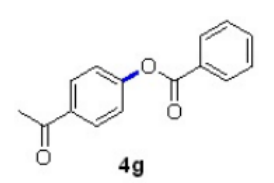

$\int||$

${ }^{1} \mathrm{H}$ NMR (400 MHz, $\mathrm{CDCl}_{3}$ )

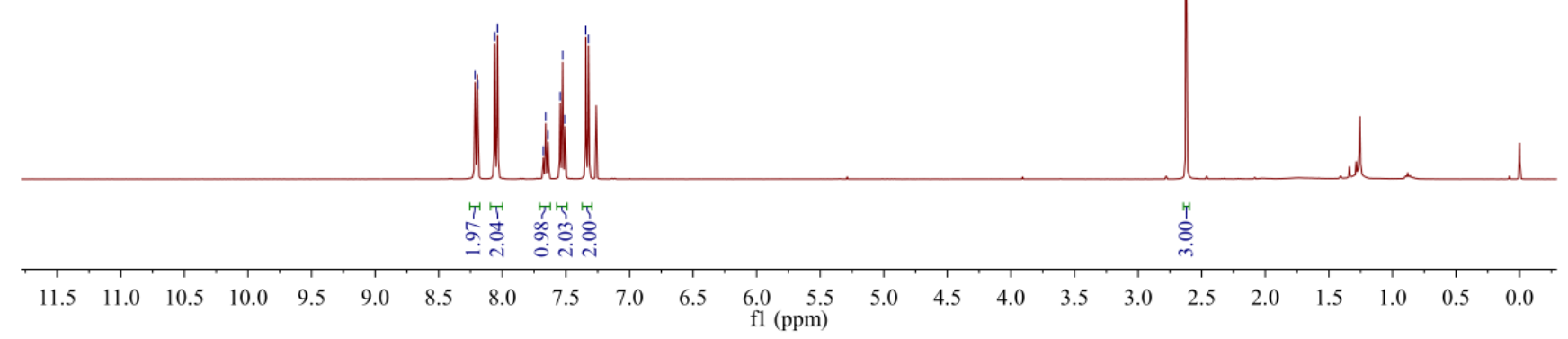




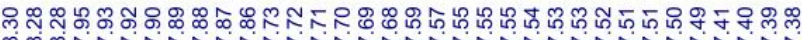
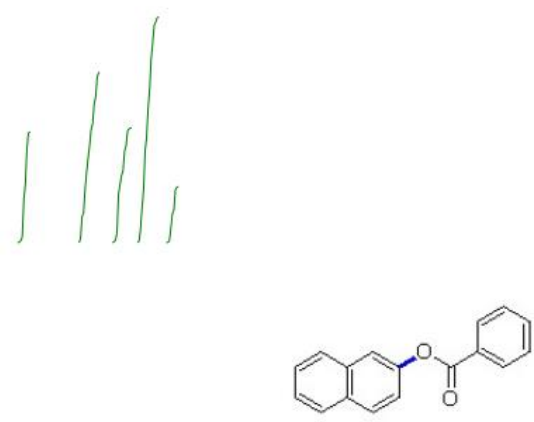

4h

${ }^{1} \mathrm{H} \mathrm{NMR}\left(400 \mathrm{MHz}, \mathrm{CDCl}_{3}\right)$

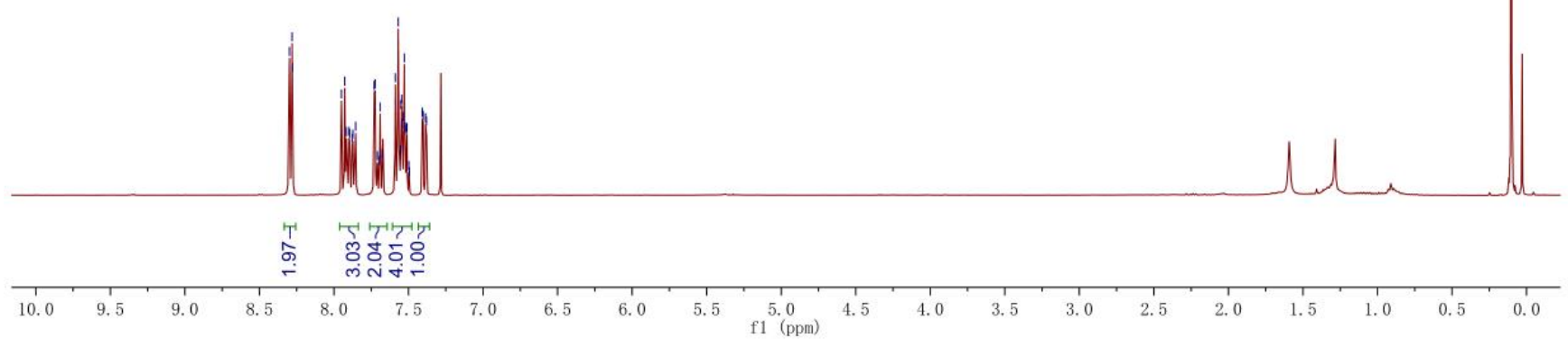

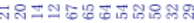

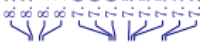

نiำ

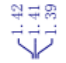

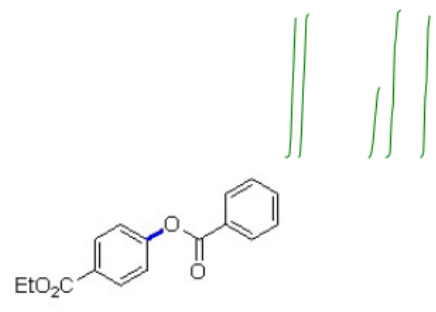

$4 \mathbf{i}$

${ }^{1} \mathrm{H} \mathrm{NMR}\left(400 \mathrm{MHz}, \mathrm{CDCl}_{3}\right)$

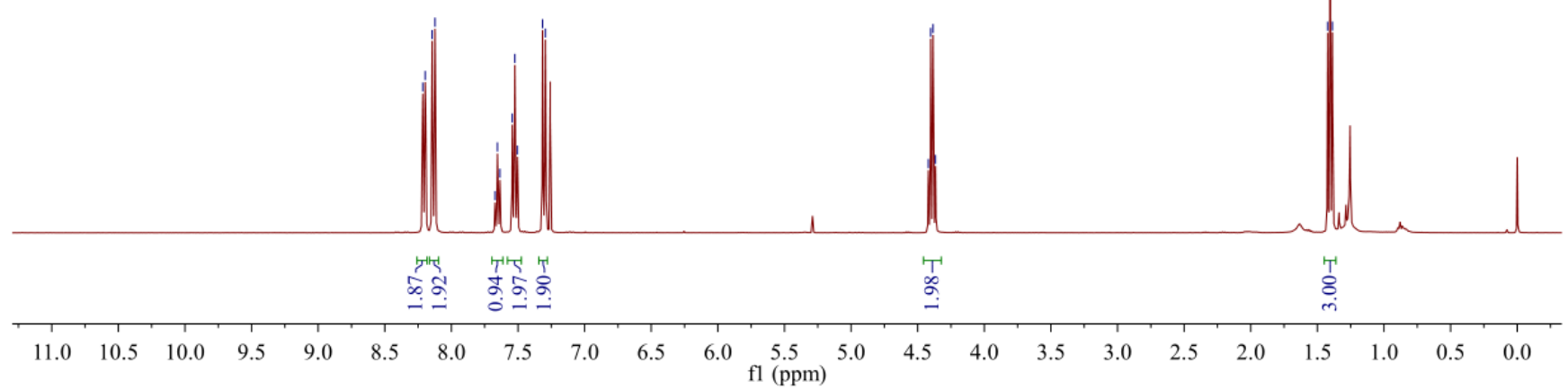




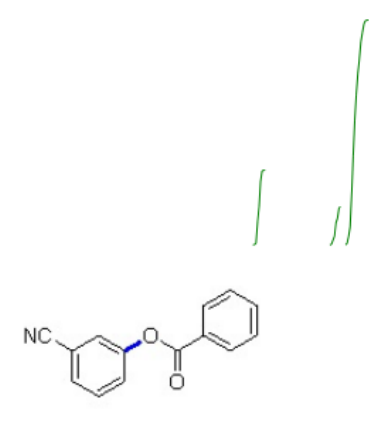

$4 j$

${ }^{1} \mathrm{H} \mathrm{NMR}\left(400 \mathrm{MHz}, \mathrm{CDCl}_{3}\right)$

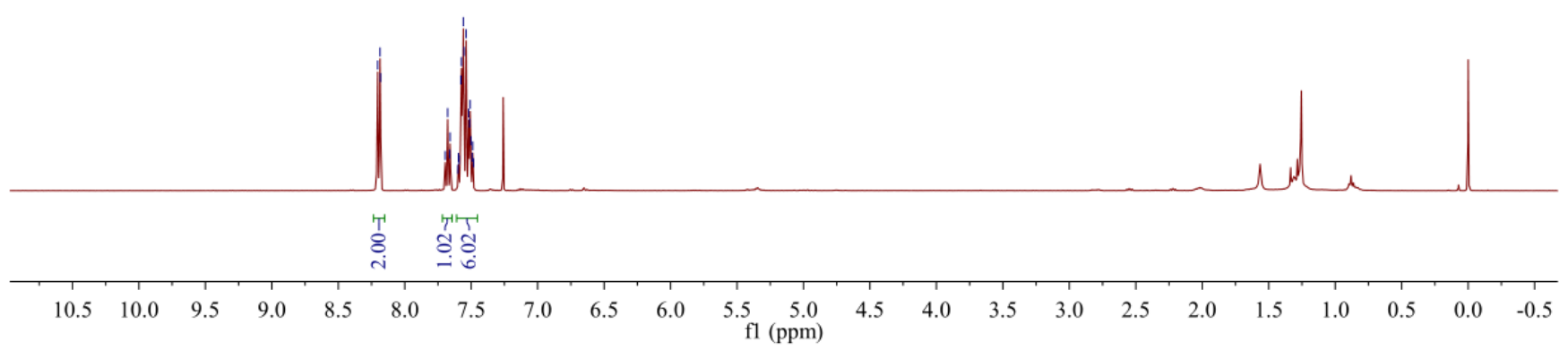

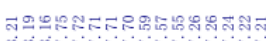

$\underbrace{\infty}_{\infty} \underbrace{\infty}_{\infty}$
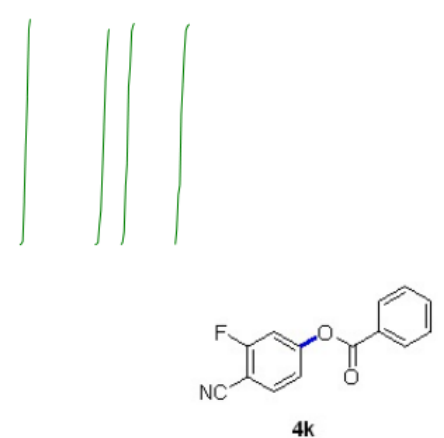

${ }^{1} \mathrm{H} \mathrm{NMR}\left(400 \mathrm{MHz}, \mathrm{CDCl}_{3}\right)$

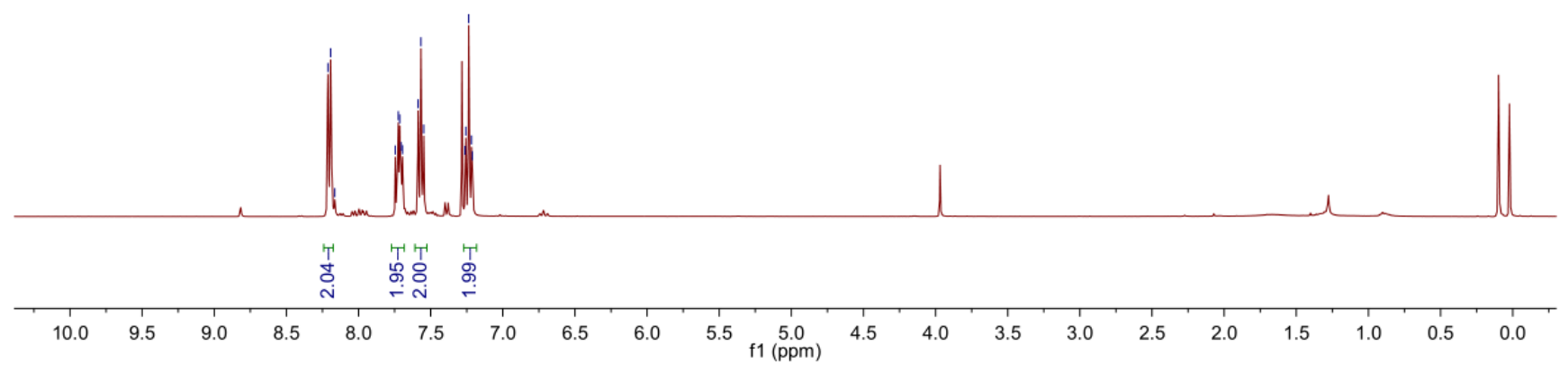



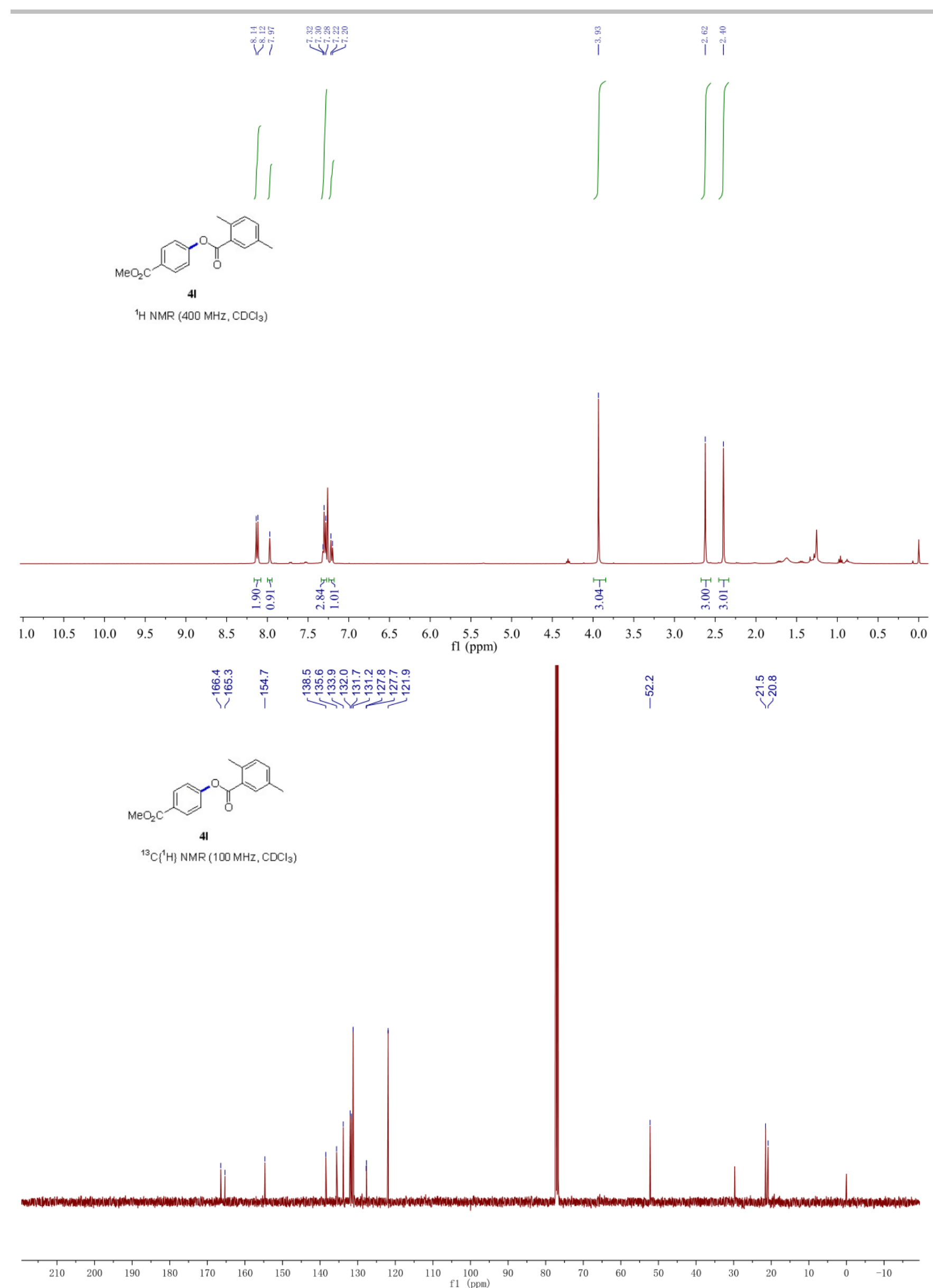


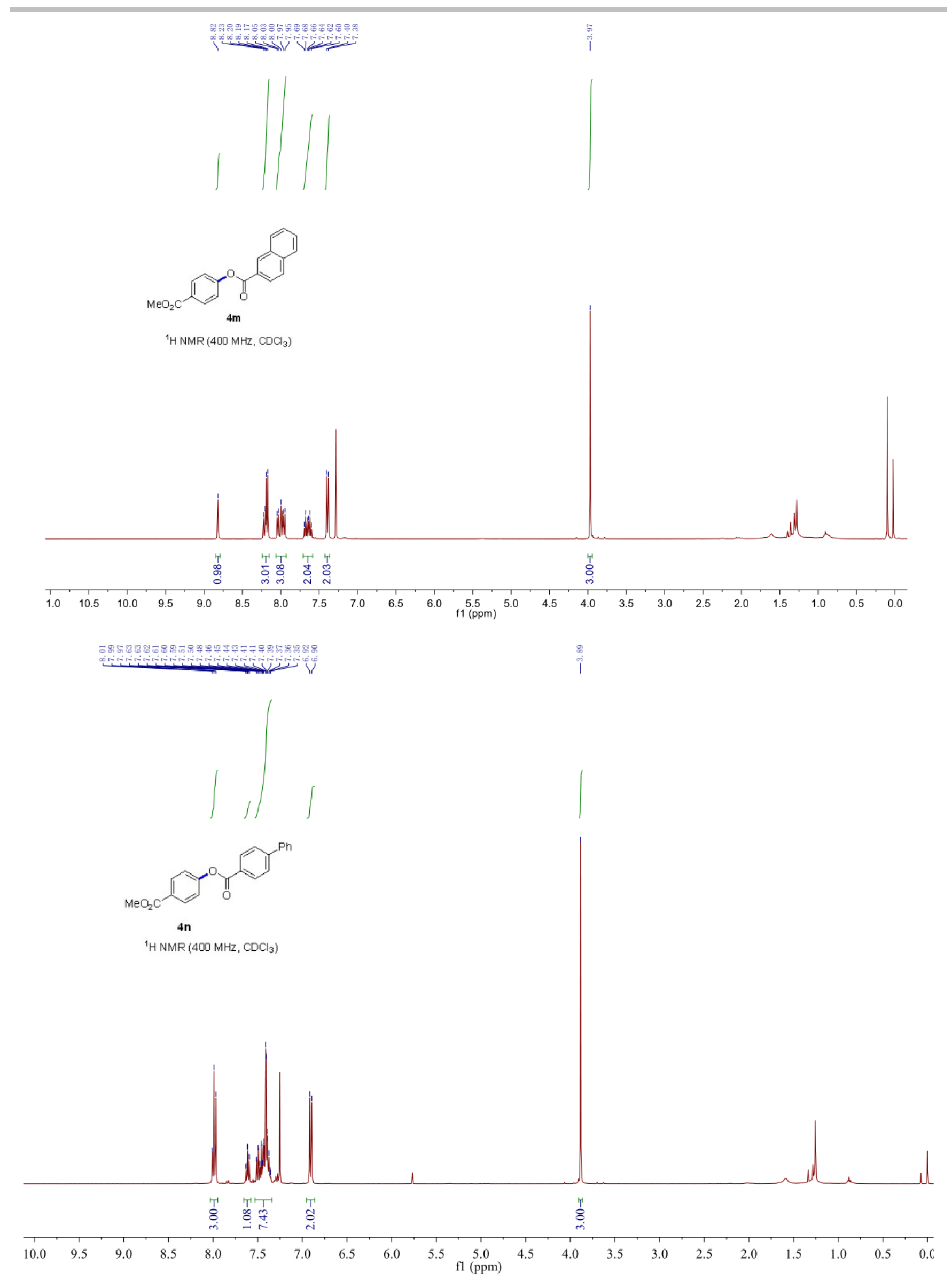


$\sum^{\dot{0} 0}$

กิำ

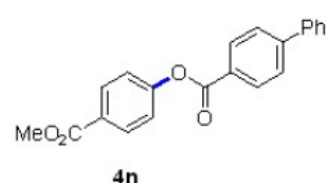

${ }^{13} \mathrm{C}\left\{{ }^{1} \mathrm{H}\right\} \mathrm{NMR}\left(100 \mathrm{MHz}, \mathrm{CDCl}_{3}\right)$
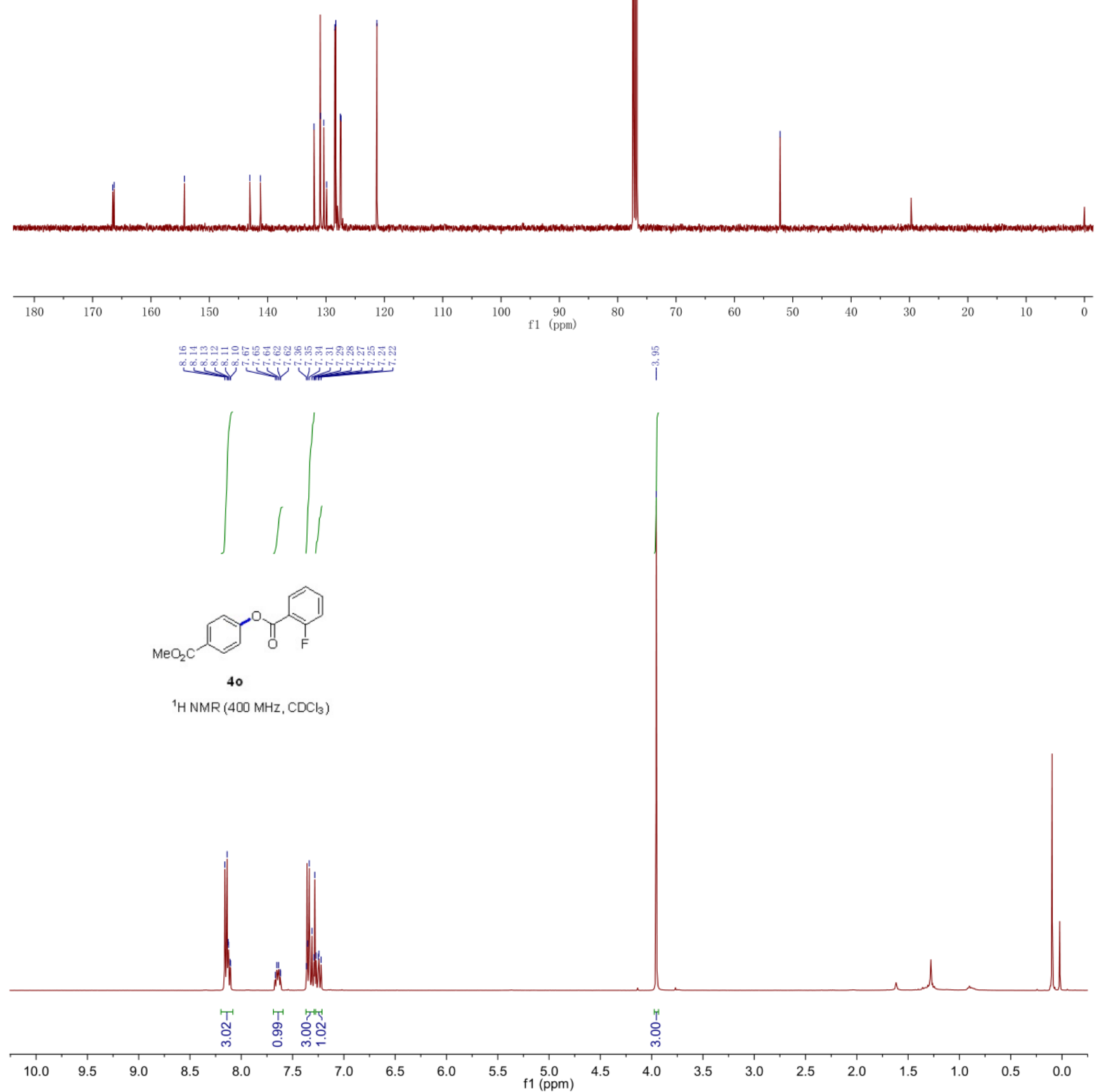

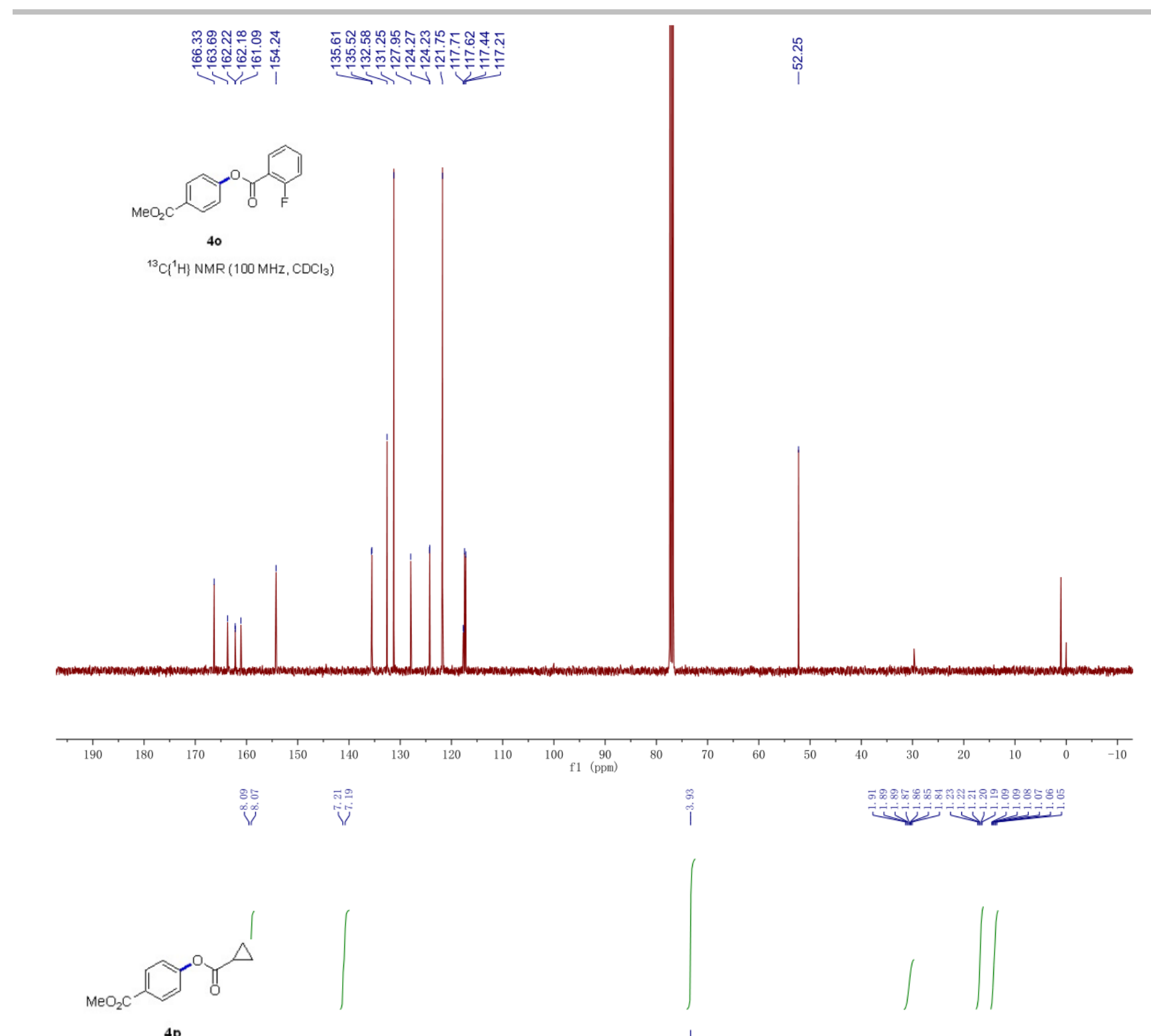

${ }^{1} \mathrm{H} \mathrm{NMR}\left(400 \mathrm{MHz}, \mathrm{CDCl}_{3}\right)$
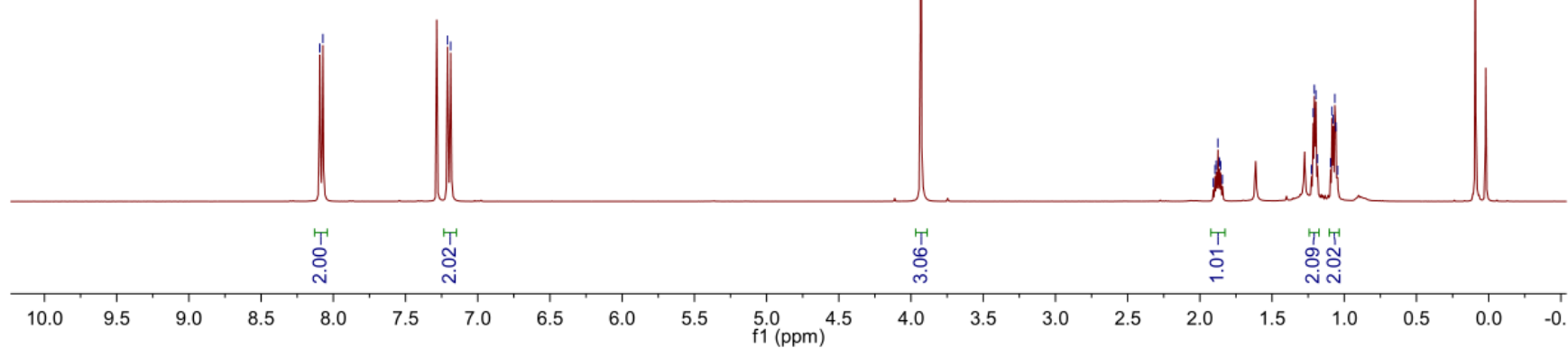

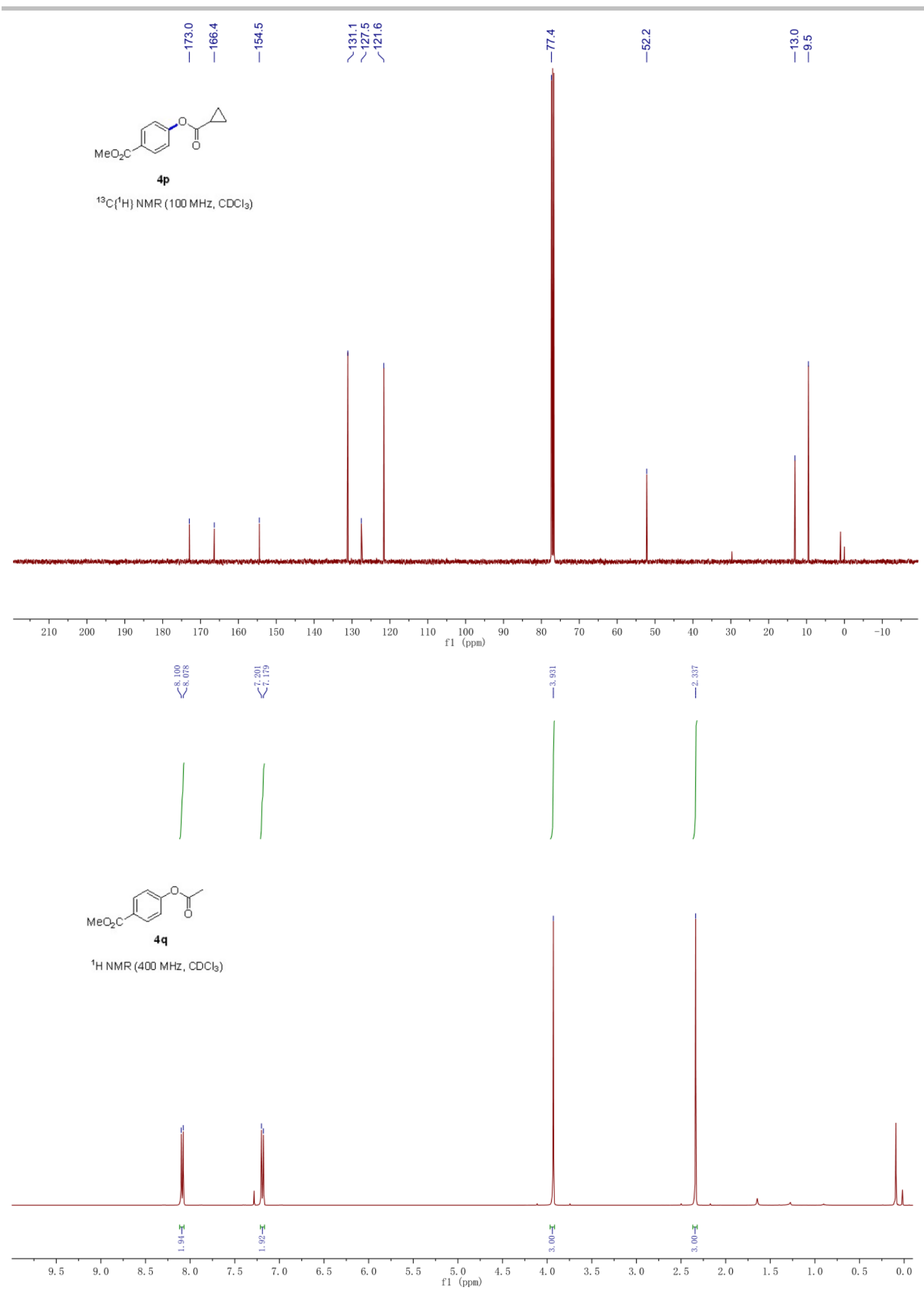


\section{Characterizations of Ni complexes}

每

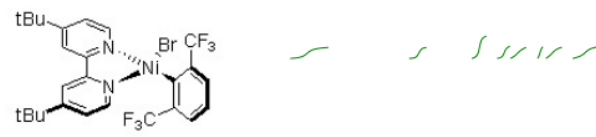

${ }^{1} \mathrm{H}$ NMR (400 MHz, $\left.\mathrm{CDCl}_{3}\right)$

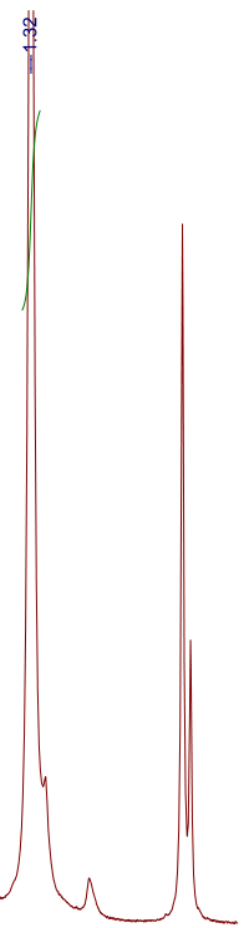

म

$\stackrel{\text { TT }}{\circ}$

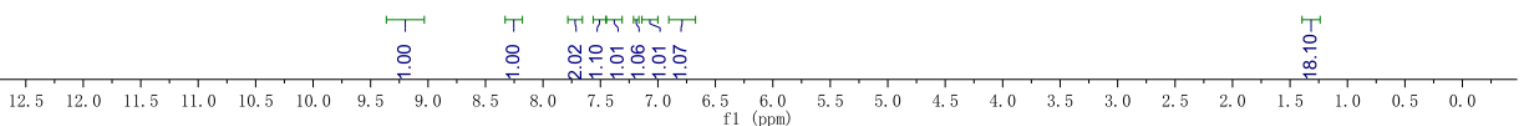

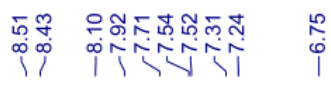

in

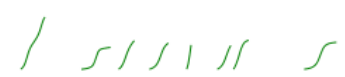
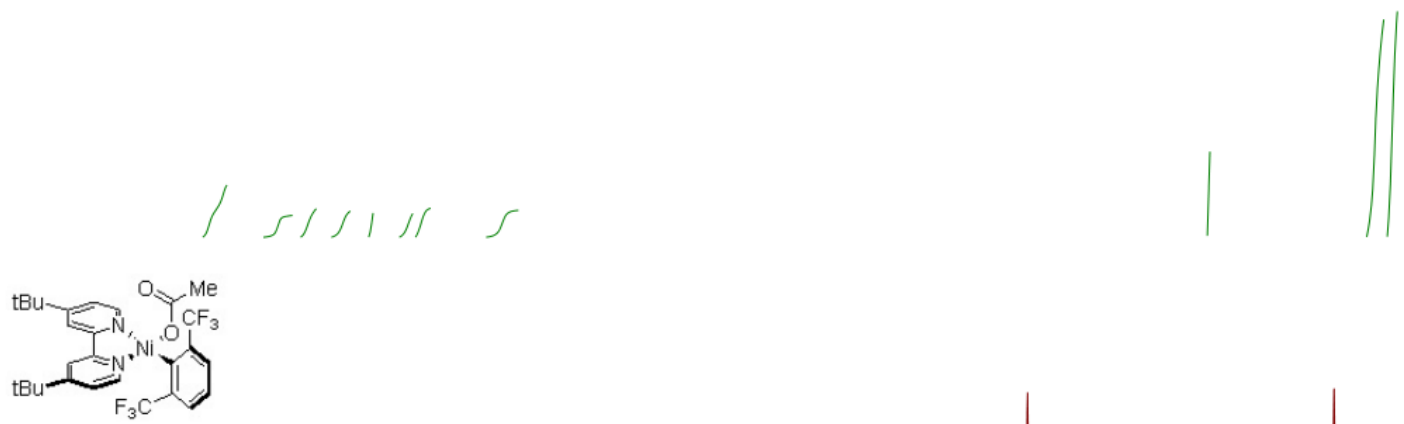

${ }^{1} \mathrm{H}$ NMR (400 MHz, DMSO- $\left.\alpha_{6}\right)$

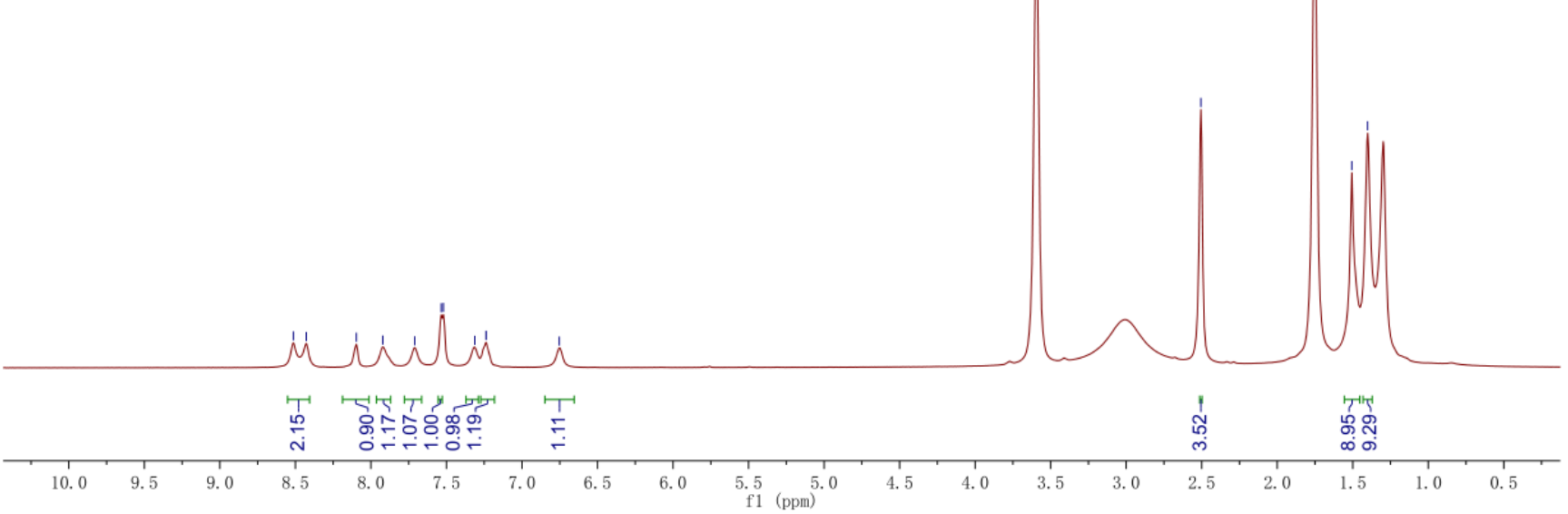

